\title{
DETERMINATION OF POLYCHLORINATED BIPHENYLS, ORGANOCHLORINE PESTICIDES AND CHLOROBENZENES IN SLUDGE AND SEDIMENT SAMPLES BY GCXGC- $\mu$ ECD
}

\author{
By
}

Alina M. Muscalu

B. Sc., Chemistry, University of Bucharest, Romania, 1997

A Research Thesis presented to Ryerson University in partial fulfilment of the requirements for the degree of Master of Applied Science in the Program of Environmental Applied Science and Management

Toronto, Ontario, Canada, 2009

CCopyright by Alina Muscalu 2009 
I hereby declare that I am the sole author of this project.

I authorize Ryerson University to lend this research project to other institutions or individuals for the purpose of scholarly research.

Alina Muscalu

I further authorize Ryerson University to reproduce this research project by photocopying or by other means, in total or in part, at the request of other institutions or individuals for the purpose of scholarly research.

Alina Muscalu 
Ryerson University requires the signatures of all persons using or photocopying this research project.

Please sign below and provide address and date.

\begin{tabular}{|c|c|c|}
\hline Signature of Borrower & Address & Date \\
\hline & & \\
\hline & & \\
\hline & & \\
\hline & & \\
\hline & & \\
\hline & & \\
\hline & & \\
\hline & & \\
\hline & & \\
\hline & & \\
\hline & & \\
\hline & & \\
\hline & & \\
\hline & & \\
\hline & & \\
\hline & & \\
\hline & & \\
\hline & & \\
\hline
\end{tabular}




\title{
DETERMINATION OF POLYCHLORINATED BIPHENYLS, ORGANOCHLORINE PESTICIDES AND CHLOROBENZENES IN SLUDGE AND SEDIMENT SAMPLES BY GCXGC- $\mu$ ECD
}

\author{
(C)Alina Muscalu, 2009 \\ Master of Applied Science \\ Environmental Applied Science and Management \\ Ryerson University
}

\begin{abstract}
\end{abstract}
Gas chromatographic analysis of polychlorinated biphenyls, organochlorine pesticides and chlorobenzenes is one of the most common analyses performed by environmental laboratories. Comprehensive two-dimensional gas chromatography allows simultaneous analysis of different classes of compounds. The objectives of this study were to achieve within- and between-class separations for target contaminants and to quantify them in sludge and sediment samples. With only few coelutions present, the results showed that DB-1xRtx-PCB is a powerful column combination providing excellent chromatographic separation. Reference materials and "real-life" sediments and sludges were analysed and the results were compared to their reference values and previous GC data. This method was shown to be precise and accurate for the standards and reference materials tested as well as a very feasible method for the sediment and sludge sample analysis. Furthermore, this GCxGC method may potentially be used to assess the presence of other compound classes including dioxins, dioxin-like compounds and new emerging contaminants in the environmental samples. 


\section{ACKNOWLEDGEMENTS}

I would like to thank my supervisor, Dr. Steven Liss for his patient guidance and expertise throughout the term of my Masters Program and my thesis project.

I would also like to express my gratitude to Dr. Eric Reiner whose continuous support and encouragement kept me focused and on track with the project work. I would not have entered into this program without his encouragement.

My appreciation also goes to the Ministry of Environment staff that helped me set up the $\mathrm{GCxGC}$ instruments for my work. Adrienne Boden, Tony Chen and John Bodnar, you've made my work a lot easier and your help is appreciated. I would like to thank Paul Helm for his advice during the method development.

Finally, I would like to thank my family for their never ending support and encouragement; daughter Andreea; son Daniel; husband Adi, your patience during all the years of "mom's working" times is greatly appreciated. Thank you. 


\section{TABLE OF CONTENTS}

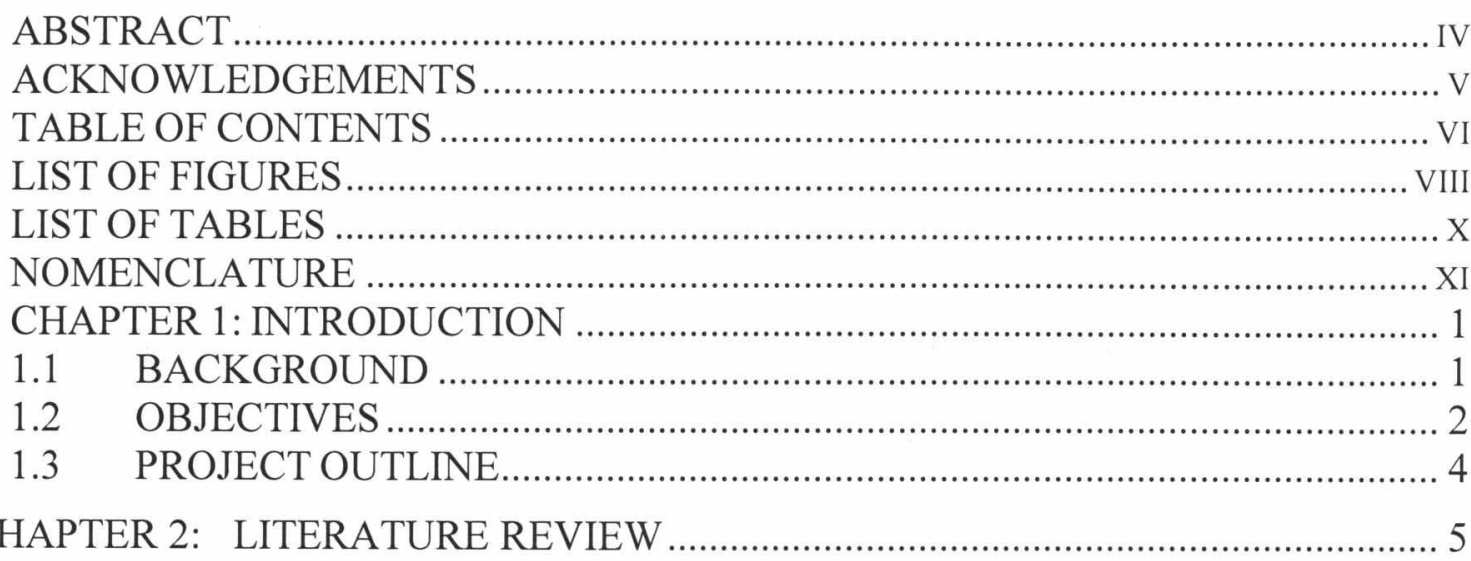

2.1 Environmental Persistent Organic Pollutants: PCBs, ......................... 5

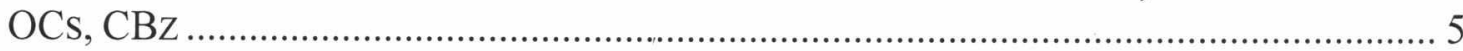

2.2 SAMPLE PREPARATION .................................................................................. 8

2.2.1 Extraction Techniques ................................................................. 8

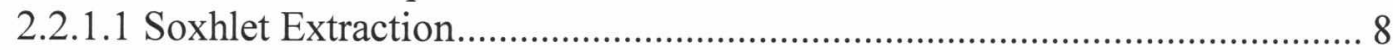

2.2.1.2 Accelerated Solvent Extraction.......................................................... 9

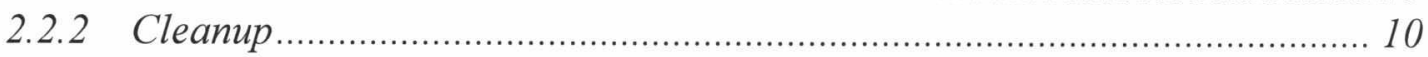

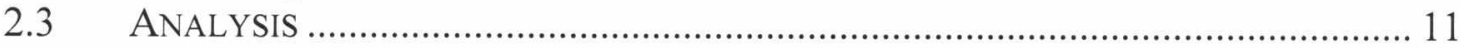

2.3.1 Gas Chromatography Analysis .......................................................... 11

2.3.2 Comprehensive two-dimensional gas chromatography .................................. 12

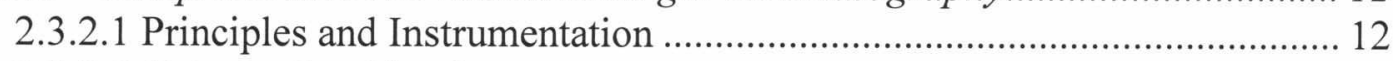

2.3.2.2 Column Combinations .............................................................................. 16

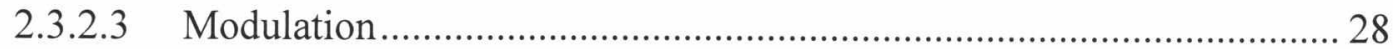

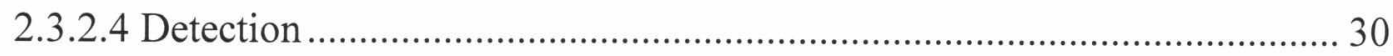

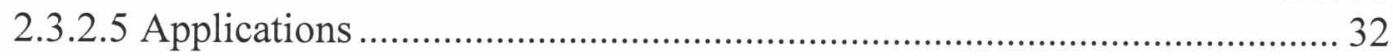

2.4. Project ObJectives And Hypothesis ......................................................... 37

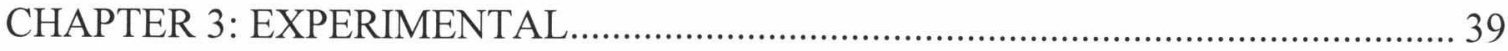

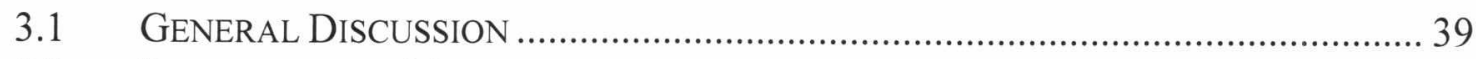

3.2 REAGENTS AND MATERIALS ....................................................................... 40

3.2.1 Standards and chemicals ................................................................. 40

3.2.2 Reference Materials and Sludge/Sediment Samples................................. 41

3.3 SAMPLE PREPARATION .................................................................................. 42

3.3.1 Quality Control Procedures ............................................................... 42

3.3.2 Automated Solvent Extraction.................................................................. 43

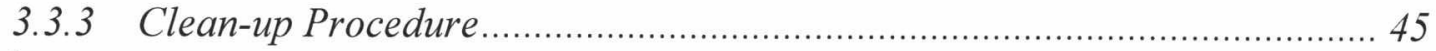

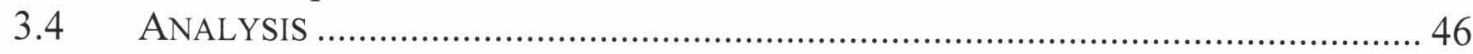




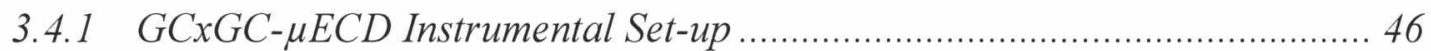

3.4.2 GCXGC-TOFMS Instrument Set-Up .................................................... 48

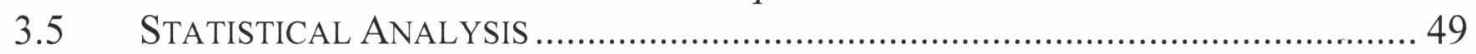

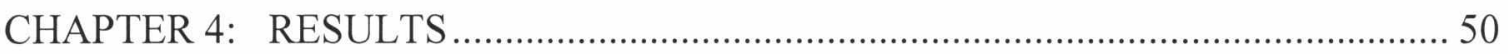

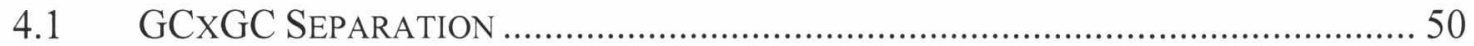

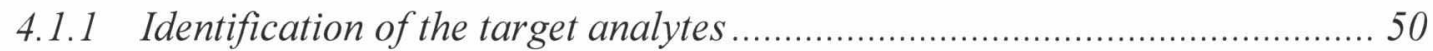

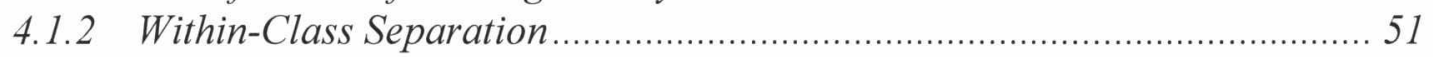

4.1.3 Between-Class Separation ........................................................................ 58

4.1.4 Screening for PCNs, Dioxins, PCDEs and other persistent organic pollutants 60

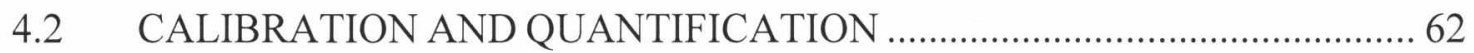

4.2.1 Data Processing Method Parameters .................................................... 63

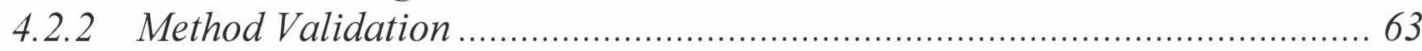

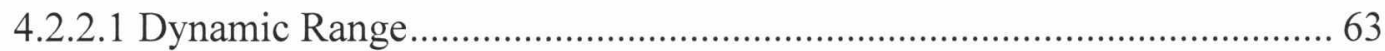

4.2.2.2 Limit of detection and Limit of quantitation........................................ 70

4.2.2.3 Precision: repeatability, reproducibility ................................................ 72

4.2.2.4 Accuracy - reference materials quantification ..................................... 74

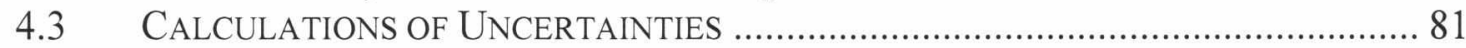

4.4 SLUdGE AND SEDIMENT SAMPLES ............................................................... 82

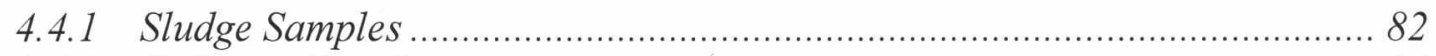

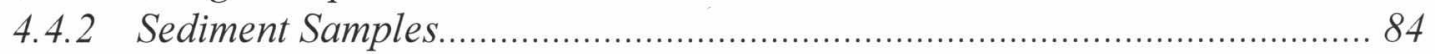

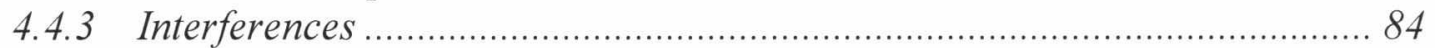

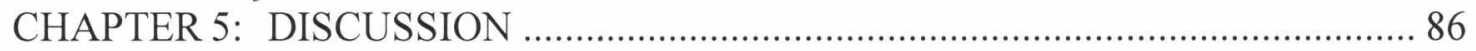

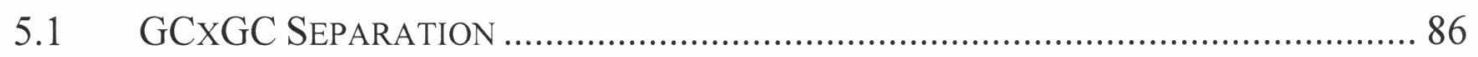

5.2 SCREENING For Other Persistent Organic Pollutants ........................... 89

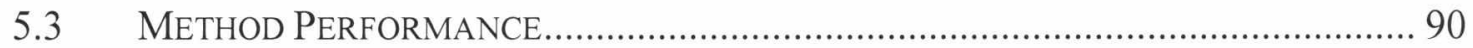

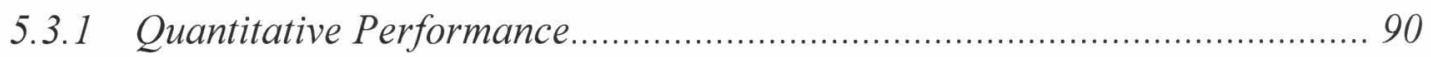

5.3.2 Samples Quantification and Method Interferences................................... 92

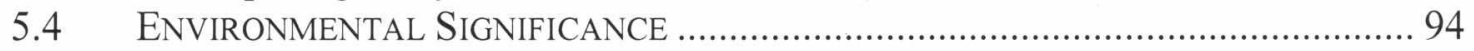

CHAPTER 6: CONCLUSION AND RECOMMENDATIONS ............................... 95

CHAPTER 7: REFERENCES ................................................................................ 98

APPENDIX A: METHODS AND MATERIALS ............................................ 105

APPENDIX B METHOD VALIDATION..................................................................... 110

APPENDIX C: UNCERTAINTIES CALCULATIONS................................................... 119

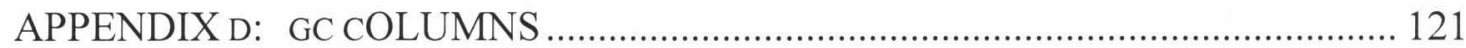




\section{LIST OF FIGURES}

FIGURE 2.1 SCHEMATIC REPRESENTATION OF A GCXGC SYSTEM: $1^{\text {ST }}$ DIMENSION COLUMN - MODULATOR - $2^{\text {ND }}$ DIMENSION COLUMN (FROM

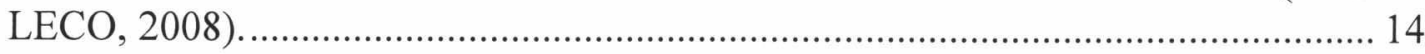

FIGURE 2.2 THE SCHEMATIC REPRESENTATION OF GCXGC CHROMATOGRAM: GENERATION AND VISUALISATION (DALLUGE ET AL., 2003).

FIGURE 2.3 CONTOUR PLOTS OF THE 209 PCBS USING THE COLUMN SET: A) DB-XLB X LC-50AND B) DB-XLB X SP-2340 (HARJU ET AL, 2003).

FIGURE 2.4 GCXGC- $\mu$ ECD TWO DIMENSIONAL CHROMATOGRAM OBTAINED FOR SELECTED OC PESTICIDES ANALYSED WITH DB-1×007-65HT

(KORYTAR ET AL., 2005). 25

FIGURE 2.5 OVERLAID GC $\times$ GC $-\mu$ ECD CHROMATOGRAMS ON DB- $1 \times$ LC -50 COLUMN

FIGURE 2.6 SCHEMATIC REPRESENTATION OF THE DESIGN OF A QUAD-JET MODULATOR: DIAGRAM OF THE QUAD-JET N $\mathrm{N}_{2}$ MODULATOR (KRISTENSON ET AL., 2003).

FIGURE 2.8 ZOOMED IN CONTOUR PLOT OF A "REAL WORLD" SOIL EXTRACT

FIGURE 3.1 EXPERIMENTAL APPROACH OF THE GCXGC-ECD STUDY............ 40

FIGURE 3.2 GRAPHICAL REPRESENTATION OF AN ASE CELL SET-UP. ........... 44 FIGURE 4.1 GCXGC- $\mu$ ECD TWO DIMENSIONAL CHROMATOGRAM OF PCB CONGENERS STANDARD REPRESENTING THEIR ORTHOGONAL SEPARATION...

FIGURE 4.2 EXAMPLES OF CRITICAL PCB PAIRS RESOLVED IN THE SECOND DIMENSION BY GCXGC, DB1XRTX-PCB COLUMN COMBINATION: A) PCB77/PCB110 AND B) PCB118/PCB149.

FIGURE 4.3 GCXGC- $\mu$ ECD TWO DIMENSIONAL CHROMATOGRAM OF OC STANDARD REPRESENTING THEIR SEPARATION BY DB1-RTX-PCB COLUMN COMBINATION.

FIGURE 4.4 GCXGC- $\mu$ ECD TWO DIMENSIONAL CHROMATOGRAM OF CB STANDARD REPRESENTING THEIR SEPARATION BY DB1-RTX-PCB COLUMN COMBINATION.

FIGURE 4.5 GCXGC- $\mu$ ECD TWO DIMENSIONAL CHROMATOGRAM OF PCB/OC/CB MIX STANDARD SOLUTION REPRESENTING THE BETWEENCLASS SEPARATION.

FIGURE 4.6 TWO DIMENSIONAL CHROMATOGRAMS REPRESENTING BETWEEN-CLASS COELUTIONS: A) HEPTACHLOR-EPOXIDE/PCB74, B) CIS-NONACHLOR/PCB114 AND C) METHOXYCHLOR/PCB171.

FIGURE 4.7 THE OVERLAY OF THE RETENTION TIMES FOR PCB, OC, CB, PCN, TOXAPHENE AND POLYCHLORINATED DIOXINS/FURANS ANALYSED BY GCXGC- $\mu$ ECD 
FIGURE 4.8 CALIBRATION CURVE AND CALIBRATION TABLE GENERATED BY CHROMATOF 3.34 SOFTWARE FOR PCB77.

FIGURE 4.9 CALIBRATION CURVE AND CALIBRATION TABLE GENERATED

BY CHROMATOF 3.34 SOFTWARE FOR O,P'-DDT.

FIGURE 4.10 CALIBRATION CURVE AND CALIBRATION TABLE GENERATED BY CHROMATOF 3.34 SOFTWARE FOR HCB.

FIGURE 4.11 GRAPHICAL REPRESENTATIONS OF SPECIFIC PCB CONGENERS AMOUNTS IN SRM1944 ANALYSED BY GC-ECD, GCXGC- $\mu$ ECD AND THEIR CERTIFIED VALUES. 77

FIGURE 4.12 GRAPHICAL REPRESENTATIONS OF SELECTED COMPOUNDS IN CNS312 ANALYSED BY GCXGC- $\mu$ ECD AND COMPARED TO THEIR CERTIFIED VALUES: A) PCB CONGENERS AND B) OC PESTICIDES.......... 79 FIGURE 4.13 TWO DIMENSIONAL CHROMATOGRAMS REPRESENTING THE ANALYSIS OF CBZ IN EC-8 SEDIMENT REFERENCE MATERIAL.

FIGURE 4.14 DATA COMPARISON FOR CBZ DETERMINATION IN SEDIMENT REFERENCE MATERIAL EC-8 BY BOTH GC-ECD AND GCXGC- $\mu$ ECD METHODS. 81

FIGURE 4.15 TWO DIMENSIONAL CHROMATOGRAM REPRESENTING A SLUDGE SAMPLE ANALYSED BY GCXGC- $\mu$ ECD 83

FIGURE 4.16 TWO DIMENSIONAL CHROMATOGRAM REPRESENTING PCA C10-13, 55.5\%CL STANDARD ANALYSED BY GCXGC- $\mu$ ECD.....

FIGURE 4.17 TWO DIMENSIONAL CHROMATOGRAMS REPRESENTING TRICLOSAN PEAK IN A) SLUDGE SAMPLE AND B) SPIKED SEDIMENT SAMPLE (QUALITY CONTROL SAMPLE). 


\section{LIST OF TABLES}

TABLE 2.1 COLUMN COMBINATIONS AND INSTRUMENTAL GCXGC CONDITIONS USED FOR SEPARATION OF PCBS AND OCS IN STANDARD MIXTURES

TABLE 3.1 THE ASE CONDITIONS USED FOR THE SEDIMENT/SLUDGE

SAMPLES EXTRACTION. 45

TABLE 3.2 INSTRUMENTAL CONDITIONS USED FOR THE GCXGC- $\mu$ ECD SYSTEM.

TABLE 3.3 THE GCXGC-TOFMS SPECIFICATIONS FOR MASS SPECTROMETER

METHOD. 48

TABLE 4.1 DATA REPRESENTING THE VARIABILITY OF INTERNAL

STANDARD BETWEEN ANALYTICAL RUNS.

TABLE 4.2 IDENTIFICATION, RETENTION TIMES AND WITHIN-RUN

REPEATABILITY FOR THE SELECTED PCB/OC/CB COMPOUNDS

ANALYSED BY GCXGC- $\mu$ ECD.

TABLE 4.3 RESULTS REPRESENTING MDL AND LOQ CALCULATIONS FOR

SELECTED TARGET ANALYTES

TABLE 4.4 WITHIN-RUN METHOD PRECISION FOR PCB, OC, CB FOR TEN

REPLICATES OF SPIKED SEDIMENT SAMPLES.

TABLE 4.5 BETWEEN-RUN METHOD PRECISION

TABLE 4.6 COMPARISON OF GC-ECD VS. GCXGC- $\mu$ ECD METHODS FOR

SEDIMENTS/SLUDGE SAMPLES ANALYSIS.

TABLE 4.7 COMPARISON DATA OF SELECTED PCBS, OCS AND CBS

ANALYSED BY CLASSICAL GC-ECD, GCXGC- $\mu$ ECD AND THEIR

REFERENCE VALUES FOR SRM1944.

TABLE 4.8 DATA COMPARISON OF THE GCXGC- $\mu$ ECD ANALYSIS ( 8

REPLICATES) AND THE CERTIFIED REFERENCE VALUES FOR CNS312

SLUDGE REFERENCE MATERIAL.

TABLE 4.9. THE COMPARISON OF THE OBTAINED CONCENTRATIONS OF

SELECTED OCS ANALYSED BY BOTH GC-ECD AND GCXGC $\mu$ ECD FOR

NEW YORK STATE ELAP 08-01 SEDIMENT SAMPLE 


\section{NOMENCLATURE}

PCB polychlorinated biphenyls

OC organochlorine pesticides

CB chlorobenzenes

PCN polychlorinated naphthalenes

GC gas chromatography

GCxGC comprehensive two-dimensional gas chromatography

$\mu$-ECD micro-electron capture detector

TOF-MS time-of-flight mass spectrometry

HCB hexachlorobenzene

DMDT methoxychlor

POP persistent organic pollutants

FID flame ionization detector

HCBD hexachlorobutadiene

PCA polychlorinated alkanes

PCDDs polychlorinateddibenzo- $p$-dioxins or dioxins

PCDFs polychlorinated dibenzofurans or furans

MAE microwave assisted extraction

SFE supercritical fluid extraction

ASE accelerated solvent extraction

1D first dimension

2D second dimension 



\section{CHAPTER 1: INTRODUCTION}

\subsection{BACKGROUND}

Organohalogenated compounds are known environmental contaminants due to their persistence and toxicity. Most of the organohalogenated compounds were commercially produced for use in agricultural, industrial and/or household applications, while others such as dioxins and furans were formed unintentionally during municipal waste incineration, in other combustion and thermal processes or as by-products in the chemical industry. Compounds such as polychlorinated biphenyls (PCB), organochlorine pesticides (OC) and chlorobenzenes (CB) have been identified in diverse environmental samples. Due to their physical and chemical properties these compounds tend to bioaccumulate and biomagnify in the food chain (Bernes, 1998; Saito and al., 2004). These findings emphasize the need to screen environmental samples and the need for development of new fast and accurate multi-analyte methods of analysis.

Sediments and sludge, where most persistent contaminants are found to accumulate, are very complex environmental matrices challenging analysts with sample preparation problems and analytical interferences (e.g. matrix effect and coeluting peaks). In order to remove most of the possible interferences, complex sample preparation including extraction, clean-up and extract fractionation is required prior to multiple instrumental analyses. Classical sample analysis for these compounds employs gas chromatography (GC) coupled with an electron capture detector (ECD) or mass 
spectrometry (MS). The ECD is often the choice for PCB, OC and $\mathrm{CB}$ detection due to its high sensitivity for halogenated compounds (Jacob de Boer, 1999; Cochran et al., 1999). A major drawback of the ECD is the lack of selectivity between various halogenated compounds, thus requiring chromatographic separation in order to obtain accurate quantitative results.

Conventional GC offers good peak capacity but it fails to separate many individual components in complex environmental samples. The introduction of comprehensive two-dimensional gas chromatography (GCxGC) provided significant increases in separating power, peak capacity and speed of analysis (Dalluge et al., 2003). GCxGC involves a serial column configuration separated by a thermal modulator. Comprehensive two-dimensional gas chromatography increases peak capacity by applying two independent separations to a sample resulting in improved resolution of target compounds in a single analysis. Previous studies involving the GCxGC technique, as presented in recent reviews (Adahchour et al., 2006), have demonstrated its advantages over the classical analysis for the separation of PCBs, OCs and CBs in environmental samples.

\subsection{OBJECTIVES}

The comprehensive multi-dimensional gas chromatography coupled with microelectron capture detector (GCxGC- $\mu \mathrm{ECD})$ proved to by a very powerful technique allowing simultaneous analysis of the target halogenated contaminants (Korytar et al., 2003; Korytar et al., 2006). Since the ECD permits only peak recognition without 
providing any structural information, further confirmation of the compounds by time-offlight mass spectrometry (TOFMS) may be required. The objectives of this project were to achieve chromatographic separation of the target compounds in one analysis prior to calibration and quantification; to accurately identify and quantify the PCBs, OCs and CBs present in sludge and sediment samples in a single analytical run by using the $\mathrm{GCxGC}$ technique. In addition to $\mathrm{PCBs}, \mathrm{OCs}$ and $\mathrm{CBz}$, other contaminant classes can be evaluated using the same instrumental set-up: dioxins and furans, toxaphene and polychlorinated naphthalenes. The retention time data for these different classes of compounds can be plotted in a graph representing the chromatographic space and later used for further assessing the presence of these contaminants in environmental samples.

The multi-step approach taken was:

i. The implementation of an environmentally friendly extraction method (e.g. pressurized solvent extraction that uses less solvent) followed by a clean-up step without any fractionation prior to GCxGC analysis;

ii. The identification, separation, calibration and quantification of the target organohalogenated contaminants within-class and between-class, in a single analytical run using $\mathrm{GCxGC}$ technique;

iii. The application of the new method to accurately identify and quantify the target analytes in complex environmental matrices such as sludges and sediments. 


\subsection{PROJECT OUTLINE}

The background information relevant to this research is reviewed in Chapter 2, outlining the properties, use and occurrence in the environment of $\mathrm{PCBs}$, OCs and $\mathrm{CBz}$, different sample preparation procedures and instrumental analyses. The second chapter describes the theoretical and practical aspects of the GCxGC technique as well as its advantages over the classical methods.

Chapter 3 outlines the experimental procedures along with the materials and instrumental set-up used in this research. Chapter 4 presents the results of the study in four parts: the separation of the target analytes, the calibration and quantification, the uncertainty calculations followed by the analysis of sludge and sediment samples. A more detailed discussion of the results follows in Chapter 5. Chapter 6 summarizes the conclusion and recommendations of this research. 


\section{CHAPTER 2: LITERATURE REVIEW}

Chapter 2 of this study is presented in four parts: overview of the PCBs, OCs and $\mathrm{CBz}$ as persistent environmental pollutants, sample preparation techniques, instrumental analysis followed by the objectives and hypothesis of the research. The emphasis of the literature review is on $\mathrm{GCxGC}$ principles since this technique was used in the research. The sample preparation steps are only briefly reviewed to strengthen the conclusion that overall the time gain, the efficiency and the decrease of solvent use are significantly improved when using the procedures selected for this study:

\subsection{ENVIRONMENTAL PERSISTENT ORGANIC POLLUTANTS: PCBS,}

\section{OCS, CBZ}

Halogenated organic compounds have been produced in large volumes in the early 1950s and used for different applications. Most of the organohalogen compounds were commercially produced for use in àgricultural, industrial, and/or household applications, while others such as dioxins were formed unintentionally during municipal waste incineration, in other combustion and thermal processes or as by-products in the chemical industry. Compounds such as polychlorinated biphenyls (PCBs), organochlorine pesticides (OCs) and chlorobenzenes $(\mathrm{CBz})$ have entered the air, water, and soil during their manufacture, use and disposal, from accidental spills and leaks during their transport and from leaks or fires in products containing PCBs. They were identified in environmental samples and are generally known environmental 
contaminants due to their persistence, toxicity and their tendency to bioaccumulate and biomagnify (Bernes, 1999).

The "dirty dozen" list of POPs includes three sub-divisions: eight OCs (dieldrin, endrin, aldrin, chlordane, heptachlor, DDT, mirex and toxaphene), two industrial chemicals (hexachlorobenzene - HCB and polychlorinated biphenyls) and two unintentionally produced compounds (polychlorinateddibenzo- $p$-dioxins - PCDDs or dioxins, and polychlorinated dibenzofurans - PCDFs or furans) (van Leewen and Boer, 2008). Even though most of these compounds are not currently produced or have been used for decades now, their presence in the environment is still in considerable levels.

Polychlorinated biphenyls are mixtures of synthetic organic chemicals with the same basic chemical structure and similar physical properties ranging from oily liquids to waxy solids. Due to their non-flammability, chemical stability, high boiling point and electrical insulating properties, PCBs were used in hundreds of industrial and commercial applications including electrical, heat transfer, and hydraulic equipment; as plasticizers in paints, plastics and rubber products; in pigments, dyes and carbonless copy paper and many other applications. The 209 possible PCB congeners were manufactured and sold under many names, the most common were the "Aroclor" series, in many of which a numerical identifier included the percentage of Chlorine (e.g., "Aroclor 1254", with 54 percent Chlorine) (Erickson, 1997; Frame, 1997). PCBs do not readily break down in the environment and thus may remain there for very long periods of time. Some PCBs can exist as a vapour in air that can travel long distances and be deposited in areas far away from the point of release. In water, a small amount of PCBs might remain dissolved, but most stick to organic particles and bottom sediments. PCBs also bind strongly to soil and 
have the tendency to bioaccumulate and to concentrate through the food chain (Bernes, 1999; EPA, 2005).

The toxicity of PCBs has been intensively studied. Twelve PCB congeners have similar toxic responses to those caused by $2,3,7,8$-tetrachlorodibenzo-p-dioxin $(2,3,7,8$ TCDD). These PCB congeners can assume a planar dioxin-like conformation. They have a lower energy barrier to assume the conformation necessary to fit into dioxin receptor. Investigation of the biological effects of PCBs in experimental animals revealed the following syndromes: decreased reproductive efficiency, changes in liver morphology, changes in plasma lipid concentrations, hepatic porphyria, dermatological effects, production of tumors in the liver, and decreased immuno-competence (Erickson, 1997; Kannan, 2000; van den Berg, 2006). In addition to the twelve dioxin-like PCBs, seven PCBs are so-called "indicator PCBs": 28, 52, 101,118, 138, 153 and 180 (from tri- to hepta-chlorination) due to their ubiquity in the environment (van Leewen, 2008).

Organochlorine pesticides such as DDT, dieldrin, endrin, aldrin, lindane ( $\gamma$ $\mathrm{BHC}), \mathrm{HCB}$, chlordane were used as pesticides, very effective and with a broad spectrum of application, as insecticides, on animals and protection of humans (e.g. against malaria). They are found to be toxic for humans and some of them are possible carcinogens. Heptachlor and chlordanes are more readily metabolized, but in the process can convert to metabolites that are continue to exist longer and may be more toxic too: heptachlor-epoxide or oxy-chlordane. 


\subsection{SAMPLE PREPARATION}

The determination of halogenated organic contaminants in complex environmental samples starts with their extraction from the matrix. The extracts undergo a rigorous clean-up procedure to remove the possible interferences present along with the target compounds, followed by the final instrumental analysis.

\subsubsection{Extraction Techniques}

Complex sample preparation such as extraction, clean-up and extract fractionation is required prior to GC analysis. The choice of extraction technique, solvents, temperature, pressure, time of extraction influence the extraction efficiency and need to be carefully selected. There are different types of extractions of sediment and sludge samples and the most common used is Soxhlet extraction. Accelerated solvent extraction is considered over the classical technique due to its advantages (see section 2.2.1.2 Accelerated Solvent Extraction). Other extraction techniques such as microwave assisted extraction (MAE), sonication and supercritical fluid extraction (SFE) have also been employed for POPs analysis in environmental samples.

\subsubsection{Soxhlet Extraction}

The most common procedure employed for the extraction of trace halogenated compounds from a wide variety of matrices such as sediments, soils and biota is Soxhlet extraction. There are numerous advantages when using this type of extraction: the method is simple and does not require expensive equipment, multiple extractions can be 
done at the same time and can be employed for many matrices and classes of contaminants. The extraction efficiency is very high but the drawbacks of the method are the long extraction times required (approximately 6-24h) and use of large amounts of solvent (van Leeuwen, 2008; Focant, Pirard and De Paw, 2004). Thus, more automated and faster extraction methods have been developed. Ultrasonic extraction was one of the techniques potentially to replace Soxhlet extraction. It has comparable extraction efficiency and the advantages of reduced extraction time, decreased volume of solvent and sample and replacement of fragile Soxhlet glassware (Erickson, 1997).

\subsubsection{Accelerated Solvent Extraction}

Different types of extraction have been demonstrated to be suitable for sediment and sludge matrices; pressurized liquid extraction (PLE or Accelerated Solvent Extraction - ASE - Dionex Corporation) being one of the techniques that has drawn attention in recent years. The extraction takes place in a stainless steel cell (of 11, 22 or $33 \mathrm{ml}$ fitted with stainless steel frits and a cellulose filter) that can be heated up to $200^{\circ} \mathrm{C}$ and pressurized to 3000 psi. Usually one or two static extractions employed. The extraction efficiency of ASE was found to be similar to that of Soxhlet extraction. In addition, ASE has some advantages over traditional techniques: the enhanced extraction efficiency achieved by solvents at high pressures and temperatures uses less solvent volume and much less time (Schantz, 2006). The ASE was successfully applied to biota and sediment samples for PCBs and OCs extraction. The conditions were optimized for high recovery in the extraction procedure for different environmental matrices: extraction time, temperature, and the use of different solvents. Different types of solvents were tried 
in order to maximize the recoveries for all compounds. An increase in extraction temperature often leads to higher recoveries, especially of volatile compounds where the temperature is one of the most important parameters. The effect of the pressure on the recovery was studied in the range between 500 and 2500 psi, and did not have any significant influence on the extraction (Saito, 2004; Ramos, Kristenson, Brinkman, 2002; Hubert et al., 2000). Toluene was found to be one of the best extraction solvents for soil and sediments samples (Hubert et al., 2000). A drawback of ASE is the crosscontamination; the cells have many parts and should be cleaned thoroughly.

\subsubsection{Cleanup}

Prior to the instrumental analysis, the extracts need to be cleaned up and split into multiple fractions. The clean-up of PCBs and OCs is often combined, the non-polar PCBs being separated from the more polar OC by silica or florisil fractionation. The PCBs and $\mathrm{CBz}$ are eluted usually with a non-polar solvent (hexane) in the first fraction followed by the elution with a more-polar solvent (ethyl ether and dichloromethane mix) to collect the OCs. Open column chromatography or pre-packed cartridges can be used (Ontario Ministry of the Environment, Method 3270, 2008; Erickson, 1997; van Leeuwen, 2008). The drawback of splitting into multiple fractions is that some of the OCs are eluting in the first fraction along with the $\mathrm{PCBs}$ and $\mathrm{CBz}$ making the chromatographic analysis more difficult. Some examples of these OCs are p,p'-DDE, o,p-DDT, mirex, photomirex, hexachlorobenzene, octachlorostyrene and trans-nonachlor. Other methods use multilayer silica columns where impregnated acidic and basic silica alternate with regular silica to remove the lipids and other oxidizable compounds present in complex matrices. 
Alumina, a classic inorganic adsorbent, was also used for the sediment and soil extracts clean-up. Similar to silica and florisil, some of the OCs were recovered in the first fraction along with the PCBs. When structural separation was required, the separation of coplanar PCBs from the other compounds and interferences, carbon clean-up was employed (Erickson, 1997; Focant et al., 2004; van Leeuwen, 2008).

Recent studies have integrated the clean-up step within the extraction process. For instance, Bjorklund et al. (Bjorklund, Sporring, Wiberg, Haglund and Holst, 2006) has added different adsorbents into the ASE extraction cell and assessed the extraction and clean-up together. He achieved the structural separation of coplanar PCBs when custom made carbon cell-inserts were made.

\subsection{ANALYSIS}

\subsubsection{Gas Chromatography Analysis}

Following the sample preparation steps, classical instrumental analysis involves several GCs equipped with different stationary phases able to separate specific classes of contaminants present in the final fractioned extracts. Typically, sample analysis for PCBs, OCs and $\mathrm{CBz}$ employs gas chromatography (GC) coupled with electron capture detector (ECD) or mass spectrometry (MS). The electron capture detector is often the choice for $\mathrm{PCB} / \mathrm{OC} / \mathrm{CB}$ detection due to its high sensitivity for halogenated compounds. A major drawback of the ECD is the lack of selectivity between halogenated compounds, therefore requiring chromatographic separation in order to obtain accurate quantitative results. In a capillary gas chromatography review J. de Boer (de Boer, 1999) summarized some of the challenges that analysts encounter when analyzing organochlorine pesticides. 
For instance, the chlordane congeners tend to split between the fractions and coelute with PCBs making their analysis difficult. Cochran and Frame (Cochran and Frame, 1999) reviewed the gas chromatography separation of PCB congeners on different stationary phases. They concluded that no single column phase can resolve all the congeners even when advanced detection techniques such as mass spectrometry are involved.

Conventional GC offers good peak capacity but it fails to separate many individual constituents in complex environmental samples. The introduction of comprehensive two-dimensional gas chromatography (GCxGC) provided significant increases in separating power, peak capacity and speed of analysis (Dalluge et al., 2003).

\subsubsection{Comprehensive two-dimensional gas chromatography}

Comprehensive two-dimensional gas chromatography, a relatively new way to solve separation problems, is successfully used for complex environmental samples. The introduction of comprehensive two-dimensional gas chromatography (GCxGC) provided significant increases in separating power, peak capacity and speed of analysis. In the past few years, many studies have demonstrated the applicability of GCxGC for different environmental matrices. The goal of this review is to summarize the principles and configuration of the $\mathrm{GCxGC}$ technique highlighting the applications on halogenated contaminants analysis.

\subsubsection{Principles and Instrumentation}

GCxGC involves two columns coupled directly, where two different separation mechanisms are applied to the entire sample. A thermal modulator serves as the interface 
component that couples the two columns. GCxGC is a truly comprehensive technique because the information gained from the separation on the first column is preserved in the second column (Dallüge, Beens and Brinkman, 2003). The peak capacity is increased by applying two independent separations to a sample, resulting in improved resolution of target compounds in a single analysis. Under optimal conditions, comprehensive GCxGC can provide an order of magnitude lower saturation of a chromatogram compared to its 1D counter-part based on similar conditions.

The instrumental set-up involves a serial column configuration usually having a 15-30 $\mathrm{m} \times 0.25-0.32 \mathrm{~mm}$ I.D. $\times 0.1-1 \mu \mathrm{m}$ film thickness as first dimension (1D) column and a much shorter, narrower $0.5-2 \mathrm{~m} \times 0.1 \mathrm{~mm}$ I.D $\times 0.1 \mu \mathrm{m}$ film thickness as second dimension (2D) column. The shorter second dimension column is necessary in order to maintain the first column separation and to ensure that the second dimension separation is completed in the run time of the first dimension analysis (Dalluge et al., 2003; Adahchour, Beens, Brinkman, 2008; Marriott and Shellie, 2002). The second dimension run time is in order of 1-10 s compared to 45-120 min first dimension separation (Dalluge et al., 2003). A schematic representation of a GCxGC instrument is presented in Figure 2.1 . 


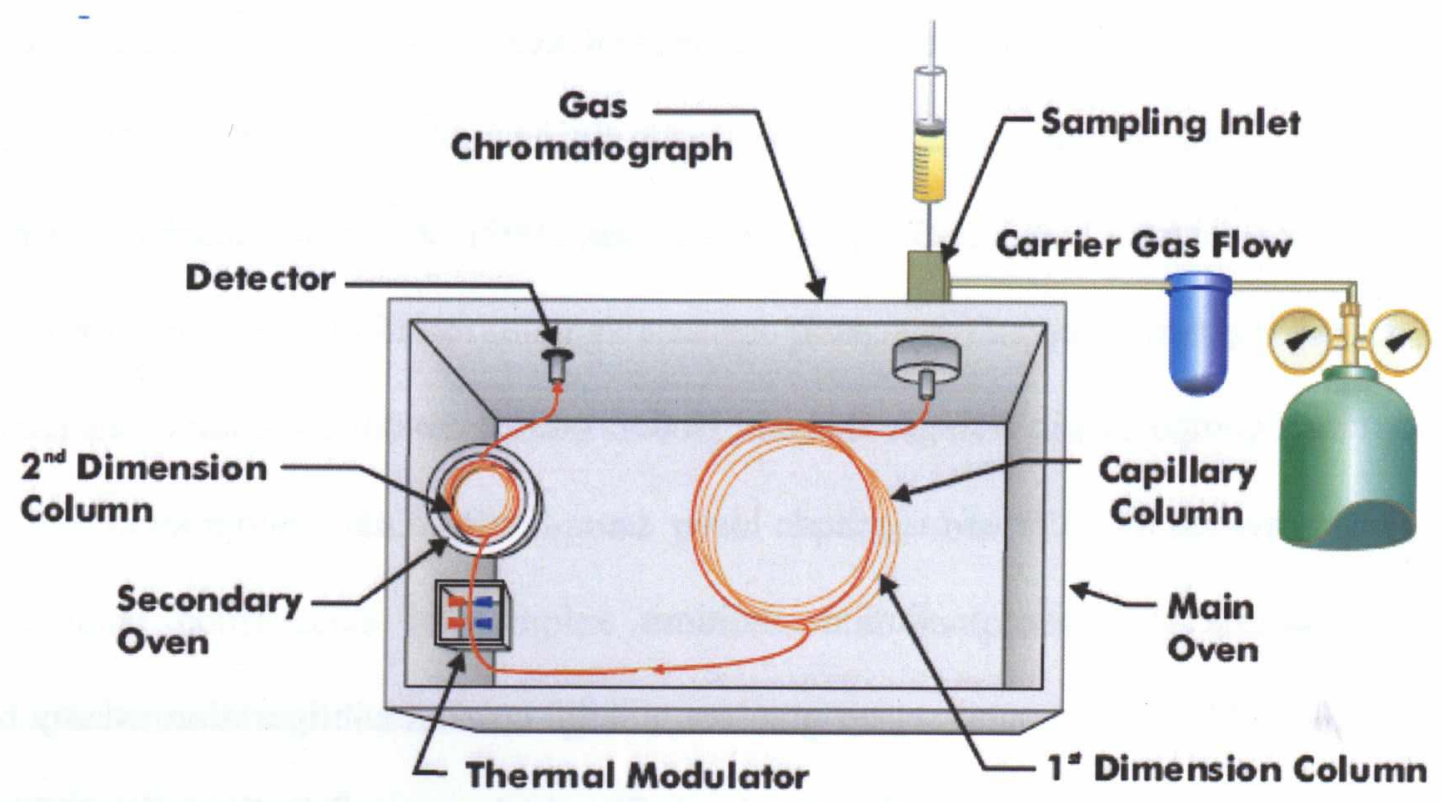

Figure 2.1 Schematic representation of a GCxGC system: $1^{\text {st }}$ dimension column modulator $-2^{\text {nd }}$ dimension column (from LECO, 2008).

The result of a GCxGC analysis, as presented by Dalluge et al. (Dalluge et al., 2003), consists of a large series of stacked side by side GCxGC chromatograms (Figure 2.2 - step 1. Modulation) that are "transformed" (Figure 2.2 - step 2. Transformation) to form a two-dimensional chromatogram. The chromatograms can be visualized as contour plots in the $2 \mathrm{D}$ plane where the colours represent the signal intensity or as threedimension plots (Figure 2.2 - step 3. Visualisation). 


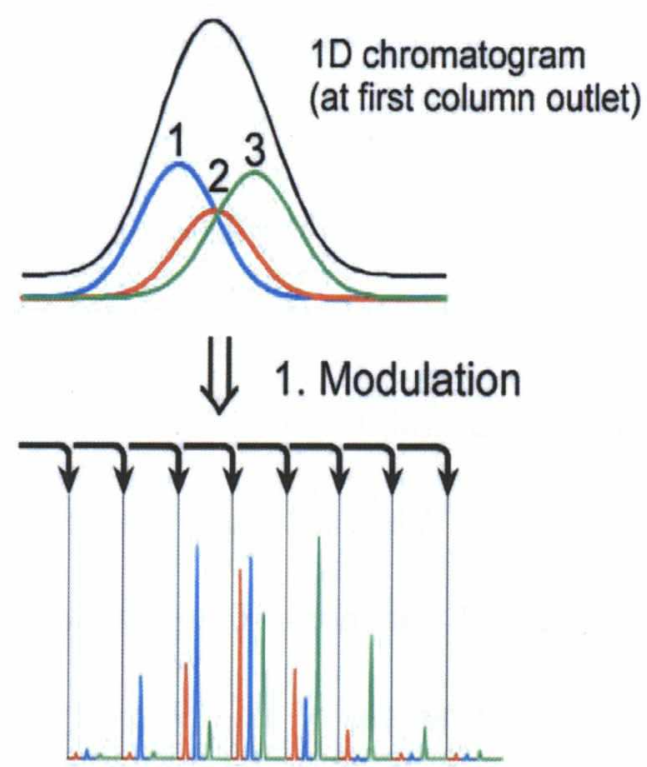

Raw 2D chromatogram (at second column outlet)

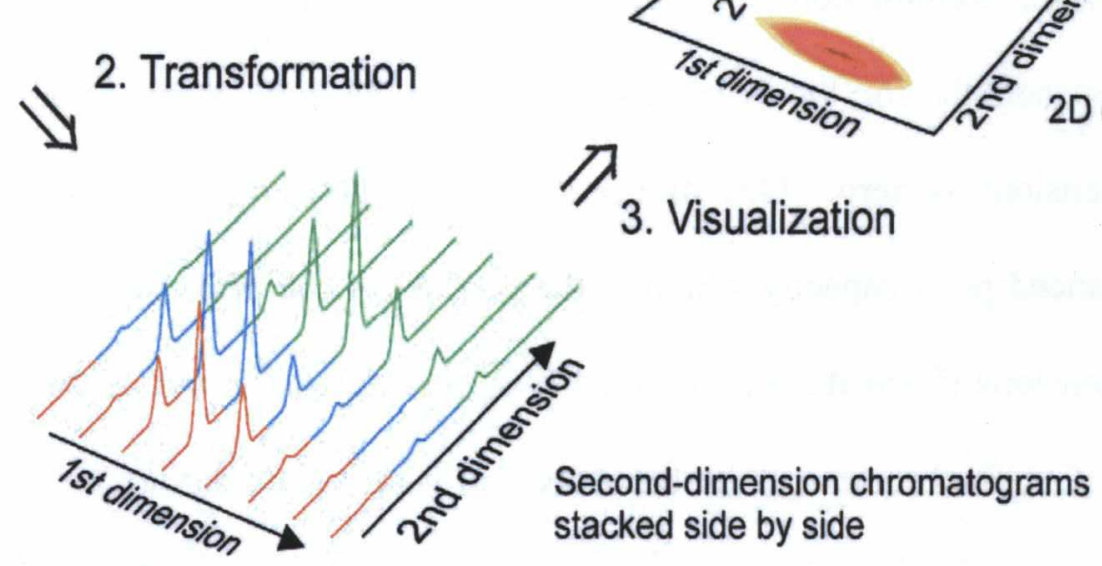

Figure 2.2 The schematic representation of GCxGC chromatogram: generation and visualisation (Dalluge et al., 2003).
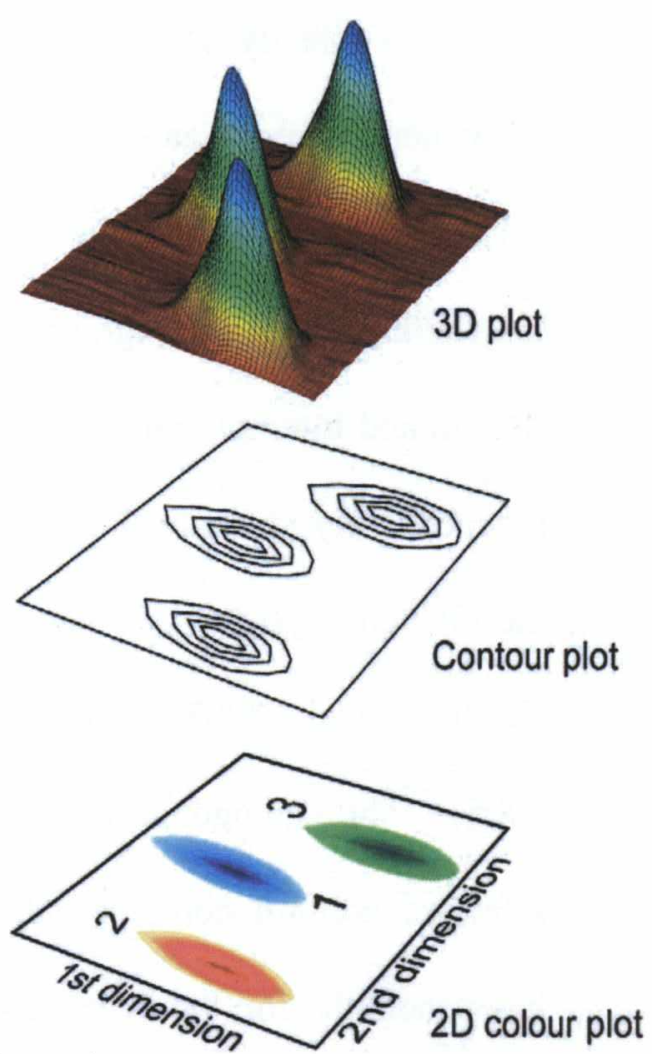

3. Visualization
Second-dimension chromatograms stacked side by side 


\subsubsection{Column Combinations}

As already described, GCxGC involves a serial column configuration separated by a thermal modulator. The role of the primary column is to provide the secondary column with sub-samples of the original sample, and the role of the secondary column is to generate a series of high speed chromatograms. The parameters of the two dimensions (length and internal diameter, column temperature, and mobile-phase linear velocity) are independently chosen (Dimandja, 2004, Pierce, 2008). When selecting the columns for the GCxGC system, one has two choices: orthogonal and non-orthogonal approaches (Dalluge et al., 2003; Adahchour et al. 2006; Venkatramani et al., 1996; Ryan et al., 2005). The orthogonal separation, usually involving a non-polar and polar or shapeselective column combination, is achieved when the separation mechanisms operate independently for the two dimensions and the synentropy (cross information) across dimensions is zero. One of the advantages of using an orthogonal separation is the enhanced peak capacity which is the product of the peak capacities of the two separate dimensions (Venkatramani et al., 1996). Structured chromatograms are distinctly visible in GCxGC chromatograms for structurally related compounds, allowing easier grouptype identification. The non-orthogonal approach, the combination of polar column as first dimension and non-polar column as the second dimension, was also studied and some significant separations were reported (Dalluge et al., 2003; Ryan et al., 2005; Haglund et al., 2001; Marriott, Massil, Hügel, 2004), but a comprehensive discussion of these findings is beyond the scope of this study. For more information about the columns used for GCxGC please see Appendix D. 
Typically orthogonal separation involves non-polar columns as first dimension (e.g. DB-1, Rtx-1, Rtx-5, HP-5MS, HT-5) and polar or shape-selective columns as second dimension (e.g. DB-17, HT-8, LC-50, Rtx-PCB). Table 2.1 shows some of the column combinations used by different researchers to separate the PCB and organochlorine pesticides in standard mixtures, as well as some of the conditions used for their analysis. 


\begin{tabular}{|c|c|c|c|c|}
\hline हैं & 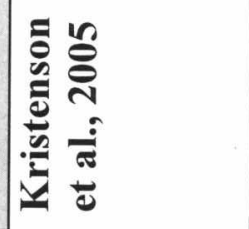 & 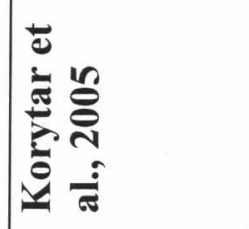 & 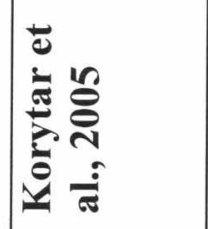 & 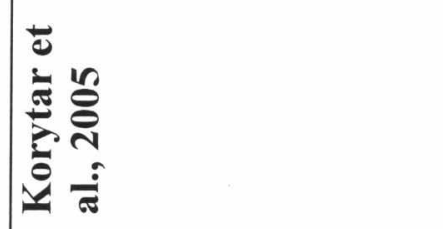 \\
\hline 㞯 & & 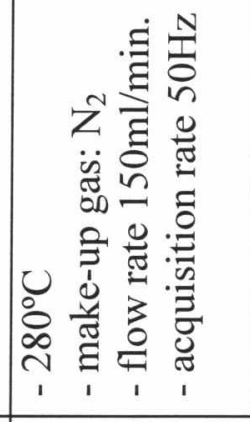 & 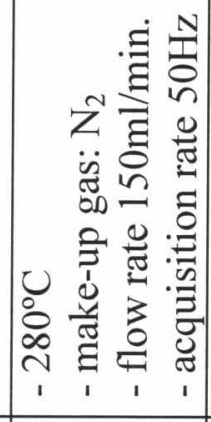 & \\
\hline 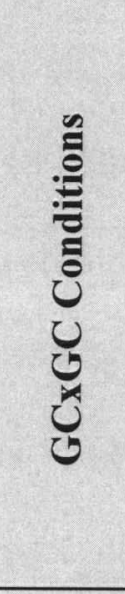 & 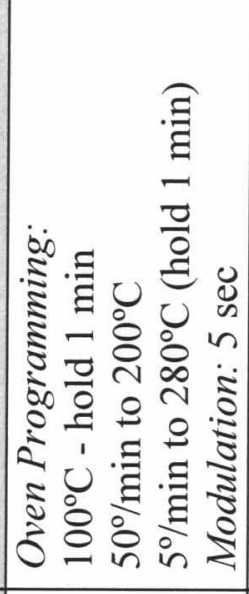 & 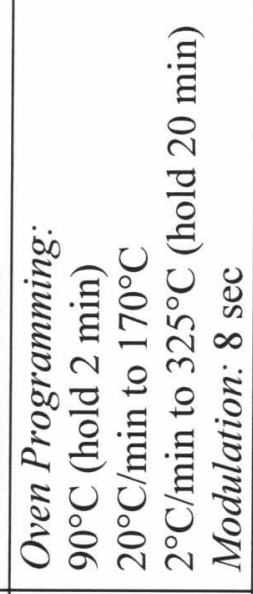 & 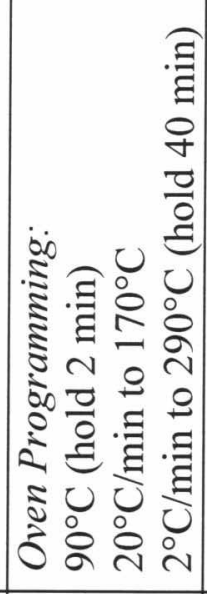 & 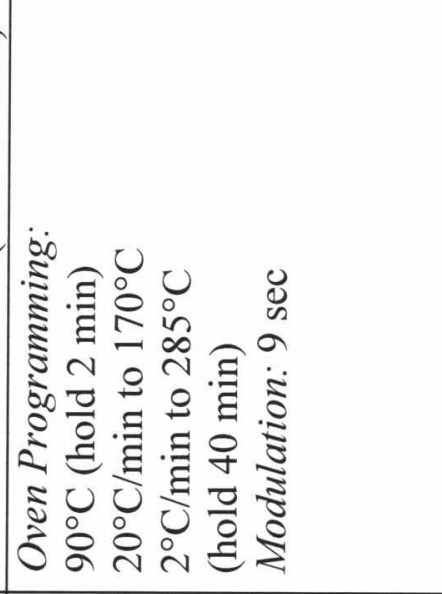 \\
\hline 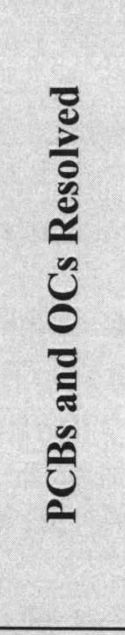 & 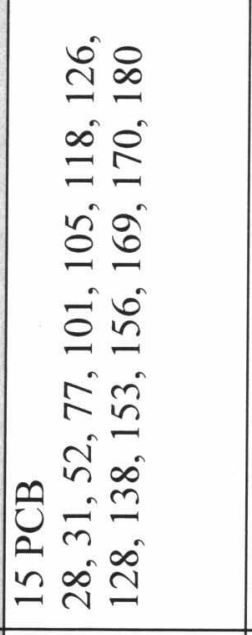 & 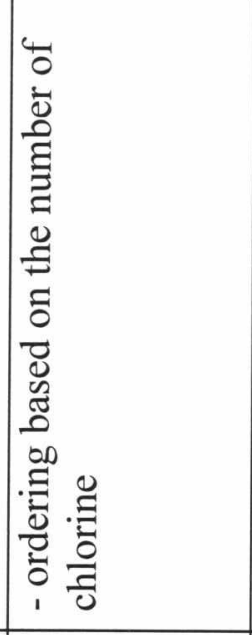 & 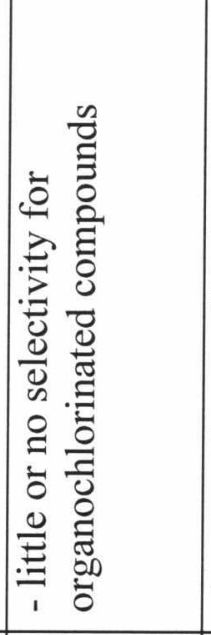 & 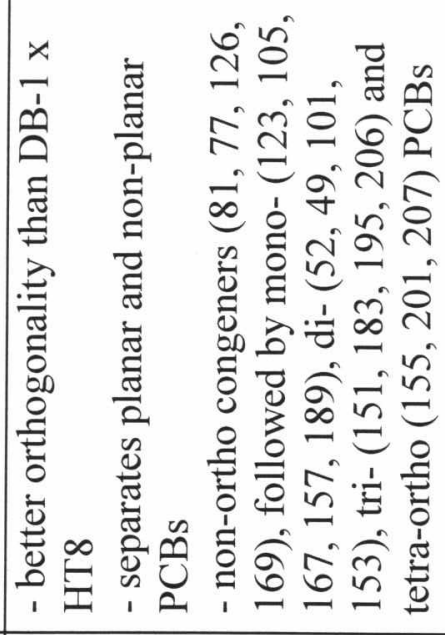 \\
\hline 㤩 & 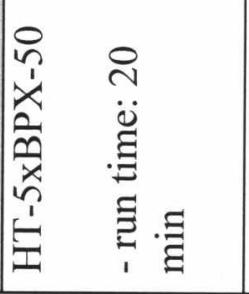 & 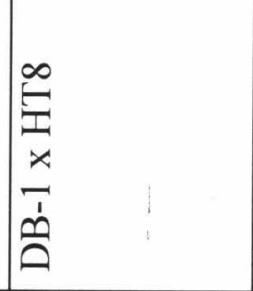 & 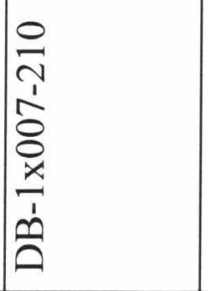 & 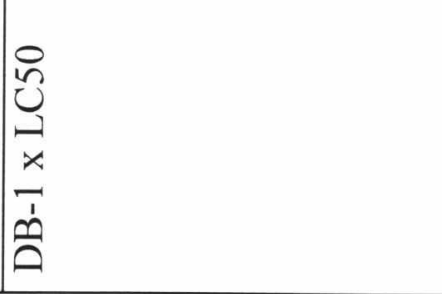 \\
\hline
\end{tabular}


Chapter 2: Literature Review

\begin{tabular}{|c|c|c|c|c|c|}
\hline$\frac{8}{8}$ & 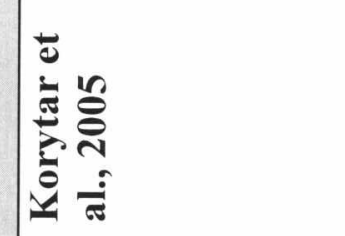 & 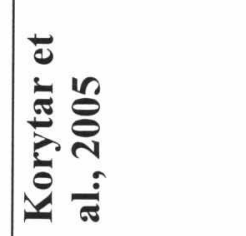 & 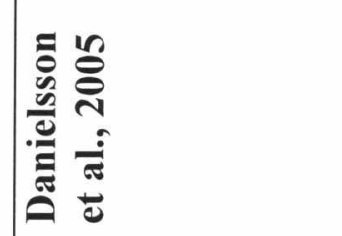 & 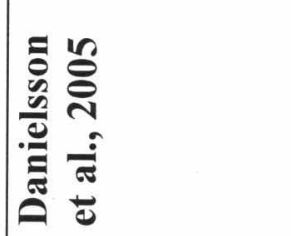 & 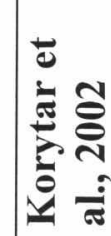 \\
\hline$\underset{\text { 它 }}{0}$ & & & 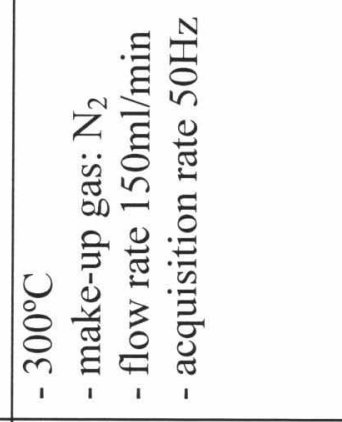 & 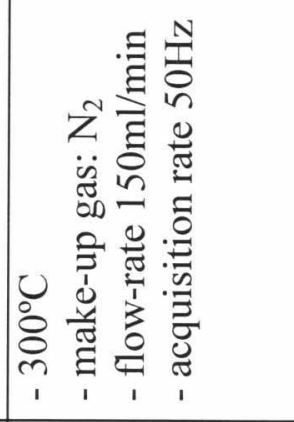 & 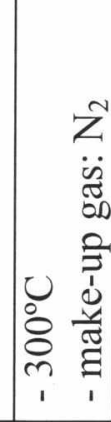 \\
\hline 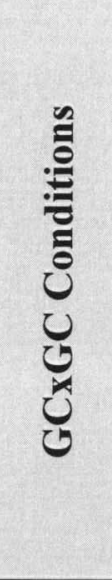 & 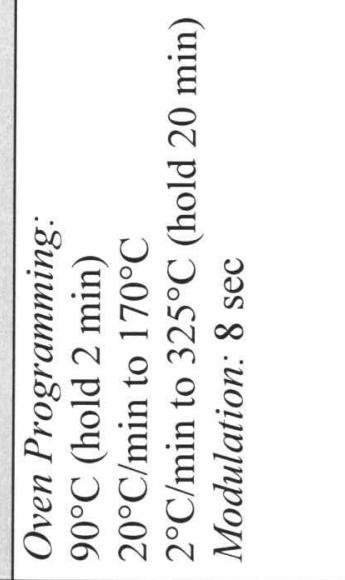 & 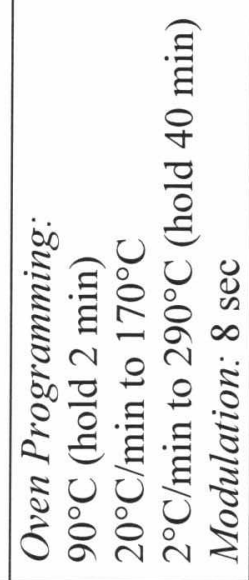 & 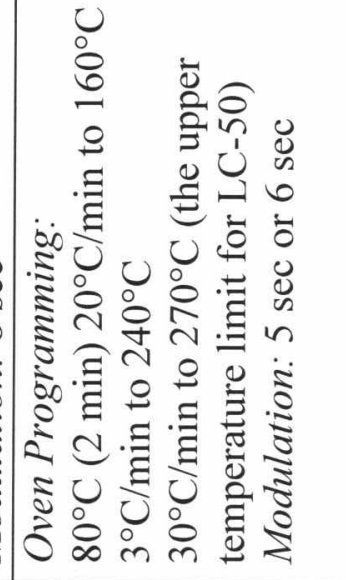 & 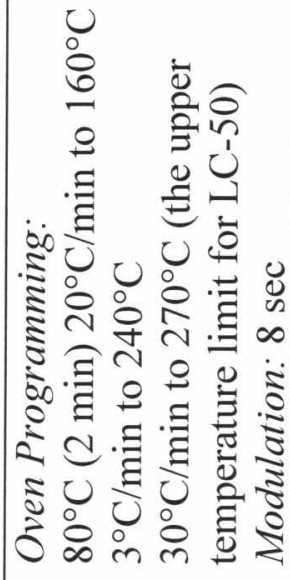 & 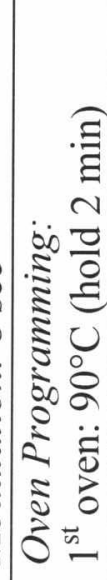 \\
\hline 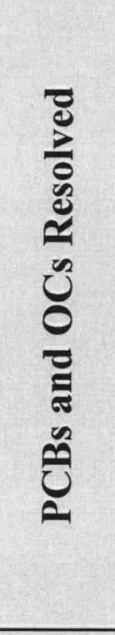 & 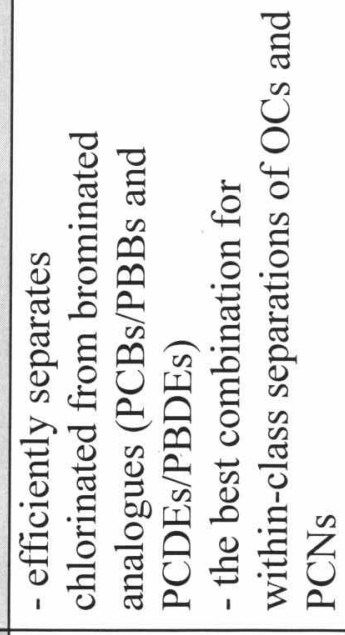 & 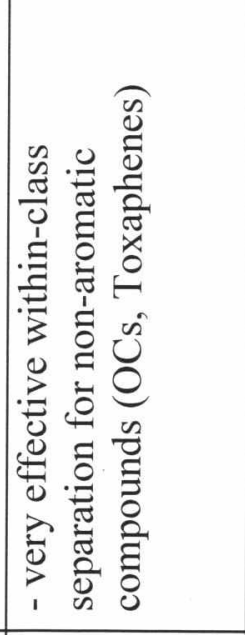 & 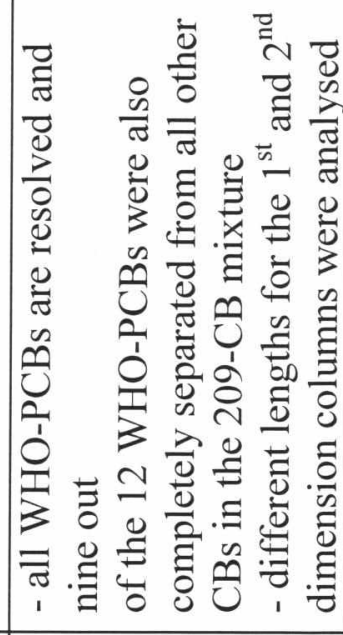 & 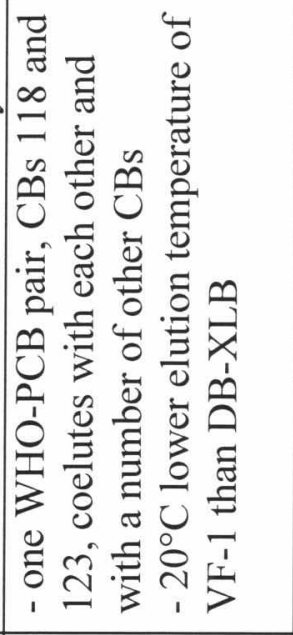 & 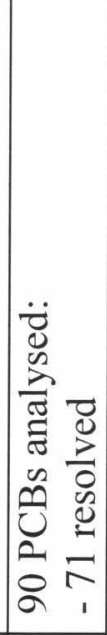 \\
\hline 豆 & 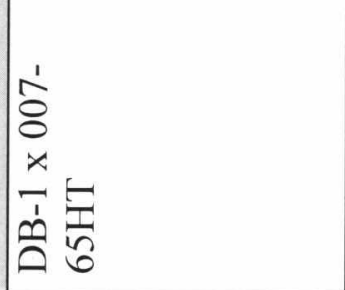 & 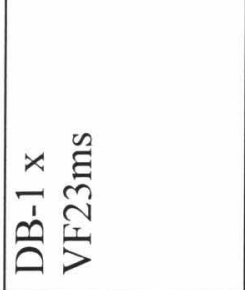 & 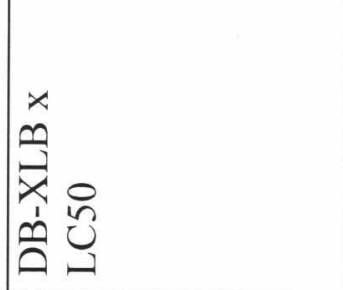 & $\begin{array}{l}8 \\
i \\
0 \\
\frac{1}{x} \\
\frac{1}{7}\end{array}$ & 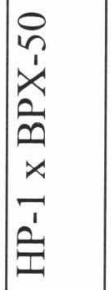 \\
\hline
\end{tabular}


Chapter 2: Literature Review

\begin{tabular}{|c|c|c|c|c|c|}
\hline$\frac{8}{8}$ & & 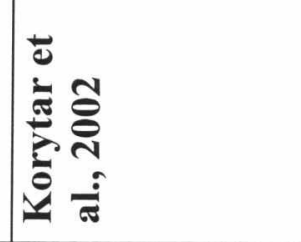 & 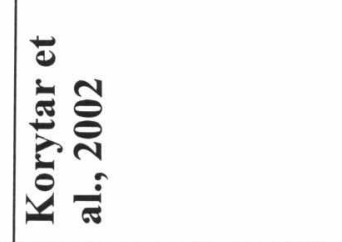 & 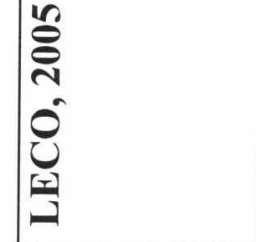 & 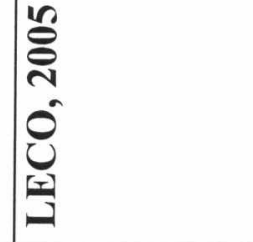 \\
\hline 己ે & 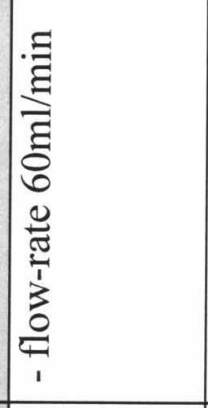 & 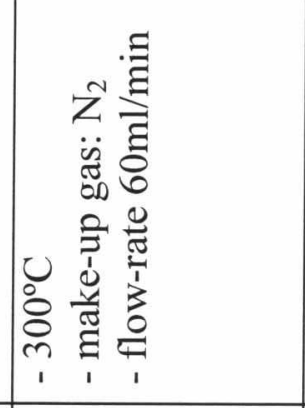 & 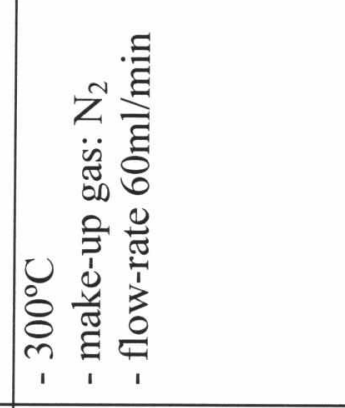 & 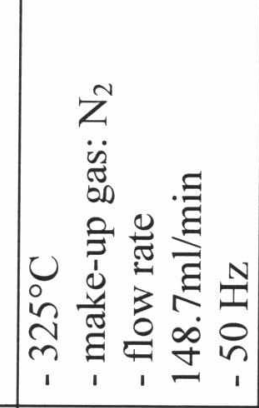 & 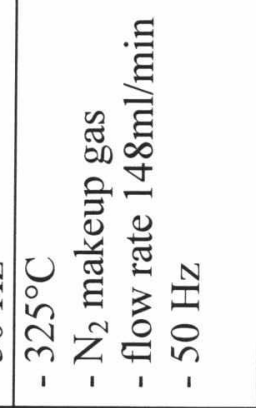 \\
\hline ن⿺ & 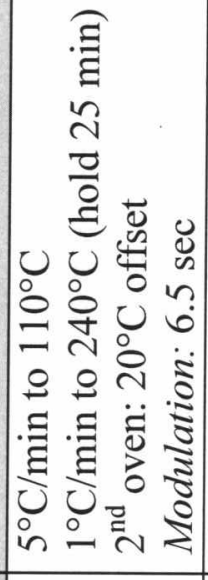 & 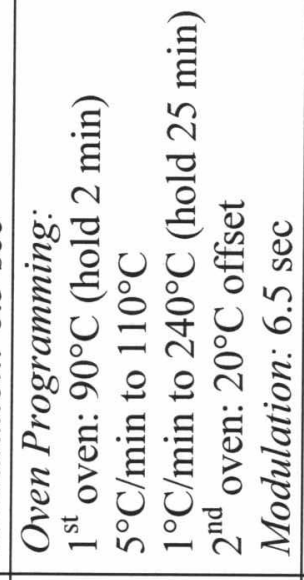 & 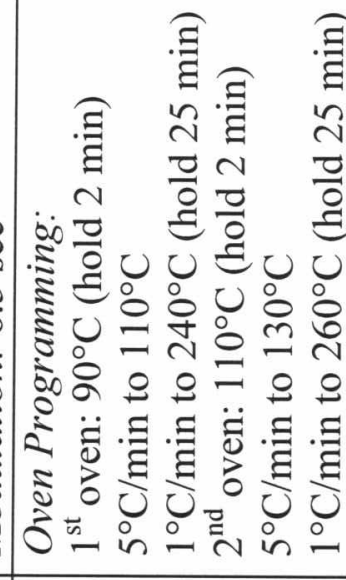 & 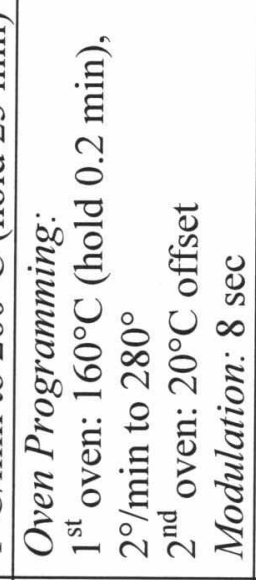 & 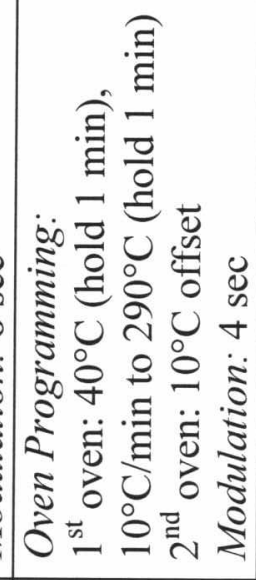 \\
\hline 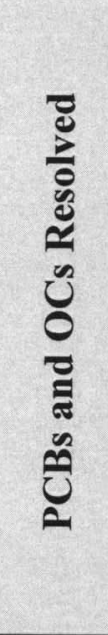 & 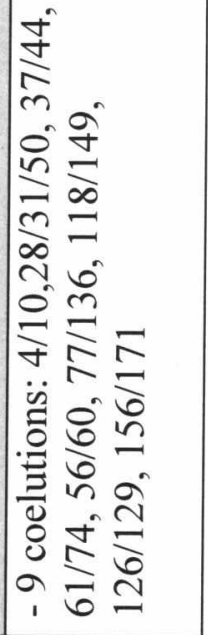 & 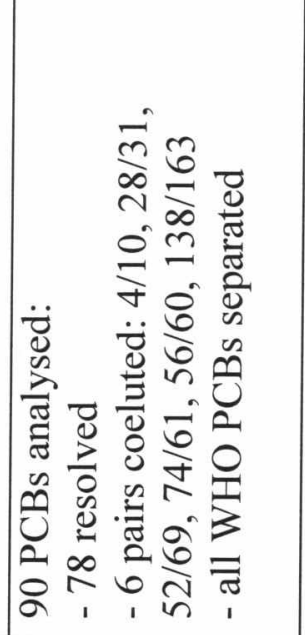 & 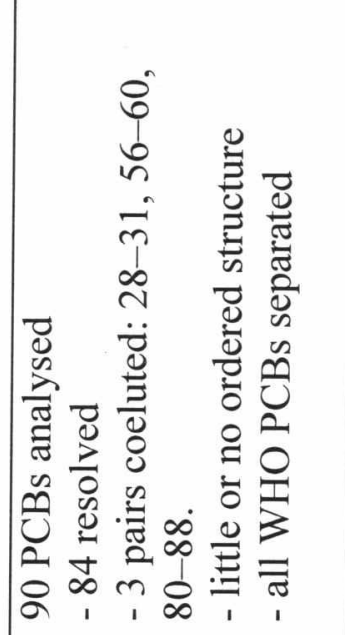 & 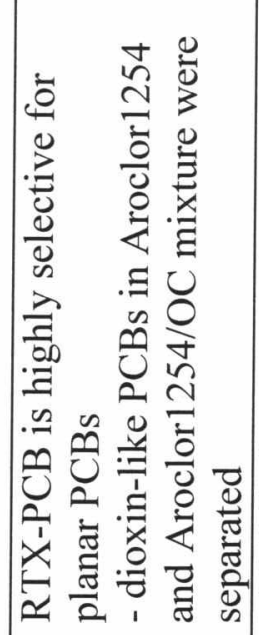 & 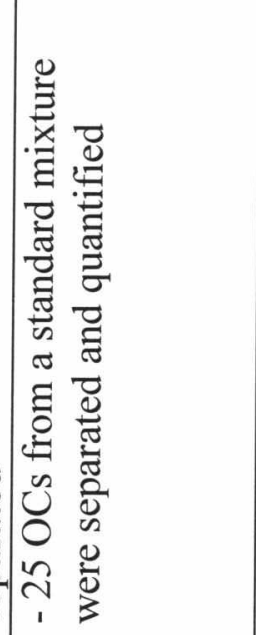 \\
\hline 三 & & 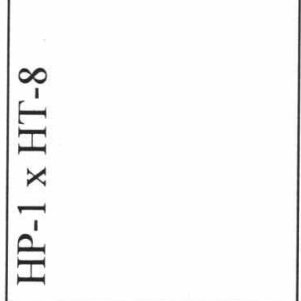 & 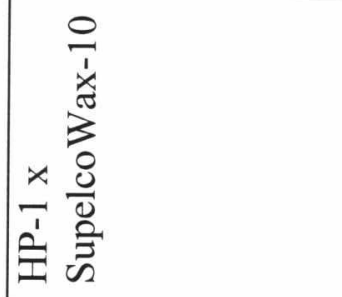 & 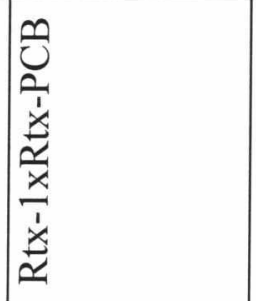 & 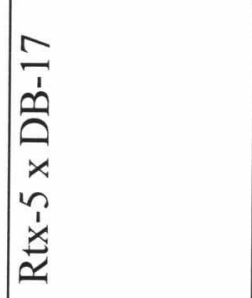 \\
\hline
\end{tabular}


Chapter 2: Literature Review

\begin{tabular}{|c|c|}
\hline 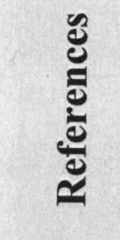 & 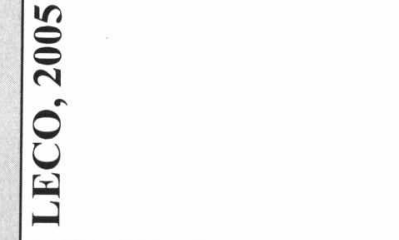 \\
\hline ક્|િ & 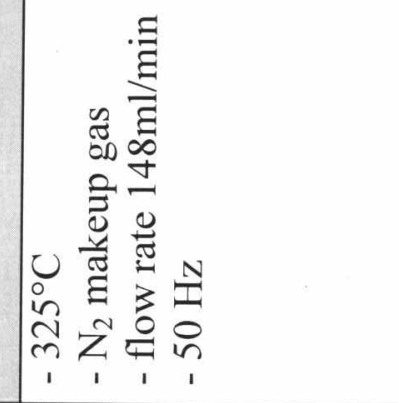 \\
\hline 节 & 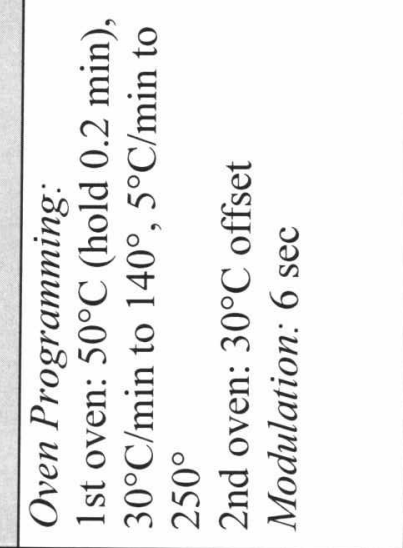 \\
\hline 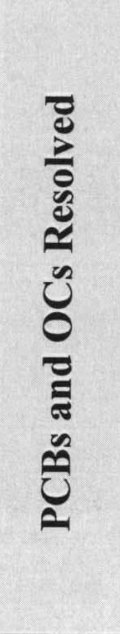 & 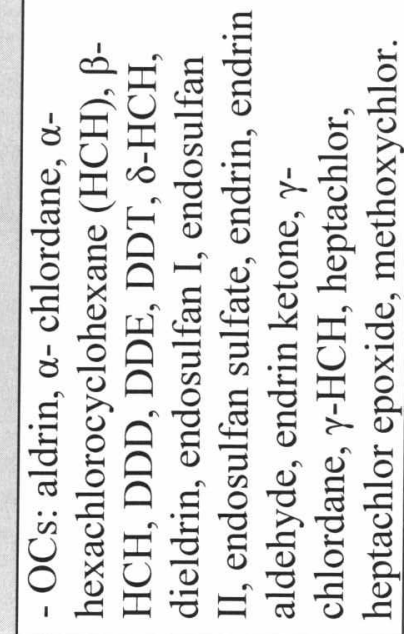 \\
\hline 总 & 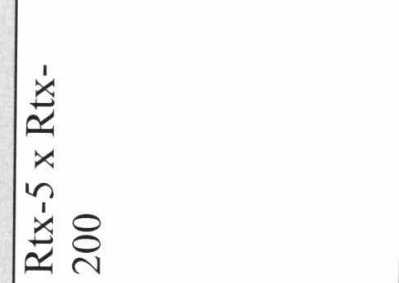 \\
\hline
\end{tabular}


In other studies researchers tried to separate all 209 PCB congeners using GCxGC-TOFMS (Focant et al., 2004) and $\mu$ ECD (Harju, Danielsson, and Haglund, 2003). Harju has achieved the separation of 181 when using DB-XLB x LC-50 column combination in a time frame of $90 \mathrm{~min}$ (Figure 2.3a). When using DB-XLB column connected to BPX-70, 194 out of 209 PCBs were separated in a time frame of 4 hours (Figure 2.3b). The DB-XLB x SP-2340 was used to analyse halogenated contaminants in seal blubber extract; 64 PCBs were identified and quantified. In addition, p,p'-DDE was found to be very abundant in this sample (Harju et al.). Using different column combinations for the GCxGC-TOF-MS system, DB-1 x HT-8, DB-XLB x HT-8, and HT8 x BPX-50, Focant (Focant et al., 2004) has successfully resolved 194 PCB congeners. The best column combination was HT-8 x BPX-50 which resolved 194 congeners in 146 min analytical run. An ordered structure was observed in the second dimension for structurally related compounds. The ordered structure of the two dimensional chromatograms provided better information of the group-type separation according to the number of chlorines and ortho-subtitution level. 

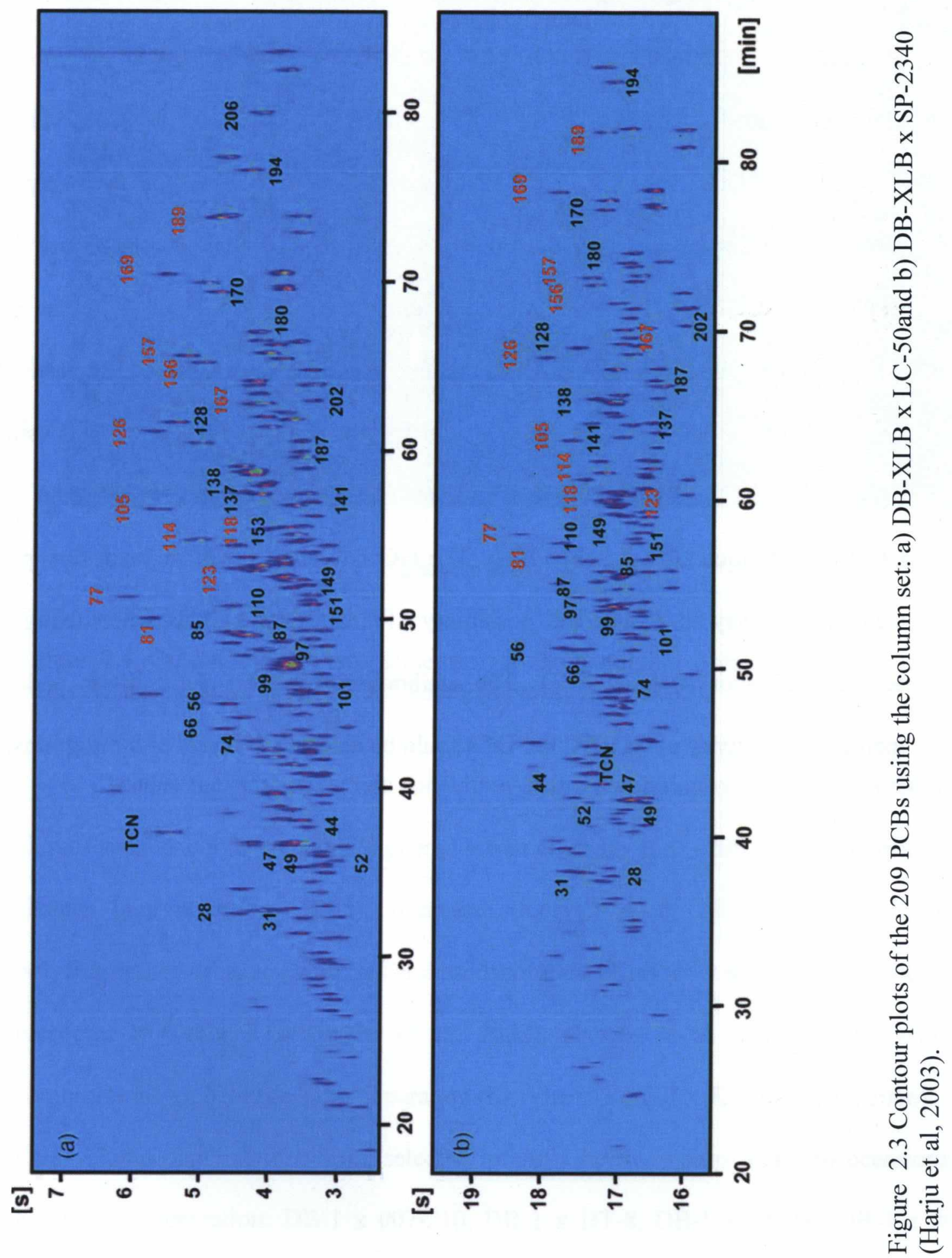
Similar to PCBs, Korytar et al. (Korytar et al., 2005) has assessed the separation of organochlorine pesticides by GCxGC- $\mu \mathrm{ECD}$ using different column combinations. They concluded that DB- $1 \times 007-65 \mathrm{HT}$ column combination showed very good distribution of OCs in the 2D plane (Figure 2.4) and solved the cis- and trans-heptachlorepoxide coelution present with $\mathrm{DB}-1 \times \mathrm{VF} 23$. Additionally, technical notes provided by LECO (LECO, 2005) regarding the separation of OCs (see Table 2.1) also provide information for their linearity and calibration. One of these studies, "OC pesticides by GCxGC" (LECO, 2005), provided a comparison of the classical GC analysis using dual column GC-ECD (Rtx-CLPesticide and Rtx-CLPesticidesII as 1D columns) and the GCxGC technique (Rtx-5 x Rtx-200). The GCxGC was shown to be a very powerful technique, a way to reduce the possibility of quantification bias when using a nonselective detector such as ECD. The calibration responses were linear and due to increased sensitivity of GCxGC the OCs could be detected at levels of femtograms. 


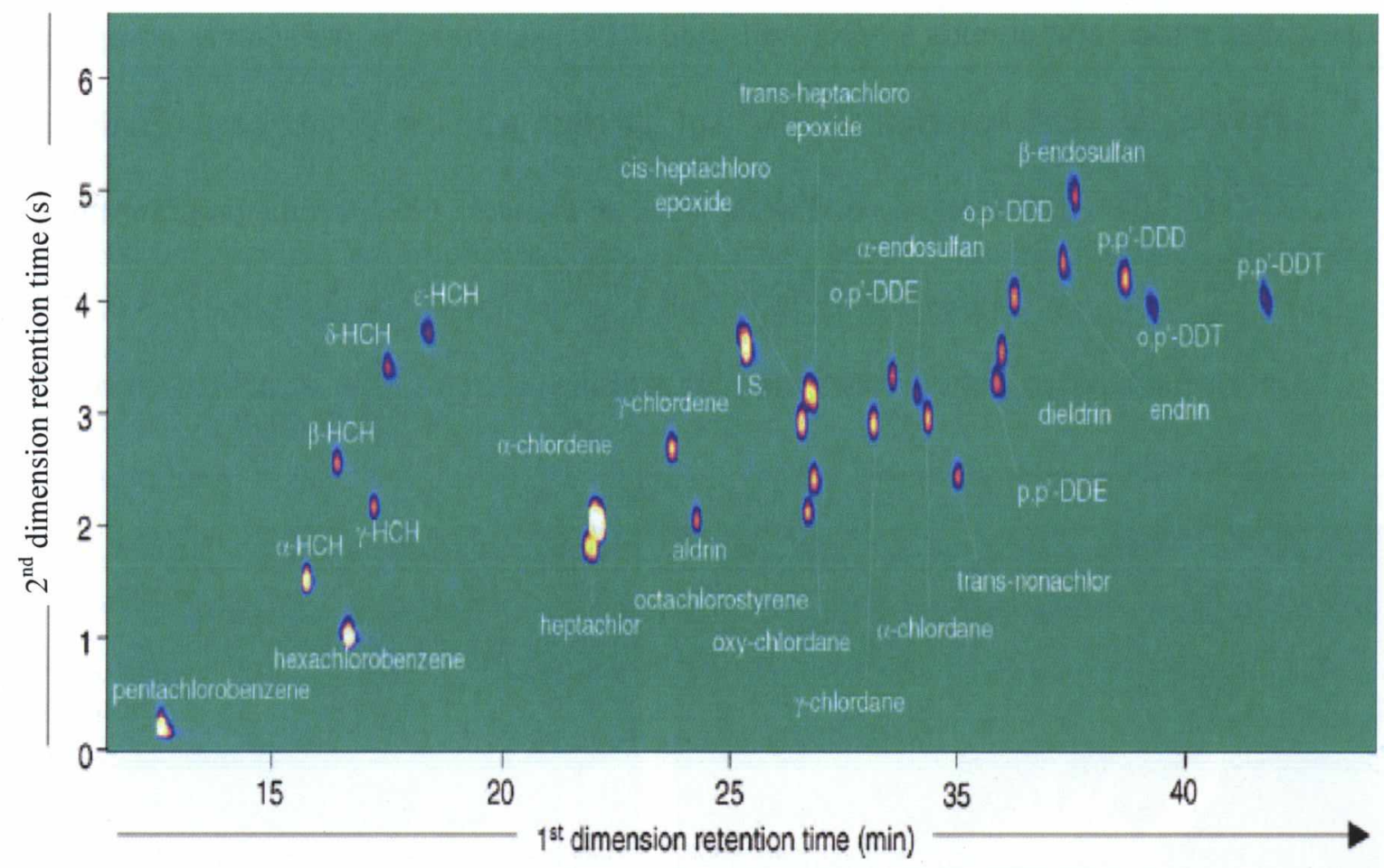

Figure 2.4 GCxGC- $\mu$ ECD two dimensional chromatogram obtained for selected $\mathrm{OC}$ pesticides analysed with DB-1×007-65HT (Korytar et al., 2005).

Besides the progress made for within-group separation of different contaminant classes such as polybrominated diphenyl ethers (Korytar et al., 2005), polychlorinated nalkanes (Korytar et al., 2005), toxaphene (Korytar et al., 2003), 2,3,7,8-substituted polychlorinated dibenzo-p-dioxins and dibenzofurans (Korytar et al., 2003), and PCBs as presented in Table 2.1 (Korytar et al., 2002), Korytar et al. has evaluated column combinations for between-class separation (Korytar et al., 2005; Korytar et al., 2006).

Five column combinations were selected to study between-class and also occasionally within-class separation: DB-1 x 007-210, DB-1 x HT-8, DB-1 x LC-50, DB-1 x 007$65 \mathrm{HT}$ and DB-1 x VF-23ms. They concluded that DB-1 x LC-50 column combination was the best choice for between-group separation: three-ring planar compounds (PCDD/Fs, PCDTs and planar PCTs) were most strongly retained, followed by the two- 
ring planar compounds ( $\mathrm{PCNs}$ and planar $\mathrm{PCBs}$ ), then the non-planar compounds that showed the least retention and did not interfere with the planar ones (Figure 2.5).The $\mathrm{GCxGC}$ chromatographic conditions were as follows; temperature programming started at $90^{\circ} \mathrm{C}$ (hold for $2 \mathrm{~min}$ ), at $20^{\circ} \mathrm{C} / \mathrm{min}$ to $170^{\circ} \mathrm{C}$, then at $2^{\circ} \mathrm{C} / \mathrm{min}$ to $285^{\circ} \mathrm{C}$ (hold for 40 min); modulation period was 9 seconds and the constant flow of helium carrier gas was $1.2 \mathrm{ml} / \mathrm{min}$. 

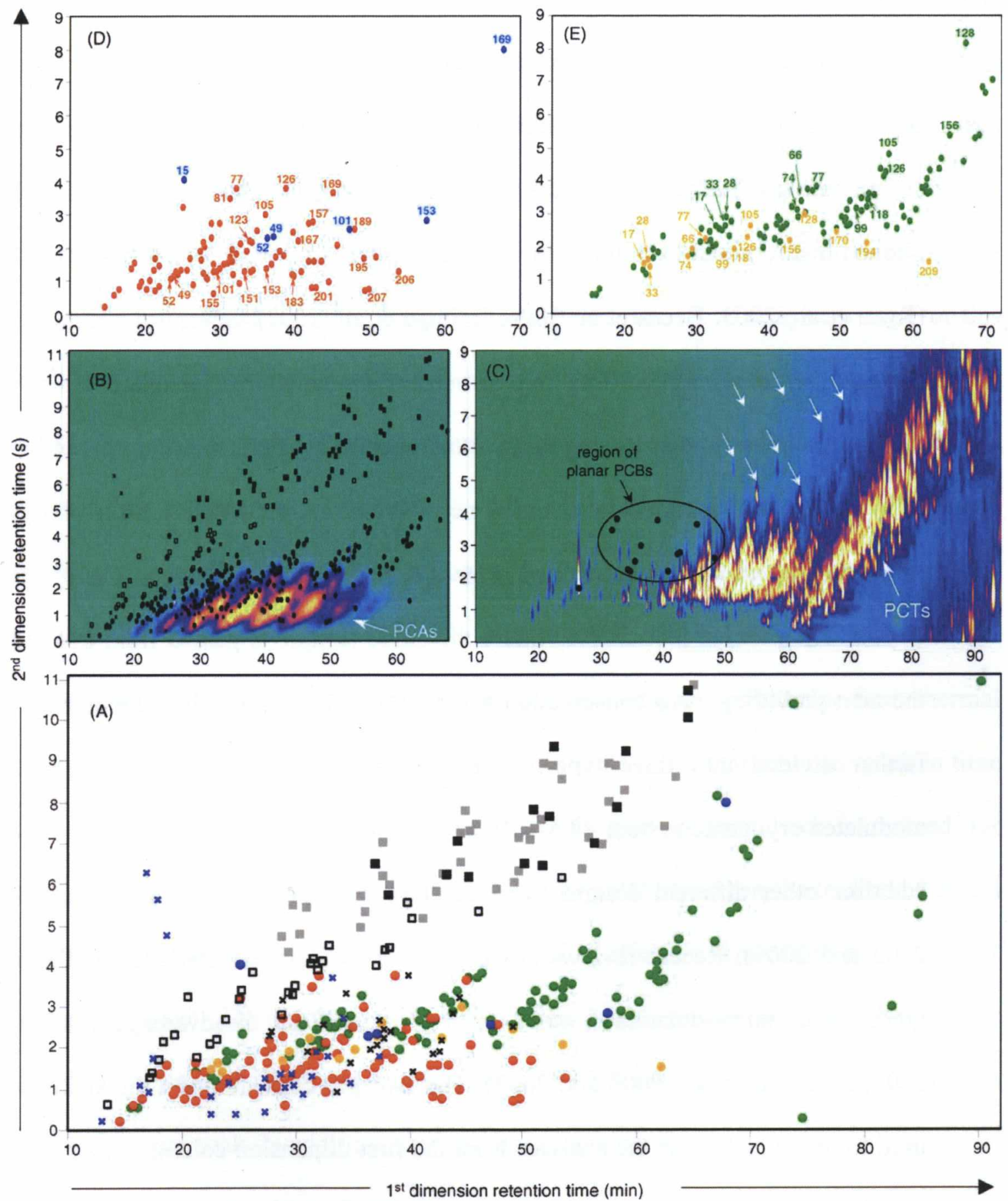

Figure 2.5 Overlaid GC $\times \mathrm{GC}-\mu \mathrm{ECD}$ chromatograms on $\mathrm{DB}-1 \times \mathrm{LC}-50$ column combination of: (A) PCBs, PBBs, PCDEs, PBDEs, PCDTs, PCNs,PCDD/Fs, OCPs, individual toxaphene standards; (B) PCAs (PCA-60) as colour contour plot and other classes as black dots; (C) PCTs (Aroclors5442 and 5460) as colour contour plot and visualized position of dioxin-like PCBs (black dots) and planar PCTs (white arrows); (D) PCBs and PBBs; (E) PBDEs and PCDEs (Korytar et al., 2005). 


\subsubsection{Modulation}

The modulator represents the interface component between the two dimension separations. The primary functions of an efficient modulator are to continuously accumulate small adjacent fractions eluting from the first column effluent, to refocus the trapped fractions and to re-inject the focused fractions into the second dimension column (Ryan et al., 2003; Beens et al. 2004; Dalluge et al., 2003). Several different modulator designs can be classified into two groups: flow-switching modulators and thermal modulators. The flow-switching modulators operate as high-frequency diversion valves $(0.1-1.0 \mathrm{~Hz})$ and require low maintenance. However, whether this form of GCxGC is truly comprehensive was questioned in several studies (Dimandja et al., 2000; Dimandja, 2004). The thermal modulators, where the entire sample is passed from one column to the next providing mass conservation and resulting in peak amplitude enhancement, are further divided into three types: heat (thermal sweeper), cryogenic (longitudinally modulated cryogenic system - LMCS), and jet-pulsed modulators (Ryan et al, 2003). In addition, other different designs of modulators were proposed (Harynuk and Gorecki, 2002 and 2003). Recent reviews summarized the main characteristics of the different types of thermal modulators as well as their advantages and disadvantages (Dalluge et al., 2003; Adachour et al., 2006 and 2008). The sweeper consisted of a thick-film capillary used to retain and focus the analytes from the first dimension column. Their re-injection into the second column was achieved by a rotating slotted heater which locally heated the capillary column. The disadvantages were the need to move very close to the fragile capillary as well as the requirement of high temperature differences (Adachour et al., 2006). LMCS, the first cryogenic modulator introduced, uses $\mathrm{CO}_{2}$ (liquid) for trapping 
and focusing the eluent from the first column. The trap then moves very fast, exposing the column and the focused fraction to the oven temperature and re-launching the focused analytes into the second column (Haglund et al., 2002). Nowadays, the jet-based modulators with no moving parts and simplified design are used the most (Figure 2.6). Single-, dual- and quad-jet modulators are designed using either $\mathrm{CO}_{2}$ or liquid $\mathrm{N}_{2}$ for cooling (Kristenson et al., 2003; Korytar et al., 2006). The GCxGC system used for this study employs a two-stage modulator similar to the one described by Crimi and Snow, 2008. The first dimension eluent is focused with a jet of cryogenically cooled nitrogen gas and then heated with a jet of hot air while a second band is simultaneously focused with a cryogenically cooled liquid nitrogen jet. This cycle is repeated, allowing the reinjection of successive focused bands onto the second column. Recently, LECO Corporation has developed a new dual-jet, quad-stage, consumable-free thermal modulator. The liquid $\mathrm{N}_{2}$ is not required for cooling the modulator that can result in time and analysis cost savings. The drawback of this type of modulator is noticed for applications that require modulating at extreme low volatility, when the traditional liquid $\mathrm{N}_{2}$ cooled modulator is required (LECO, 2008). For effective separations the modulator timing is critical. The resulted second-dimension peaks are very narrow (50-600 ms); therefore, the second dimension run-time should be $2-8 \mathrm{~s}$ in order to achieve at least three modulations per peak. In addition, very fast detectors are required. 


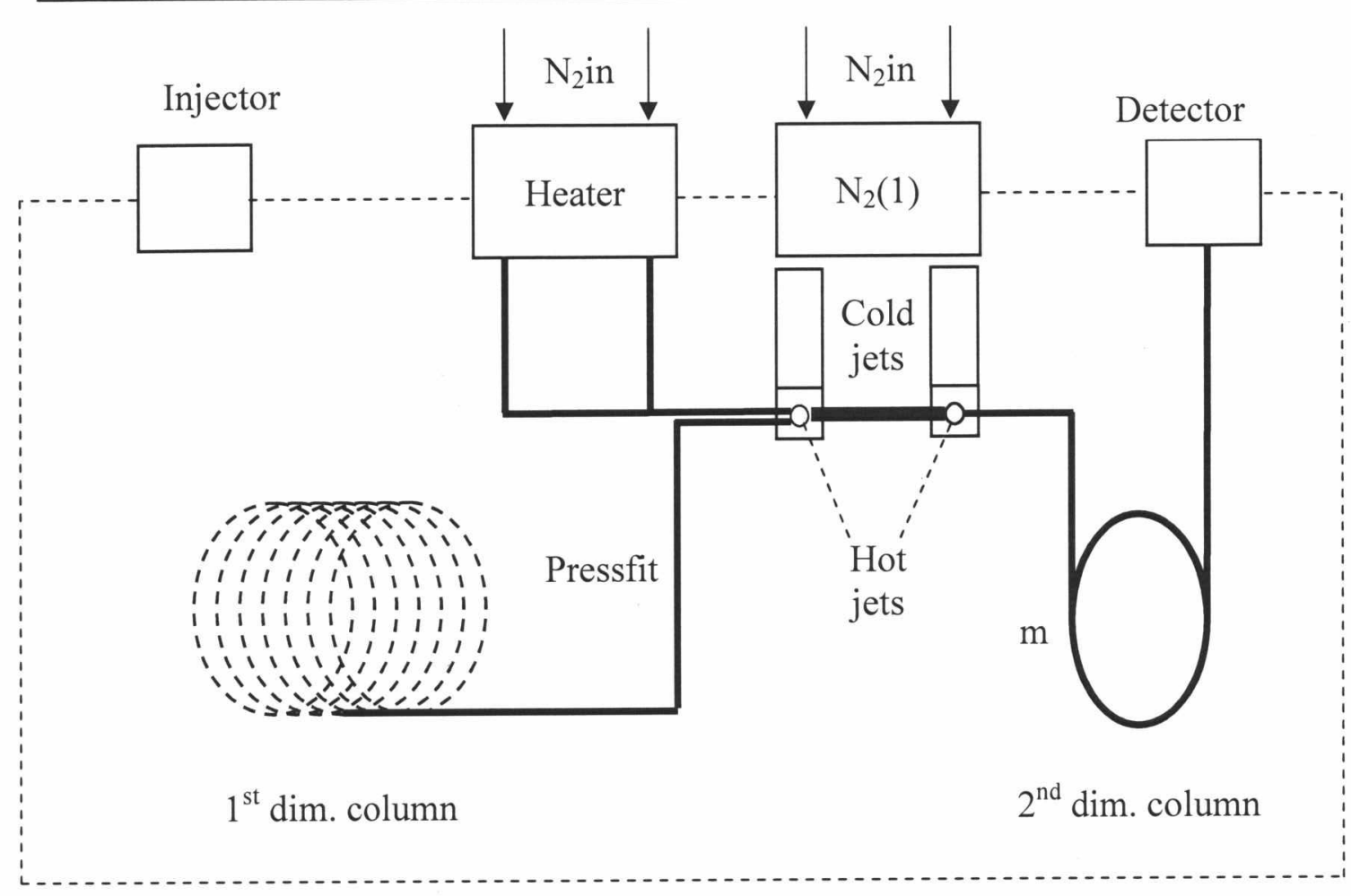

Figure 2.6 Schematic representation of the design of a quad-jet modulator: diagram of the quad-jet $\mathrm{N}_{2}$ modulator (Adapted from Kristenson et al., 2003).

\subsubsection{Detection}

Due to a very fast separation in the second dimension (peak width $50-600 \mathrm{~ms}$ ) the narrow peaks require fast detectors with a small internal volume and a short detector rise time. Also a high data acquisition rate is required to ensure a proper reconstruction of the second dimension chromatogram.

The detectors used in GCxGC systems are mass spectrometer detectors (TOFMS) and element-selective detectors such as FID, $\mu \mathrm{ECD}, \mathrm{SCD}, \mathrm{NCD}$. The elementselective detectors permit only the peak recognition but not structural information; therefore, TOF-MS is indispensable to allow the identification of numerous separated compounds. 
The FID detectors, the first detectors applied to $\mathrm{GCxGC}$, have a negligible internal volume and can acquire data at frequencies of 50-200 $\mathrm{Hz}$ (von Muhlen, Khummueng, Zini, Caramao and Marriott, 2006).

The focus of this study is to determine trace levels of halogenated contaminants in environmental samples and the $\mu \mathrm{ECD}$ is often the choice for $\mathrm{PCB} / \mathrm{OC} / \mathrm{CB}$ detection due to its high sensitivity for these compounds (de Boer, 1999; Cochran and Frame, 1999). The $\mu \mathrm{ECD}$ detectors have an internal volume of $30-150 \mu \mathrm{l}$ and the data acquisition frequency is typically $50 \mathrm{~Hz}$ (LECO Corp., 2005). In order to combine the $\mu \mathrm{ECD}$ with the GCxGC system, it is necessary to operate with higher make-up gas flow (Korytar et al., 2002). The best results were obtained when operated at $150 \mathrm{ml} / \mathrm{min}$ make-up gas flow and temperatures above $300^{\circ} \mathrm{C}$ (Danielsson et al, 2005).

Since the $\mu \mathrm{ECD}$ detector provides peak recognition but not structural information, a mass spectral identification is required. Due to the modulation process, most $\mathrm{GCxGC}$ peaks are very narrow, requiring a fast detector. Time-of-flight mass spectrometers (TOF-MS) are the detectors of choice because of their high scanning rate used to ensure accurate characterization of the peaks produced by GCxGC. The TOF-MS is the only detector that can acquire 50 or more mass spectra per second that are required for proper reconstruction of chromatograms and quantification. Using a GCxGC-TOFMS system the ion chromatograms can be used to extract specific groups of compounds based on their unique mass fragmentation patterns and thus to provide an individual analyte identification. Also, TOF-MS allows the mass spectral deconvolution of overlapping peaks when the fragmentation patterns are different (Adahchour et al., 2006; Focant et al., 2004; Dalluge et al., 2003). 


\subsubsection{Applications}

PCBs, $\mathrm{OCs}$ and $\mathrm{CBz}$ are routinely analysed in many sample matrices: fish, fatty food, and environmental samples. The GCxGC technique was successfully used with FID, $\mu \mathrm{ECD}$ and TOFMS detectors and applied successfully in many fields: petrochemical (GCxGC-FID, TOF-MS); organic pollutants such as pesticides, PCBs, dioxin, PAHs in food, sediments, biota, and water (GCxGC-FID, $\mu$ ECD, TOF-MS); cigarette smoke characterization (GCxGC-TOF-MS); breath analysis (GCxGC-FID, TOF-MS); blood plasma for pesticides determination (GCxGC-FID, TOF-MS); essential oils and food extracts (GCxGC-FID, TOF-MS). Previously published reviews of the GCxGC technique have summarized the applications in the field (Dalluge et al., 2003; Santos and Galceran, 2003; Panić and Górecki, 2006; Adachour et al., 2006; Adachor et al., 2008). The applications further pointed out in this part of the literature review will be as much as possible related to the environmental contaminants and matrices of interest for this research.

Korytar has studied the PCB separation using different column combinations for the GCxGC system (Korytar et al., 2002) and then applied the technique to a cod liver sample, sediment and dust samples. Figure 2.7 represents a two dimensional chromatogram showing the PCB separation in a cod liver sample using HP-1 as a first dimension column and HT-8 column as second dimension. All 12 priority PCBs along with the most toxic dioxins and furans were separated. The practicability of DB$\mathrm{XLB} \times \mathrm{LC}-50$ column set was demonstrated for the $\mathrm{PCDD} / \mathrm{F}$ fraction of a sediment sample, after fractionation on a carbon column, where a properly tuned GCxGC system could accommodate a very high number of compounds in the 2D plane and could 
separate dioxins from co-extractants. Similar, the potential of DB- $1 \times 007-65 \mathrm{HT}$ was demonstrated for PCA and PBDE determination in dust sample. These findings show the capability of $\mathrm{GCxGC}$ to analyse complex environmental samples in a single analytical run. 


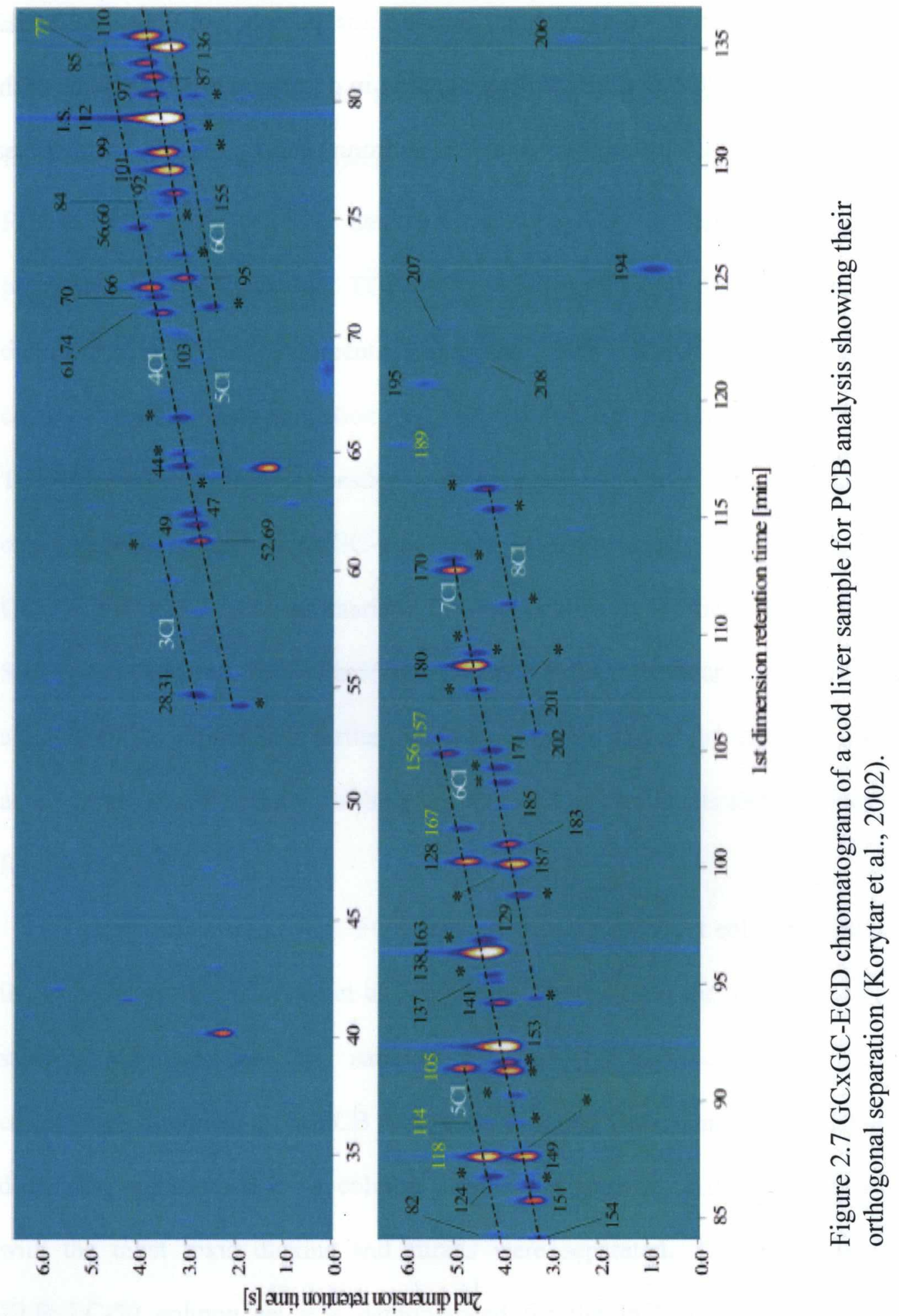


New methods using comprehensive two-dimensional gas chromatography and isotope dilution time-of-flight mass spectrometry (GCxGC-ID-TOF-MS) for the simultaneous measurement of selected polychlorinated biphenyls, organochlorine pesticides, dioxins and brominated flame retardants were presented in serum and milk samples for human monitoring as well as in foodstuffs by Focant et al. (Focant et al., 2004; Focant, Eppe, Scippo, Massart, Pirard, Maghuin-Rogister, 2004). Potential interfering compounds are separated from analytes of interests in the chromatographic GCxGC space due to the increased peak capacity, ensuring sufficient specificity for the low-mass-resolution TOFMS instrument.

Applications of the GCxGC technique, using Rtx-5 x Rtx-200 column set-up, for "real-world" soil extracts were presented in LECO's technical notes. The quantified OC amounts were further compared with classical GC analysis data. The comparison showed how the classical parallel dual-column GC-ECD results were biased high for specific compounds, while the GCxGC analysis further resolved coeluted peaks in the second dimension and significantly reduced the bias. (Figure 2.8) (LECO, Form No. 203-821244, 2005). 


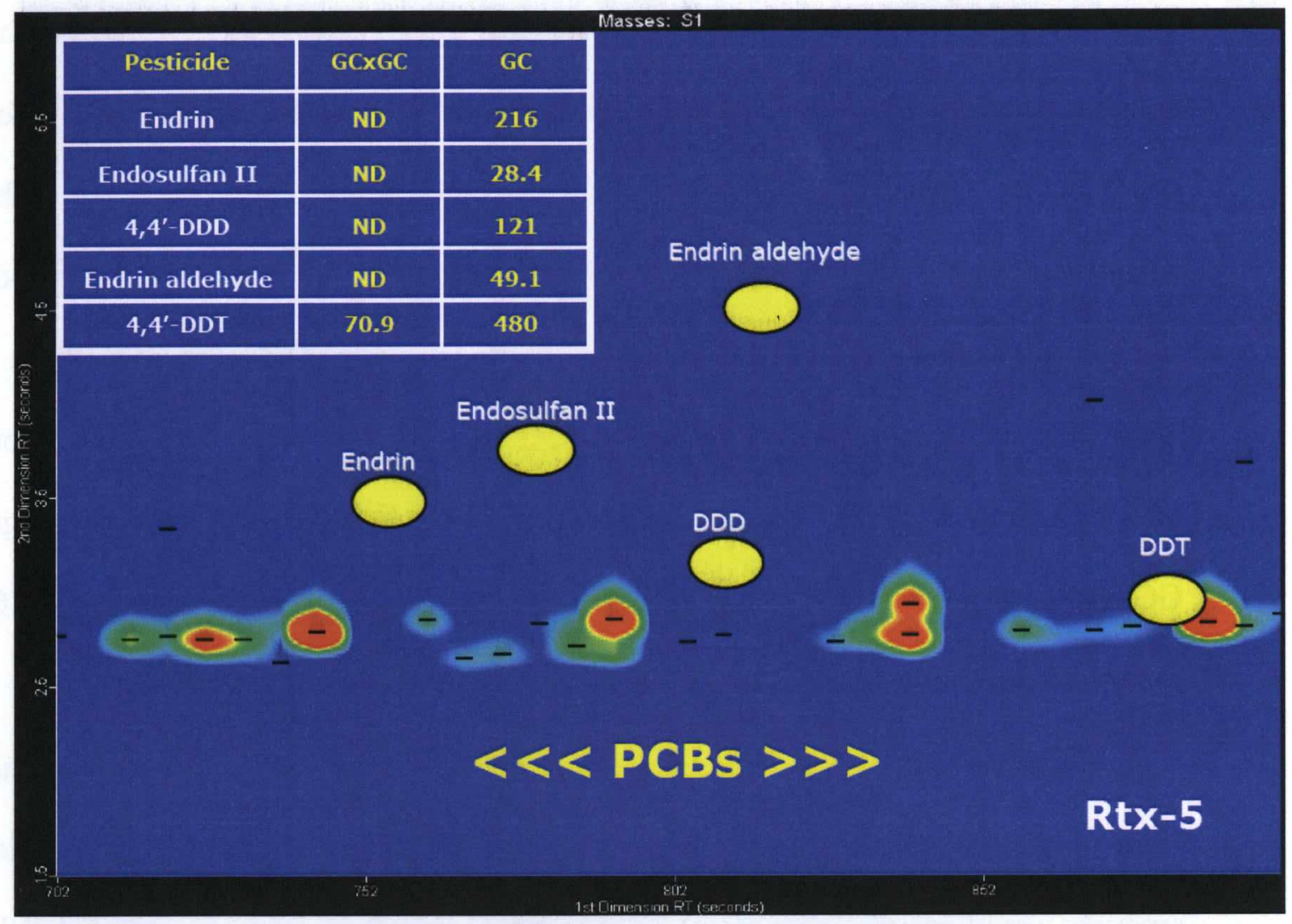

Figure 2.8 Zoomed in contour plot of a "real world" soil extract showing PCBs eluting along a relatively straight line in the first dimension and the OCs (yellow ovals) separated in the $2 \mathrm{D}$ and less prone to interference (and high quantitative bias), as seen in the inset table results (LECO, 2005).

A recent review of the $\mathrm{GCxGC}$ technique as applied on screening the persistent organohalogenated contaminants in environmental samples, summarized some of the column combinations previously presented in different studies: ZB-5, HT-8, DB-17 and BP-10 as first dimension and combined with columns of increasing polarity in the second dimension, i.e. HT-8, BPX-50 and Carbowax (Bordajandi et al., 2008). The review concluded that although none of the columns assessed in the study allowed a complete separation among the all classes of contaminants investigated, some of the column combinations provided satisfactory separations among selected families: HT- $8 \times$ BPX-50 
for PBDEs and PCDD/Fs, DB-17×HT-8 for PCNs and OCPs, BP-10×BPX-50 for CTT, PCDD/Fs and PBDEs. To further separate all the expected classes of contaminants, one should consider the parallel use of GCxGC equipped with different column combinations.

\subsection{PROJECT OBJECTIVES AND HYPOTHESIS}

This chapter has given a review of the relevant literature with regards to applicability of $\mathrm{GCxGC}$ technique for the PCBs, OCs and $\mathrm{CBz}$ analysis. The comprehensive multi-dimensional gas chromatography coupled with micro-electron capture detector has shown to be a very powerful technique allowing simultaneous analysis of the halogenated contaminants. Furthermore, the improved separation power of GCxGC allows the implementation of faster and more environmental friendly extraction and clean-up methods prior to instrumental analysis.

PCBs, OCs and $\mathrm{CBz}$ are ubiquitous in the environment and they are routinely analysed by many laboratories following complex sample preparation and fractionation steps. It was shown that $\mathrm{GCxGC}$ is a feasible technique for analysing these compounds of interests in one run with excellent separations; however, the applicability of GCxGC was not extensively studied for soil, sediment and sludge samples. The objectives of this project are to accurately identify and quantify the $\mathrm{PCBs}$, $\mathrm{OCs}$ and $\mathrm{CBs}$ present in sludge and sediment samples in a single analytical run by using the GCxGC technique. The column selection for this study, DB-1 x Rtx-PCB, was based on previous reported data for PCBs and OCs simultaneous separation (LECO, 2005). The first step is to achieve chromatographic separation for all the target compounds in one analysis prior to calibration and quantification. In addition to $\mathrm{PCBs}, \mathrm{OCs}$ and $\mathrm{CBz}$, other contaminant 
classes will be evaluated to "map" their elution in the chromatographic space when using the same instrumental set-up. This might serve as a preliminary assessment of the presence of other contaminant classes in environmental samples. Reference materials along with sediments and sludge samples previously analysed by classical GC analysis (Dioxin and Toxic Organics Section, Ontario Ministry of the Environment) will be analysed with the new GCxGC method and their results compared. The premise is that all target contaminants can be analysed simultaneously without any necessary fractionation prior to GCxGC analysis. Once the method is developed and proved to be precise and accurate it would be expected that the compounds of interest present in real-life samples can be accurately identified and quantified. 


\section{CHAPTER 3: EXPERIMENTAL}

\subsection{GENERAL DISCUSSION}

This study involved the development of a new method for the analysis of PCBs,

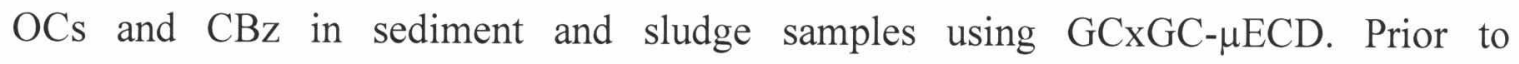
instrumental analysis, the extraction and clean-up procedures were optimized to obtain the best recoveries of the target analytes with reduced solvent use and less sample preparation time. While the previous chapter, Literature Review - Chapter 2, described the theoretical aspects of the procedures involved, Chapter 3 describes in detail the equipment, the experimental conditions and chemicals used. This work was conducted at the Ontario Ministry of the Environment, Laboratory Services Branch, Dioxin and Toxic Organics unit and the experimental approach is presented in Figure 3.1. 


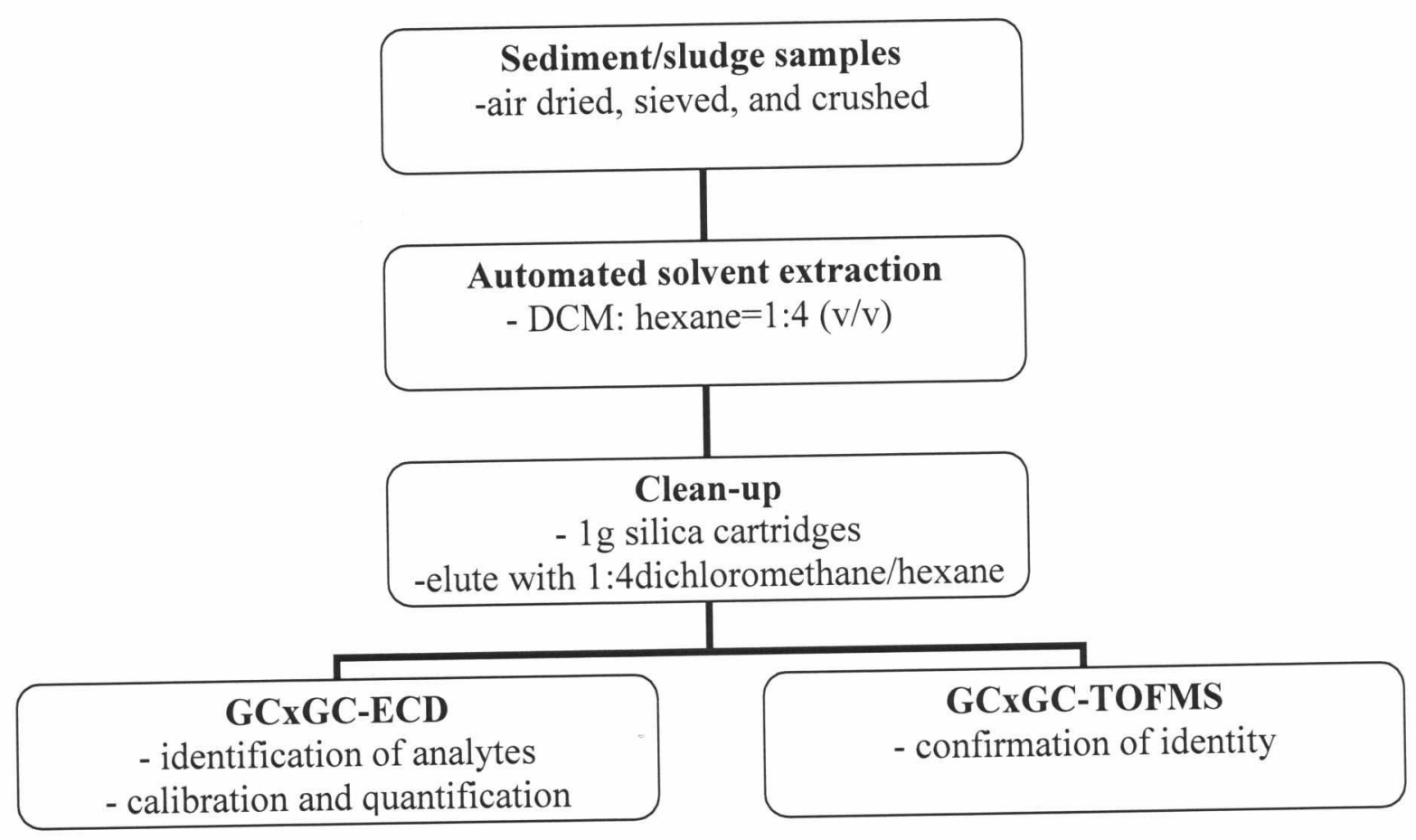

Figure 3.1 Experimental approach of the GCxGC-ECD study.

\subsection{REAGENTS AND MATERIALS}

\subsubsection{Standards and chemicals}

Polychlorinated biphenyl standards were obtained from Wellington Laboratories (Guelph ON, Canada) having different congener composition and concentration:

i. $\quad$ PCB BP-MS containing 62 congeners was used for calibration.

ii. $\quad$ PCB BP-EC containing 62 congeners was used for preparing the spiking solution.

iii. PCB BP-MS-PL1, -PL2 and -PL3 were used for identification purposes. 
The congeners present in these PCB standards as well as their concentration are listed in Appendix A.

Along with $\mathrm{PCBs}, \mathrm{CBz}$ standard mixture of 15 chlorobenzenes, OC standard mixture of 23 compounds, decachlorobiphenyl and 1,3,5-tribromobenzene were purchased from UltraScientific (North Kingstown, RI, USA).

Six level calibration standard solutions of $\mathrm{PCB} / \mathrm{OC} / \mathrm{CBz}$ were prepared by mixing the above $\mathrm{PCB}$ (BP-MS), $\mathrm{OC}$ and $\mathrm{CB}$ standards in isooctane with the final concentrations ranging from 1 to $500 \mathrm{ng} / \mathrm{mL}$. Similarly, an $\mathrm{OC} / \mathrm{CBz}$ spiking solution and decachlorobiphenyl/1,3,5-tribromobenzene surrogate solution was prepared with the final concentration of $500 \mathrm{ng} / \mathrm{mL}$. In addition, 4,4'-dibromooctafluorobiphenyl was used as internal standard for PCB congeners' quantification. Prior to injection, $10 \mu \mathrm{L} / \mathrm{mL}$ of 4,4'-dibromooctafluorobiphenyl standard solution at $1 \mu \mathrm{g} / \mathrm{ml}$ were added in each sample.

The solvents used for extraction, clean-up and stock solutions were distilled-inglass grade and are listed in Appendix A.

\subsubsection{Reference Materials and Sludge/Sediment Samples}

The method's accuracy was assessed by analysing standard reference materials for both sediment and sludge matrices. Thus, SRM1944 sediment reference material was purchased from NIST (Gaithersburg, MD, USA), EC-8 sediment reference material was obtained from Environment Canada (National Water Research Institute, Burlington, ON, Canada) and CNS-312 sludge reference material was acquired from RT-Corp. (Laramie, WY, USA). 
The sediments and sludges were selected from previously analysed samples by classical GC-ECD analysis. Sediments were obtained from an inter-laboratory study, NY State - ELAP 08-01 Inter-laboratory Study for Solid Waste. The sludges were obtained from a wastewater treatment plant (WWTP) in Ontario.

\subsection{SAMPLE PREPARATION}

\subsubsection{Quality Control Procedures}

In order to reach the data quality objectives, a quality control procedure need to be established for each method. All the sediment and sludge samples are processed together with a method blank, appropriate method spikes, duplicates and reference materials. The method blank is a check for any possible contamination during the sample preparation and analysis; it is not expected to have any concentration of the target analytes above the quantification limits. The recoveries of the analytes are checked by using spiked blank sediment which is processed along with the "real" samples.

The sediment blank material was prepared from previously analyzed samples that do not contain detectable amounts of the components under test. The sediment was collected, solvent rinsed for two weeks using a large Soxhlet system and analyzed by classical GC-ECD. The dried material was then placed in a sealed jar (PCB5 type, amber glass) and kept at room temperature.

The samples were spiked as follows:

i. Method Blank (MB1): $100 \mu \mathrm{L}$ of decachlorobiphenyl/1,3,5tribromobenzene surrogate solution at $500 \mathrm{ng} / \mathrm{mL}$. 
ii. Method Spike (SP1): $100 \mu \mathrm{l}$ of $\mathrm{CB} / \mathrm{OC}$ spiking solution all compounds at $500 \mathrm{ng} / \mathrm{mL}$ (Appendix A), $50 \mu \mathrm{L}$ of BP-EC at 1-50 $\mu \mathrm{g} / \mathrm{mL}$ and $100 \mu \mathrm{L}$ of decachlorobiphenyl/1,3,5-tribromobenzene surrogate solution at $500 \mathrm{ng} / \mathrm{mL}$.

iii. Samples and duplicates: $100 \mu \mathrm{L}$ of decachlorobiphenyl/1,3,5tribromobenzene surrogate solution at $500 \mathrm{ng} / \mathrm{mL}$.

iv. Reference materials used: SRM 1944, EC-8 and CNS312 were not spiked.

\subsubsection{Automated Solvent Extraction}

As presented in Chapter 2, previous studies showed different methods of extraction using pressurized solvent extraction of PCBs, OCs and CBs along with their clean-up procedure before instrument analysis. Enhanced extraction efficiency can be achieved by solvents at high pressures and temperatures when certain intermolecular bonds can be broken (Ramos et al., 2002).

The sediment, soil or sludge samples analyzed were air dried, crushed and sieved prior to extraction. Using a mortar and pestle the samples were ground, sieved if necessary by using a No. 8 mesh sieve and then homogenized. A weight of one gram from each sample was loaded into an $11 \mathrm{~mL}$ stainless steal ASE cell with stainless steel frits and cellulose filters. Ottawa sand (purchased from Anachemia, Montreal, QC, Canada) was used to fill out the dead volume in the extraction cells. Figure 3.2 represents the schematic of an extraction cell. 


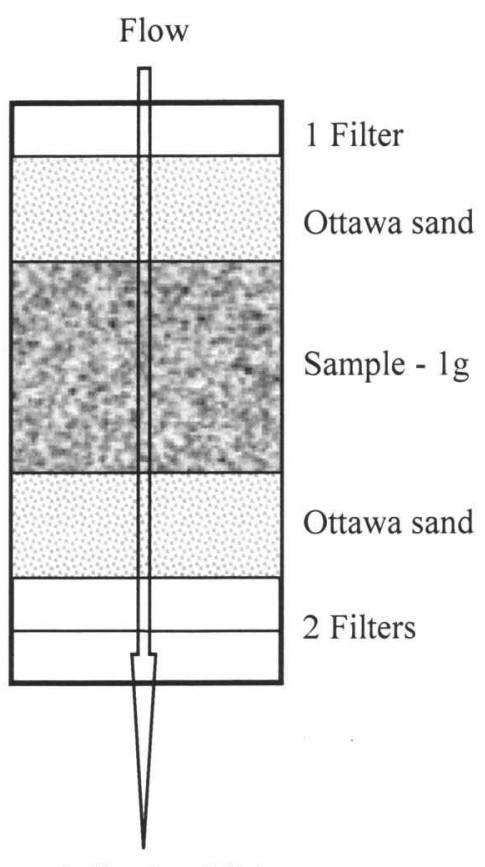

Collection Vial

Figure 3.2 Graphical representation of an ASE cell set-up.

Sediment/sludge samples were extracted with 1:4 dichloromethane/hexane $(\mathrm{v} / \mathrm{v})$ using automated solvent extraction (ASE 200 - Dionex Corporation, Sunnyvale, CA, USA). The ASE conditions employed in this research were optimized for high recovery in the extraction procedure by selecting the extraction time, the most efficient temperature, and the use of different solvents (Table 3.1). 
Table 3.1 The ASE conditions used for the sediment/sludge samples extraction.

\begin{tabular}{|l|l|}
\hline Cell volume: & $11 \mathrm{~mL}$ \\
\hline Temperature: & $100^{\circ} \mathrm{C}$ \\
\hline Static time: & $5 \mathrm{~min}$ \\
\hline Cycle: & 1 \\
\hline Solvent: & $1: 4$ dichloromethane/hexane $(\mathrm{v} / \mathrm{v})$ \\
\hline Heat time: & $5 \mathrm{~min}$ \\
\hline Flush volume: & $60 \%$ \\
\hline Pressure & $1500 \mathrm{psi}$ \\
\hline Purge time: & $90 \mathrm{sec}$ \\
\hline
\end{tabular}

\subsubsection{Clean-up Procedure}

Sediment and sludge samples are very complex matrices; therefore a clean-up procedure must be employed prior to instrumental analysis to remove possible interferences (e.g. lipids). The ASE extracts were evaporated to approximately $1 \mathrm{~mL}$ final volume in isooctane using a Zymark Turbovap LV evaporating system (Zymark Corporation, Hopkinton, MA, USA), applied to $1 \mathrm{~g}$ silica pre-packed cartridges (SepPakTM Plus, Mega Bond Elut HFTM, Varian, Mississauga, ON, Canada) and eluted with solvent.

The following are the steps used in the clean-up procedure:

i. Silica cartridges were conditioned with $5 \mathrm{~mL}$ of $1: 4$ dichloromethane/hexane (v/v).

ii. The samples were applied to the pre-conditioned silica cartridges and the extraction vials were rinsed two times with approximately 
$1.5 \mathrm{~mL}$ of $1: 4$ dichloromethane/hexane $(\mathrm{v} / \mathrm{v})$. The two rinses were added to the corresponding silica cartridge after the samples were completely adsorbed without letting the adsorbent to get dried.

iii. The cartridges were then eluted with $15 \mathrm{~mL}$ of 1:4 dichloromethane/hexane (v/v) and collected in the same vial as the previous rinses. The $15 \mathrm{~mL}$ elution solvent was chosen based on previous in-house work (Paul Helm, Ontario Ministry of the Environment, 2007 - personal conversation).

The cleaned-up extracts were evaporated to $1 \mathrm{~mL}$ final volume in iso-octane using a Zymark Turbovap LV evaporating system. Copper treatment (10-30 mesh) was applied to all the samples prior to analysis to remove sulphur interferences (MoE LSB Method $3270,2008)$.

\subsection{ANALYSIS}

\subsubsection{GCxGC- $\mu$ ECD Instrumental Set-up}

The PCBs, OCs and CBs standard solutions along with the sediment/sludge final extracts were analysed using a GCxGC- $\mu \mathrm{ECD}$ system provided by LECO Corporation (Benton Harbour, MI, USA). The GCxGC system is equipped with a split/splitless injector, an Agilent Technologies 6890 gas chromatograph (Agilent Technologies, Santa Clara, CA, USA), a stationary quadruple jet dual-stage modulator (LECO Corporation), and $\mu \mathrm{ECD}$ detector (Agilent Technologies). The gas chromatograph features a secondary oven and that can be independently controlled, thus different temperature ramps can be 
set up for both ovens in the same time. The system is controlled by a computer using the ChromaTOF-FID software, version 3.34, provided by LECO Corporation.

The following chromatographic column combination was used: a $30 \mathrm{~m}, 0.25 \mathrm{~mm}$ i.d., $0.25 \mu \mathrm{m}$ film thickness DB1 (100\% dimethylpolysiloxane) from J\&W Scientific (Folsom, CA, USA) as the first dimension column, and a $1.6 \mathrm{~m}, 0.18 \mathrm{~mm}$ id, $0.18 \mu \mathrm{m}$ film thickness Rtx-PCB from Restek Corporation (Bellefonte, PA, USA) as a second dimension column. The connections between the first dimension and second dimension columns were made using a deactivated pres-fit connector (Restek Corporation). The GCxGC- $\mu$ ECD conditions are presented in Table 3.2.

Table 3.2 Instrumental conditions used for the GCxGC- $\mu \mathrm{ECD}$ system.

\begin{tabular}{|l|l|}
\hline Injector & $\begin{array}{l}\text { Temperature: } 250^{\circ} \mathrm{C} \\
1 \mu \mathrm{L} \text { splitless injection }\end{array}$ \\
\hline Carrier Gas & $\mathbf{H e}, 1.5 \mathrm{ml} / \mathrm{min}$ flow rate \\
\hline First Dimension Column & $\begin{array}{l}\text { DB1 }-30 \mathrm{~m} \times 0.25 \mathrm{~mm} \text { i.d. } \times 0.25 \mu \mathrm{m} \text { film } \\
\text { thickness }\end{array}$ \\
\hline Second Dimension Column & $\begin{array}{l}\text { Rtx-PCB }-1.6 \mathrm{~m} \times 0.18 \mathrm{~mm} \text { i.d. } \times 0.18 \mu \mathrm{m} \\
\text { film thickness }\end{array}$ \\
\hline Modulation & $\begin{array}{l}\mathbf{4} \text { sec } \\
\text { Hot pulse: } 1 \mathrm{sec}\end{array}$ \\
\hline$\mu$ ECD Detector & $\begin{array}{l}325^{\circ} \mathrm{C} \\
\text { Make-up gas: methane in argon (P5) at } \\
\mathbf{1 5 0} \mathrm{mL} / \mathbf{m i n} \text { flow }\end{array}$ \\
\hline
\end{tabular}

All instrumental conditions such as modulation time, secondary column length, carrier gas flow rates were optimized to avoid wrap-around of the analytes and to achieve the best within- and between-class separations. The $\mu \mathrm{ECD}$ was run at a flow rate of 
$150 \mathrm{ml} / \mathrm{min}$ as previous studies showed this produced the best results (Korytar et al., 2006).

\subsubsection{GCxGC-TOFMS Instrument Set-Up}

Besides the GCxGC- $\mu$ ECD analysis, further confirmation by GCxGC-TOFMS (LECO Corporation, Benton Harbour, MI, USA) was employed in the preliminary study to confirm the retention times of the analytes identified by $\mu \mathrm{ECD}$. The GC conditions for this system are the same as the ones presented in Table 3.2; additionally, a mass spectrometer method was created (Table 3.3).

Table 3.3 The GCxGC-TOFMS specifications for mass spectrometer method.

\begin{tabular}{|l|l|}
\hline Injector & $\begin{array}{l}\text { Temperature: } 250^{\circ} \mathrm{C} \\
1 \mu \mathrm{L} \text { splitless injection }\end{array}$ \\
\hline First Dimension Column & $\begin{array}{l}\text { DB1 }-30 \mathrm{~m} \times 0.25 \mathrm{~mm} \text { i.d. } \times 0.25 \mu \mathrm{m} \text { film } \\
\text { thickness }\end{array}$ \\
\hline Second Dimension Column & $\begin{array}{l}\text { Rtx-PCB }-1.6 \mathrm{~m} \times 0.18 \mathrm{~mm} \text { i.d. x } 0.18 \mu \mathrm{m} \text { film } \\
\text { thickness }\end{array}$ \\
\hline Modulation & $\begin{array}{l}4 \text { sec } \\
\text { Hot pulse: } 1 \mathrm{sec}\end{array}$ \\
\hline TOF-MS Detector & $\begin{array}{l}300^{\circ} \mathrm{C} \\
\text { Transfer line temperature } 250^{\circ} \mathrm{C}\end{array}$ \\
\hline
\end{tabular}




\subsection{STATISTICAL ANALYSIS}

Method precision - reproducibility and repeatability - was assessed and statistical calculations were performed using SPSS student v.14 statistical package (SPSS, 2007) and Microsoft Excel for Windows XP. The accepted relative standard deviations (\%) for the target compounds should be in within $\pm 25 \%$ recovery limits.

The standard reference materials were analysed by $\mathrm{GCxGC}$ and the results were compared to their expected values specified in the certificate of analysis. The data was plotted using Microsoft Excel and statistical calculations were employed for assessing the uncertainties of the method. 


\section{CHAPTER 4: RESULTS}

Chapter 4 of this study is presented in four parts: the separation of the target analytes, the calibration and quantification, the uncertainties calculations of the method and the analysis of sludge and sediment samples. All the data for this research was determined following the sample preparation procedures and the optimized instrumental GCxGC- $\mu \mathrm{ECD}$ conditions shown in the previous chapter.

\subsection{GCXGC SEPARATION}

The introduction of comprehensive two-dimensional gas chromatography provided significant increases in peak capacity, sensitivity and speed of analysis by applying two independent separations to a sample (Dalluge et al., 2003). The enhanced selectivity of GCxGC enabled $\mu \mathrm{ECD}$, a less selective detector, to be used for the analysis of persistent environmental contaminants simultaneously in a single analytical run (Korytar et al., 2003 and 2006). As a result, GCxGC coupled with $\mu$ ECD detector was used to achieve the separation of target organic contaminants in a single analytical run and the obtained data is presented in the following section.

\subsubsection{Identification of the target analytes}

After optimizing the $\mathrm{GCxGC}$ method to obtain the best chromatographic separation of the target analytes, the next step was to identify each of the components present in standard mixes. Since $\mu \mathrm{ECD}$ does not provide any mass spectral information, the retention times of each component in the $\mathrm{PCB} / \mathrm{OC} / \mathrm{CB}$ standard mix needed to be 
determined. For this purpose, individual constituent standards along with standard mixes containing a small number of components/congeners (e.g., BPMS-PL1, -PL2, -PL3) were analysed using the established GCxGC method and their retention times compared to the ones from the $\mathrm{PCB} / \mathrm{OC} / \mathrm{CB}$ standard mix. The $\mu \mathrm{ECD}$ data was based on retention time results only; thus, further confirmation by GCxGC-TOFMS was employed. Target analytes identified by GCxGC- $\mu \mathrm{ECD}$ were confirmed by GCxGC-TOFMS. Figures 4.1 to 4.5 represent the final identification of each compound present in the standard mixes analysed.

\subsubsection{Within-Class Separation}

One of the goals of the study was to separate the target halogenated environmental pollutants within their class using DB-1 x Rtx-PCB. When the PCB, OC, CB standard solutions were analysed separately for each of the individual classes of contaminants, within-class separation was achieved with no coelutions for the OC standard (Figure 4.3) and only one coelution for PCB and CB standards (Figure 4.1 and 4.4). 


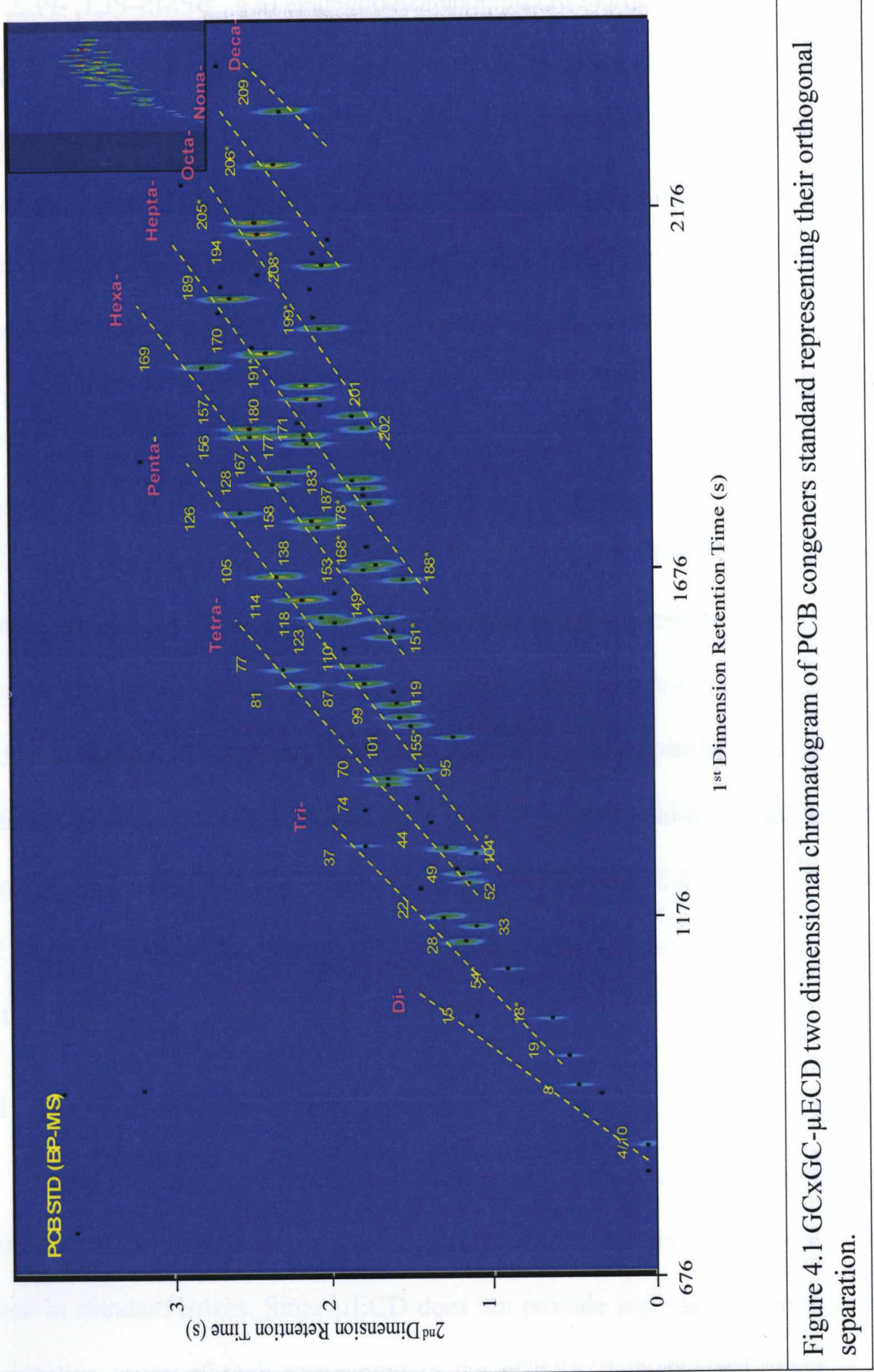


The two dimensional chromatogram representing PCBs, shows that orthogonal separation was achieved when using DB1x Rtx-PCB column combination. An ordered structure is observed in the second dimension for structurally related compounds, in this case PCBs. These findings were similar with the previous published data for different column combinations (Korytar et al., 2003).

The PCB congeners are separated according to their degree of chlorination as well as with their planar structure. Due to the selectivity of Rtx-PCB for the planar compounds (LECO Technical Note, 2005), the non- and mono-ortho PCBs (PCBs 37, 77, 81, 126 and 169) elute later in the second dimension. The dotted lines in Figure 4.1 represent the level of chlorination of PCBs, from mono- to decachlorobiphenyl.

One of the advantages of this technique over the classical GC analysis, as previous studies have shown, is the second dimension separation. Therefore, peaks that coelute on a classical DB1 column in 1D analysis (Frame and al., 1996) are further resolved by Rtx-PCB. Some examples of these coeluting peaks resolved by GCxGC (Figures $4.2 \mathrm{a}$ and $\mathrm{b}$ ) are PCB77/PCB110 and PCB118/PCB149. 


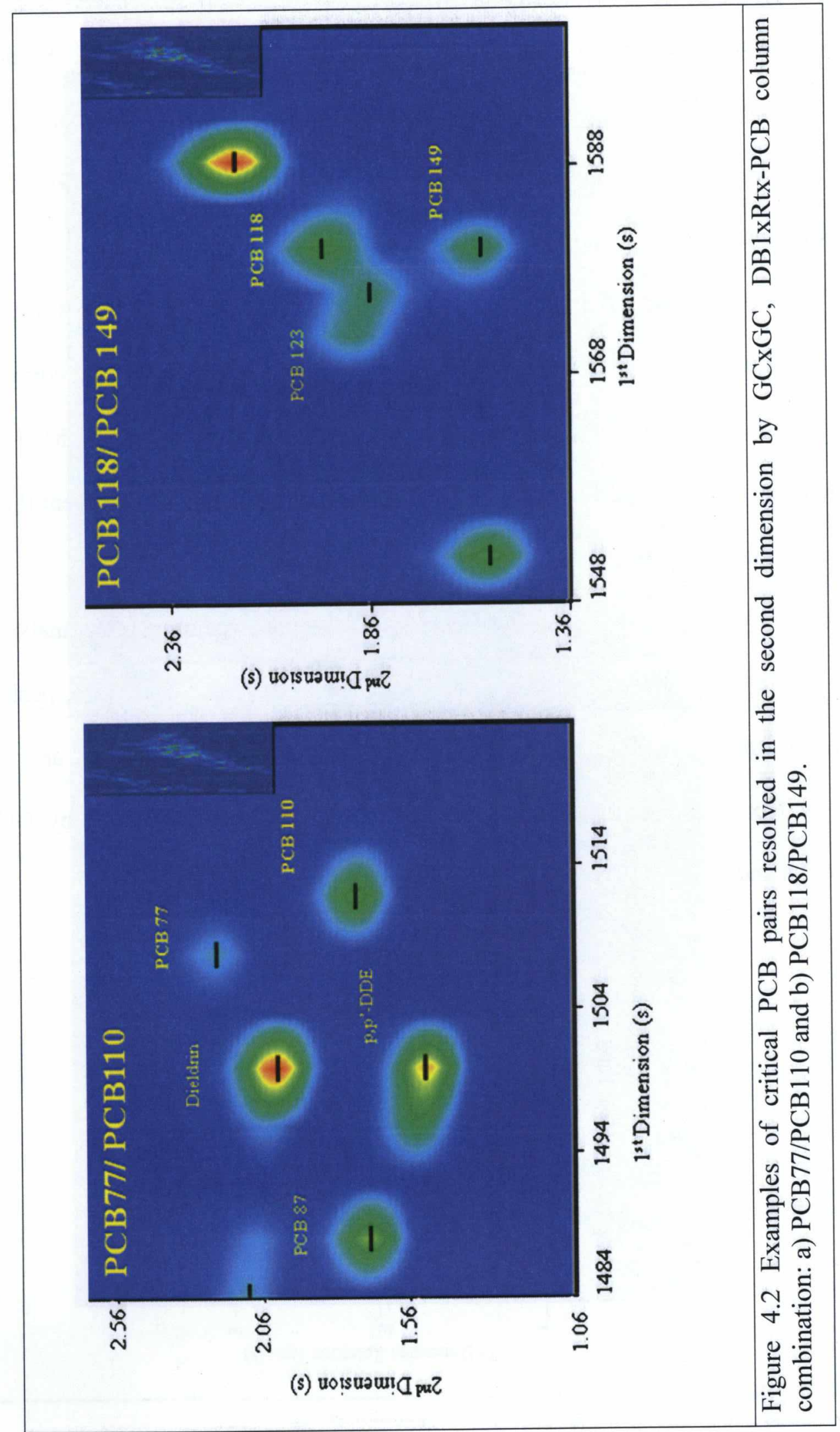


Within-class separation was achieved with no coelutions for the OCs standard analysed, all 25 compounds were separated in one analytical run (Figure 4.3).

For the $\mathrm{CBz}$ standard analysis by $\mathrm{GCxGC}-\mu \mathrm{ECD}$ one coelution was found: 1,2,3,5-TCB/ 1,2,4,5-TCB (Figure 4.4). 


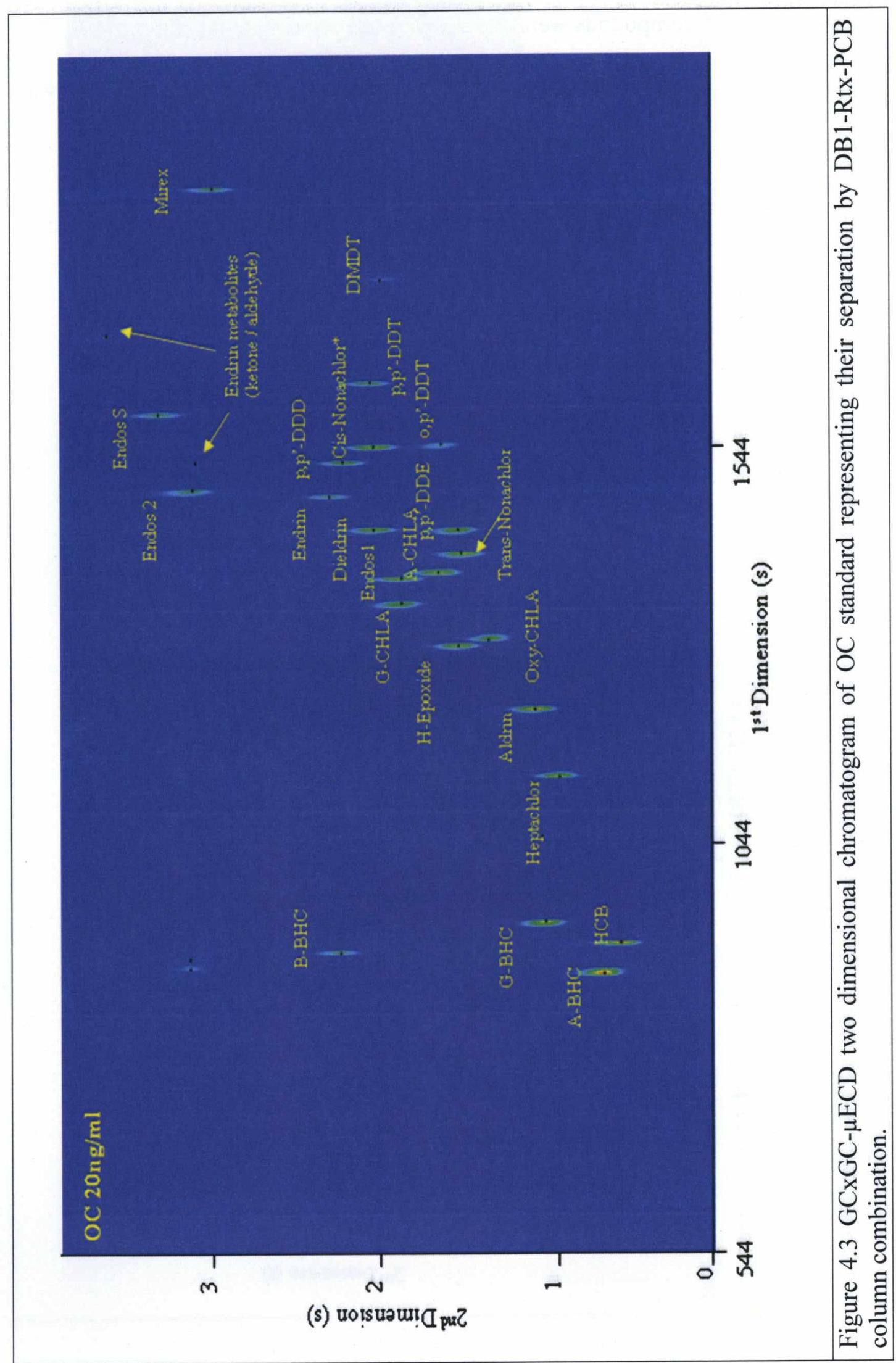




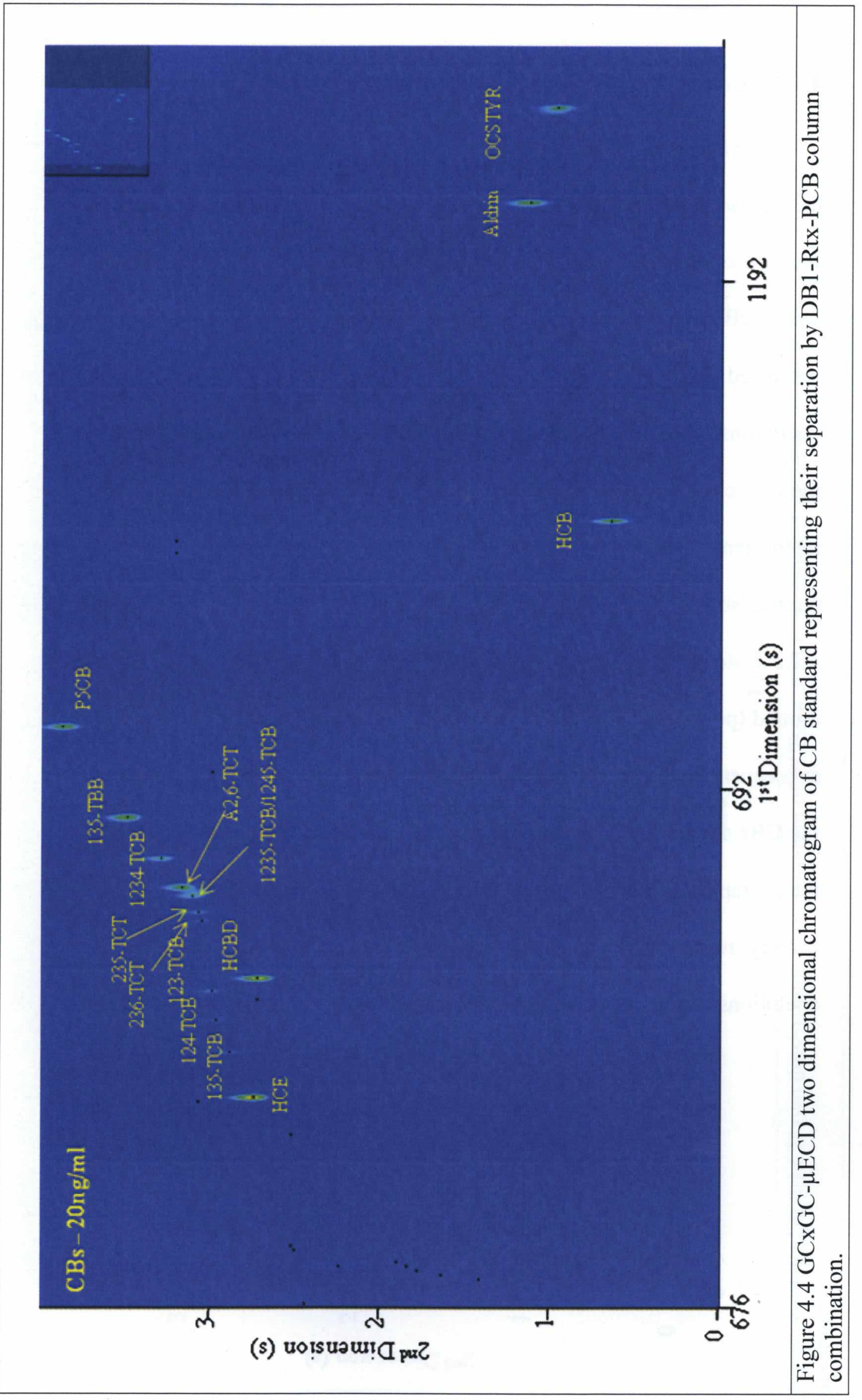




\subsubsection{Between-Class Separation}

After assessing the within-class chromatographic separation, the next goal was to achieve separation of all three target classes of compounds in a single analytical run. A mixture containing $62 \mathrm{PCBs}, 23 \mathrm{OCs}$ and $15 \mathrm{CBz}$ (96 compounds in total) was analyzed using DB1xRtx-PCB column configuration and the two dimensional chromatogram is presented in Figure 4.5. Separation was achieved with only three between-class coelutions: heptachlor-epoxide/PCB74, cis-nonachlor/PCB114, and methoxychlor/PCB171 (Figure 4.6). The classical GC-ECD analysis involves four instruments that analyze each different compound classe of interest separately. A comparison of the techniques will be described in a different section of this study, section 4.2.2.5 Accuracy, to emphasize the significance of the research. Additionally, wraparound (peaks that spend more time in the 2D than one modulation cycle and elute within subsequent modulation cycles) is observed for chlorobenzenes in this separation. Since the $\mathrm{CBz}$ do not interfere with any other analytes of interest in the chromatographic space, their wrap-around is not an issue for quantification purposes. Furthermore, the separation is very reproducible between the analytical runs. In addition to $\mathrm{GCxGC}-\mu \mathrm{ECD}$, the coelutions were confirmed by GCxGC-TOFMS. 


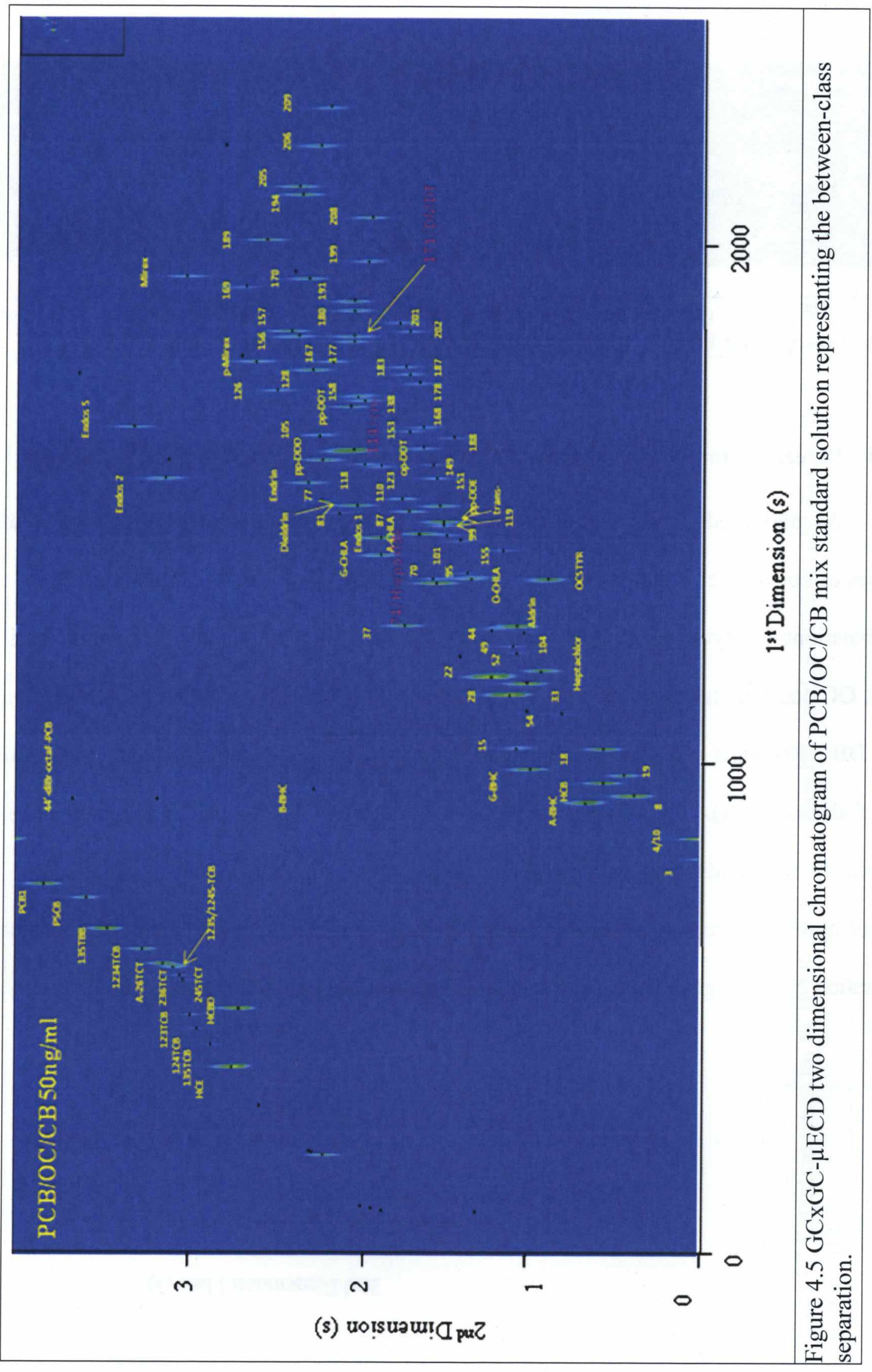



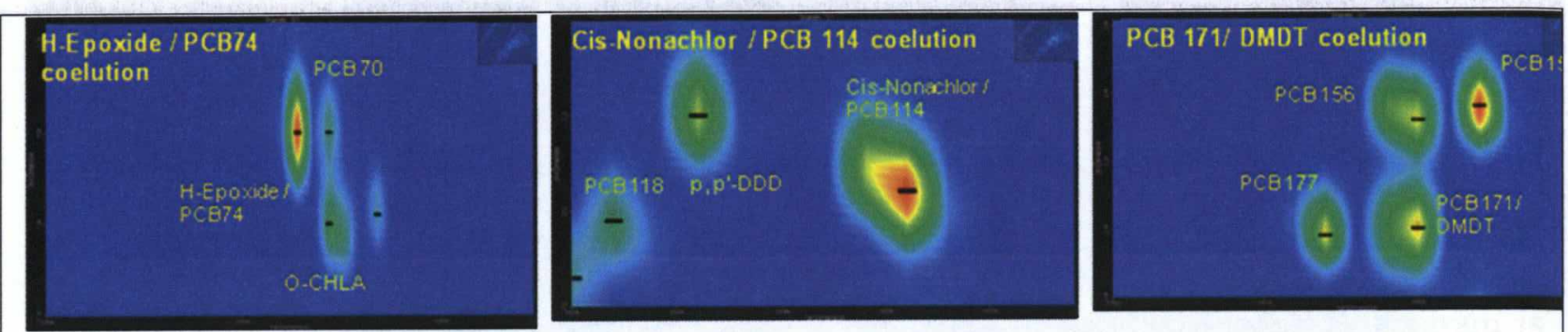

Figure 4.6 Two dimensional chromatograms representing between-class coelutions: a) heptachlor-epoxide/PCB74, b) cis-nonachlor/PCB114 and c) methoxychlor/PCB171.

\subsubsection{Screening for PCNs, Dioxins, PCDEs and other persistent organic pollutants}

As presented in the literature review section, previous studies showed how different classes of contaminants can be separated in a single analytical run when using different column combinations (Korytar et al., 2002 and 2005; Bordajandi et al., 2008). Therefore, besides the $\mathrm{PCB}, \mathrm{OC}$ and $\mathrm{CB}$ standards previously discussed, other contaminant classes were evaluated for the DB1xRtx-PCB column combination: dioxins/furans, toxaphene and polychlorinated naphthalenes (PCN). Figure 4.7 represents an overlay of $\mathrm{GCxGC}-\mu \mathrm{ECD}$ chromatograms of all classes of compounds mentioned above.

By applying two independent separations to the sample, $\mathrm{GCxGC}$ technique enhanced the separation of the target analytes and increased the peak capacity (Dimandja, 2004). 


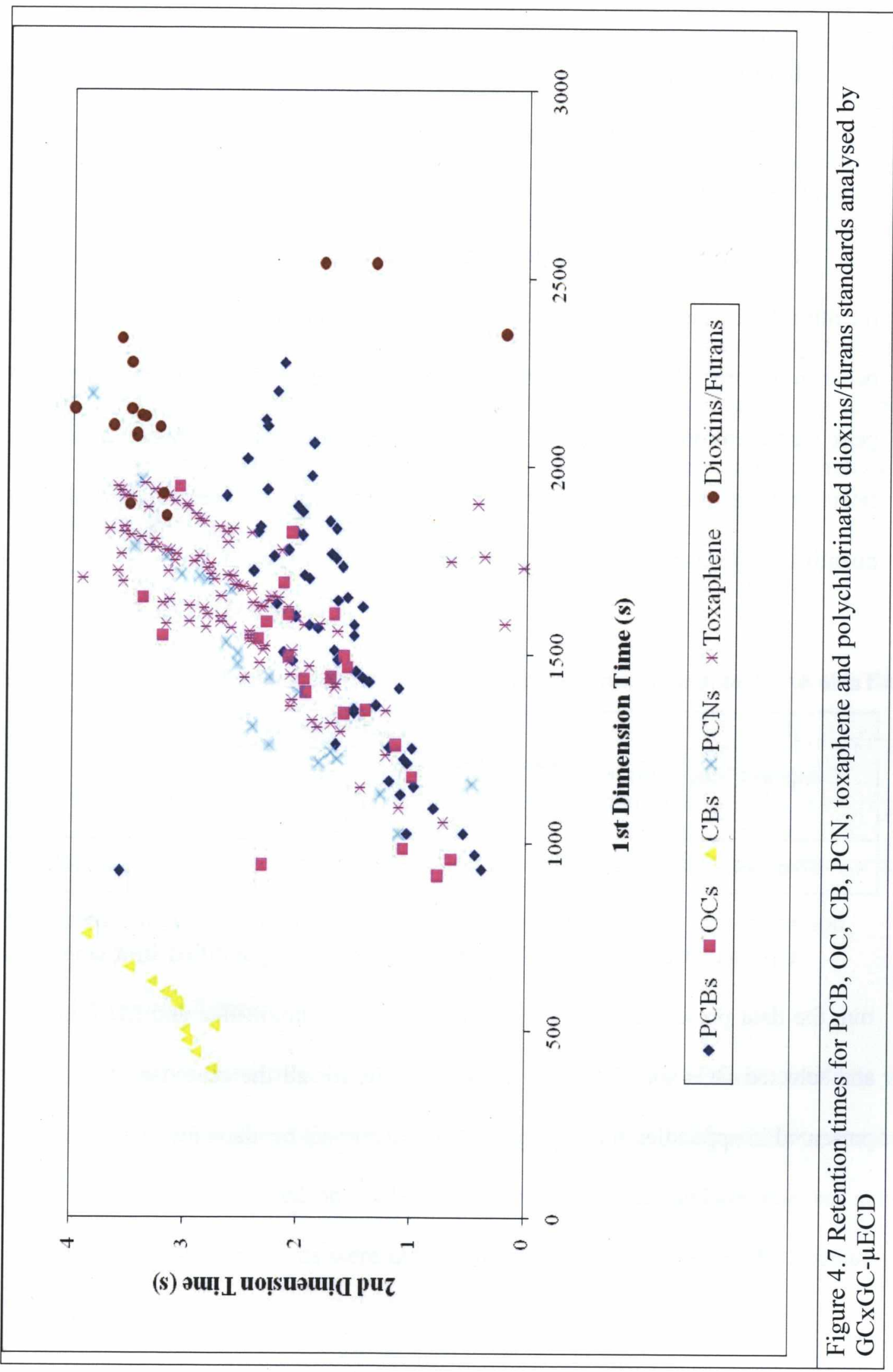




\subsection{CALIBRATION AND QUANTIFICATION}

In order to quantify the target analytes six-level calibration curves were built. An external standard method was used to quantify $\mathrm{OCs}$ and $\mathrm{CBz}$ and an internal standard method was used for PCB quantification.

In addition to quantification, the internal standard was also monitored to check the retention time stability between analytical runs (Korytar et al., 2006). A small leak can occur in the press-fit connectors and the chromatographic peaks will be shifted. Since the peak identification using an ECD detector is retention time dependent, making sure that retention times are accurate is very important. Thus, the internal standard used for PCBs quantification was monitored for retention time shifts (Table 4.1).

Table 4.1 Data representing the variability of internal standard between analytical runs.

\begin{tabular}{|c|c|c|c|c|c|c|c|}
\hline & \multirow{2}{*}{ Compound Name - ISTD } & \multirow{2}{*}{$\begin{array}{c}\text { Concentration } \\
(\mathbf{p g} / \boldsymbol{\mu L})\end{array}$} & \multicolumn{2}{|c|}{$\begin{array}{c}\text { R.T.Mean (s) } \\
\mathbf{n}=\mathbf{1 0}\end{array}$} & R.T. SD (s) & \multicolumn{3}{|c|}{ Area } \\
\cline { 5 - 9 } & & 1D & 2D & 1D & 2D & $\begin{array}{c}\text { Mean } \\
\mathbf{n}=10\end{array}$ & $\begin{array}{c}\text { RSD } \\
(\%)\end{array}$ \\
\hline 4,4'-dibromooctafluorobiphenyl & 10 & 924 & 3.652 & 0.01 & 0.01 & 1491364.00 & 12.07 \\
\hline
\end{tabular}

Given that almost one hundred compounds are quantified in a single analytical run, the data presented in this study will be for the dioxin-like and EU indicator PCBs, and selected OCs and CBz. The detailed results for all the other target analytes will be presented in appendies and appropriate references will be made for each section. 


\subsubsection{Data Processing Method Parameters}

Standards (PCBs, OCs and CBz standard mixes), reference materials and sample extracts were injected in the GCxGC- $\mu \mathrm{ECD}$ system and the resulting data was recorded using ChromaTOF-GC software version 3.34 (LECO Corporation). The software was used for data acquisition, instrument control and data analysis (integration, quantification and reporting).

In order to process the chromatographic data, a data processing method was created. The method includes the time selected for baseline tracking, the signal to noise $(\mathrm{S} / \mathrm{N})$ that selects which peaks will be picked up for quantification, the calibration tables selected to quantify the compounds of interest.

\subsubsection{Method Validation}

Method validation defines the analytical requirements and confirms that the new method meets specific requirements (MoE, LSBSOP.027, 2008). Following the identification of the compounds presented in the previous section, the next steps for validating the method were to determine the linearity and establish the dynamic range of the instrument, to confirm accuracy and to establish the precision of the method.

\subsubsection{Dynamic Range}

Linearity is determined by a series of injections of five or more standards whose concentrations cover the expected concentration range. The calibration curves for this specific method were based on six-level standards. The intermediate standard solutions prepared from pure standards were used to prepare the standards for the calibration and spiking solution. 
Standards PCB/OC/CB mixtures ranging from $1-500 \mathrm{ng} / \mathrm{ml}$ were directly injected in the GCxGC- $\mu \mathrm{ECD}$ system and data were recorded using ChromaTOFv.3.34 software (LECO Corporation). Table 4.2 provides the composition and levels of selected standards along with a summary of the calibration settings and results.

Table 4.2 Identification, retention times and within-run repeatability for the selected $\mathrm{PCB} / \mathrm{OC} / \mathrm{CB}$ compounds analysed by $\mathrm{GCx} \mathrm{GC}-\mu \mathrm{ECD}$

\begin{tabular}{|c|c|c|c|c|c|c|c|c|}
\hline \multirow{2}{*}{$\begin{array}{l}\text { Compound Name } \\
\text { Dioxin-like PCBs }\end{array}$} & \multicolumn{2}{|c|}{$\begin{array}{l}\text { Retention } \\
\text { Time (s) }\end{array}$} & \multicolumn{3}{|c|}{ Calibration } & \multicolumn{3}{|c|}{$\begin{array}{c}\text { Repeatability } \\
\text { (Std. } 50 \mathrm{ng} / \mathrm{mL} \text { ) }\end{array}$} \\
\hline & 1D & 2D & $\begin{array}{c}\text { Dynamic } \\
\text { Range } \\
\text { (pg/uL) }\end{array}$ & $\mathbf{R}$ & $\begin{array}{l}\text { Curve } \\
\text { Type }\end{array}$ & $\begin{array}{l}\text { Mean } \\
(n=10)\end{array}$ & SD & $\begin{array}{l}\text { RSD } \\
(\%)\end{array}$ \\
\hline PCB77 & 1508 & 2.32 & $1-500$ & 0.999 & Linear & 47.44 & 1.29 & 2.72 \\
\hline PCB81 & 1484 & 2.22 & $1-500$ & 0.999 & Quadratic & 54.40 & 0.28 & 0.51 \\
\hline PCB126 & 1724 & 2.56 & $1-500$ & 0.999 & Quadratic & 63.18 & 1.17 & 1.84 \\
\hline PCB169 & 1928 & 2.76 & $1-500$ & 0.999 & Quadratic & 52.40 & 0.51 & 0.97 \\
\hline PCB 105 & 1636 & 2.34 & $1-500$ & 0.999 & Quadratic & 52.16 & 0.30 & 0.58 \\
\hline PCB114/cis-nonachlor & 1604 & 2.18 & $2-1000$ & 0.999 & Quadratic & 113.64 & 1.20 & 1.06 \\
\hline PCB 118 & 1580 & 2.06 & $1-500$ & 0.999 & Quadratic & 55.91 & 1.57 & 2.80 \\
\hline PCB 123 & 1572 & 1.98 & $1-500$ & 0.999 & Quadratic & 52.55 & 0.62 & 1.18 \\
\hline PCB156 & 1832 & 2.16 & $1-500$ & 0.999 & Quadratic & 54.45 & 0.71 & 1.30 \\
\hline PCB157 & 1840 & 2.52 & $1-500$ & 0.999 & Quadratic & 54.06 & 0.40 & 0.74 \\
\hline PCB167 & 1780 & 2.26 & $1-500$ & 0.999 & Quadratic & 52.17 & 0.34 & 0.66 \\
\hline PCB189 & 2020 & 2.64 & $1-500$ & 0.999 & Quadratic & 55.88 & 1.05 & 1.89 \\
\hline \multicolumn{9}{|l|}{ EU Indicator PCBs } \\
\hline PCB28 (250ng/mL) & 1128 & 1.22 & $1-500$ & 0.999 & Quadratic & 262.32 & 0.75 & 0.29 \\
\hline PCB52 & 1212 & 1.18 & $1-500$ & 0.999 & Quadratic & 54.62 & 0.14 & 0.25 \\
\hline PCB101 & 1428 & 1.52 & $1-500$ & 0.999 & Quadratic & 52.74 & 0.16 & 0.30 \\
\hline PCB118 & 1580 & 2.06 & $1-500$ & 0.999 & Quadratic & 55.91 & 1.57 & 2.80 \\
\hline PCB138 & 1704 & 2.08 & $1-500$ & 0.999 & Quadratic & 52.54 & 0.29 & 0.56 \\
\hline PCB153 & 1644 & 1.80 & $1-500$ & 0.999 & Quadratic & 51.74 & 1.42 & 2.74 \\
\hline \multicolumn{9}{|l|}{ OC Pesticides } \\
\hline$\alpha$-Chlordane & 1444 & 1.72 & $1-500$ & 0.999 & Quadratic & 51.78 & 3.77 & 7.29 \\
\hline$\gamma$-Chlordane & 1404 & 1.94 & $1-500$ & 0.999 & Quadratic & 52.04 & 0.56 & 1.07 \\
\hline $\mathrm{p}, \mathrm{p}^{\prime}-\mathrm{DDE}$ & 1500 & 1.60 & $1-500$ & 0.999 & Quadratic & 48.75 & 0.56 & 1.14 \\
\hline o,p'-DDT & 1612 & 1.70 & $1-500$ & 0.999 & Quadratic & 50.35 & 0.71 & 1.42 \\
\hline p,p'-DDD & 1588 & 2.28 & $1-500$ & 0.999 & Quadratic & 50.94 & 0.95 & 1.87 \\
\hline p,p'-DDT & 1692 & 2.14 & $1-500$ & 0.999 & Quadratic & 50.77 & 0.75 & 1.47 \\
\hline \multicolumn{9}{|l|}{ CBs } \\
\hline HCB & 956 & 0.60 & $1-500$ & 0.999 & Quadratic & 46.85 & 0.50 & 1.06 \\
\hline $1,2,4-\mathrm{TCB}$ & 472 & 2.94 & $1-500$ & 0.999 & Quadratic & 49.29 & 1.65 & 3.36 \\
\hline $1,3,5-\mathrm{TCB}$ & 440 & 2.86 & $1-500$ & 0.999 & Quadratic & 48.57 & 0.48 & 0.99 \\
\hline
\end{tabular}


Figures $4.8,4.9$ and 4.10 provide examples of calibration curves and calibration tables for selected compounds from each target contaminant classes. All of the 96 compounds analysed had a coefficient of linearity greater than 0.995 .

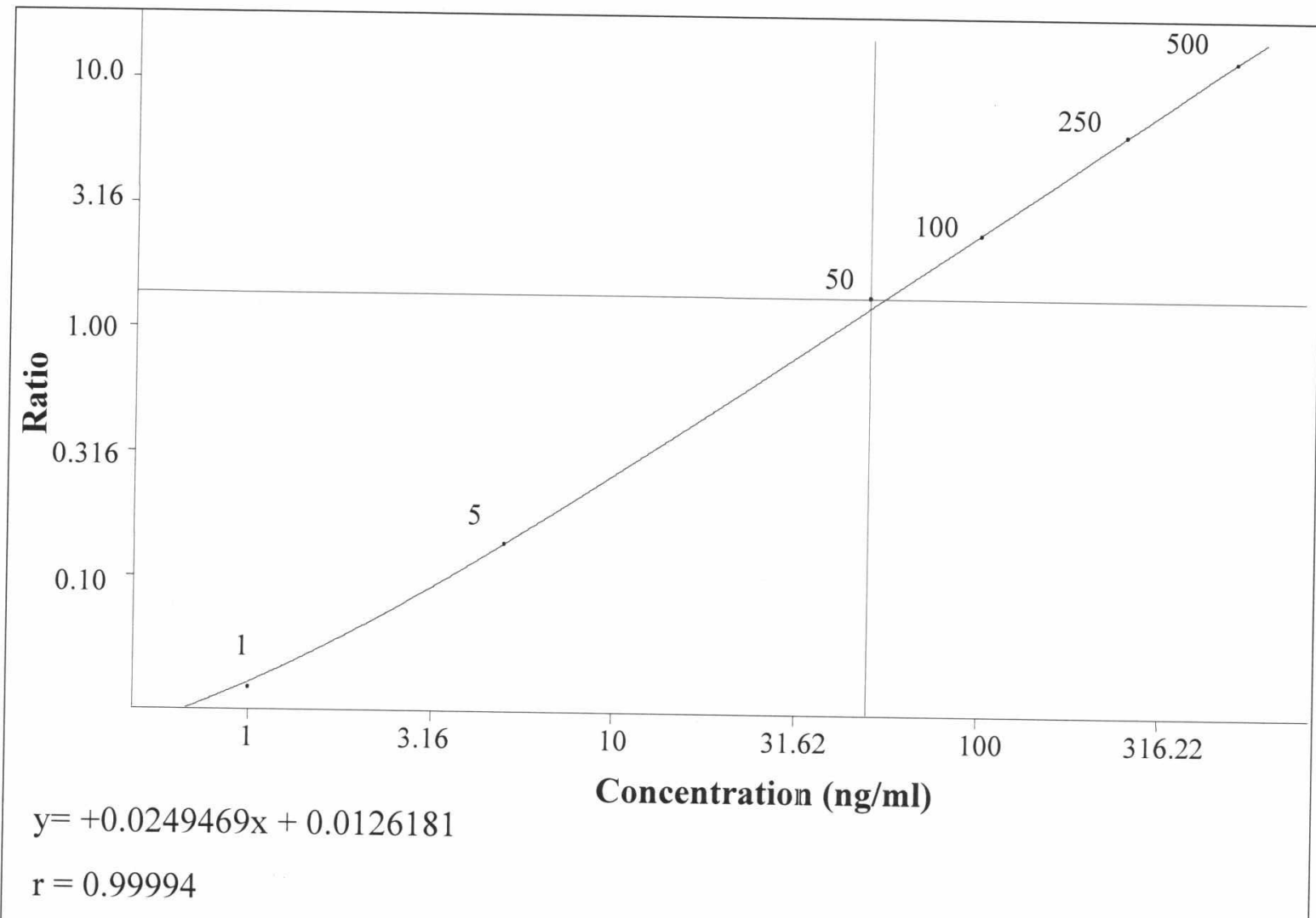

\begin{tabular}{|c|c|c|c|c|c|c|}
\hline $\begin{array}{c}\text { Standard } \\
\text { PCBc (ng/ml) }\end{array}$ & Height & Area & $\begin{array}{c}\text { Calc. } \\
\text { Conc. }\end{array}$ & $\begin{array}{c}\text { \% Diff. } \\
\text { Conc. }\end{array}$ & Weighting & RF \\
\hline 1 & 4347.2 & 47216 & 0.93 & 7.13 & 1 & 0.358 \\
\hline 5 & 24513 & 281871 & 4.99 & 0.28 & 0.2 & 0.274 \\
\hline 50 & 237531 & 2639629 & 54.78 & 9.55 & 0.02 & 0.276 \\
\hline 100 & 415987 & 4553975 & 98.77 & 1.23 & 0.01 & 0.248 \\
\hline 250 & 1007256 & 11300009 & 248.93 & 0.43 & 0.004 & 0.249 \\
\hline 500 & 1740823 & 20046125 & 497.61 & 0.48 & 0.002 & 0.249 \\
\hline
\end{tabular}

Figure 4.8 Calibration curve and calibration table generated by ChromaTof 3.34 software for PCB77. 
Chapter 4: Results

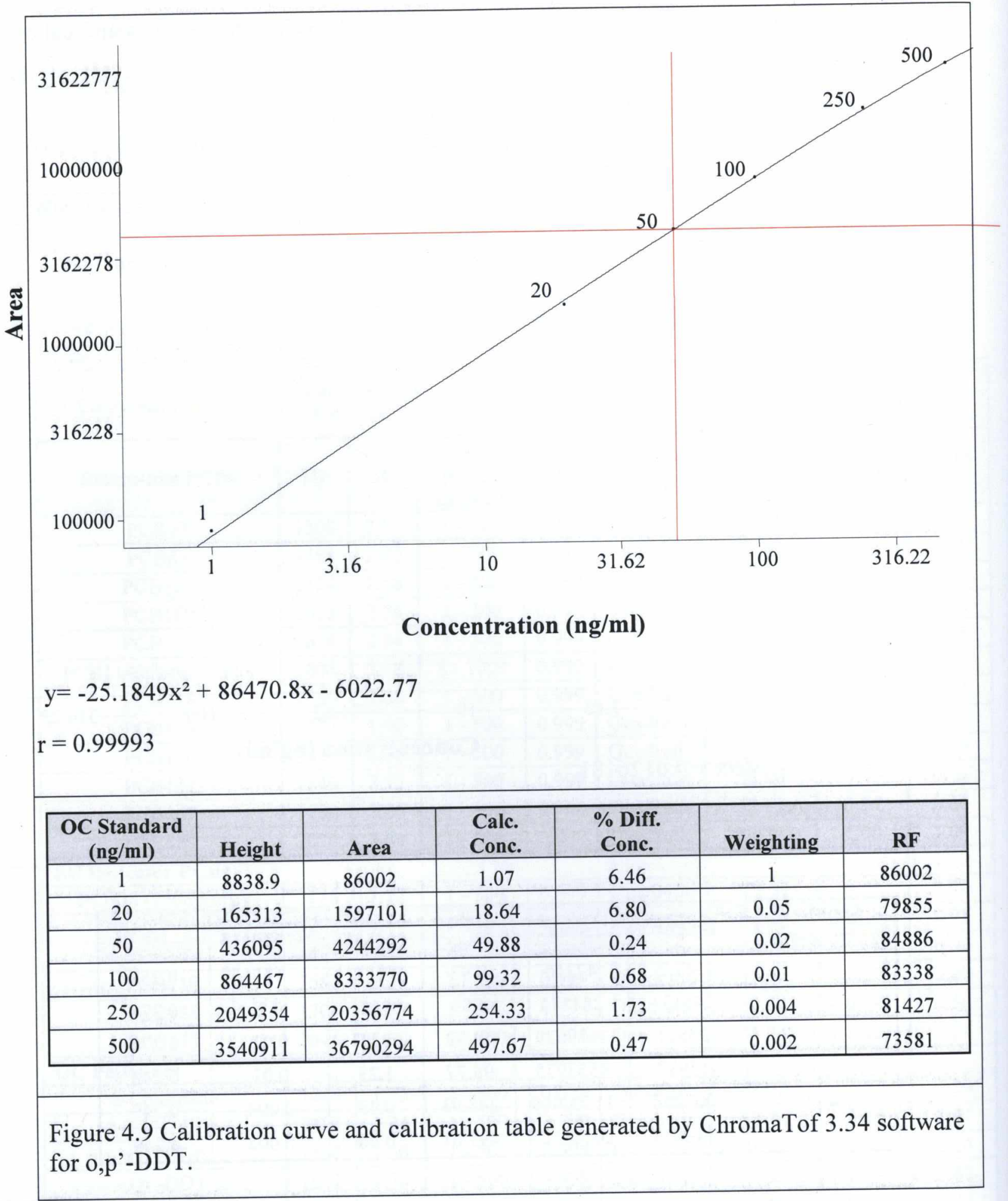




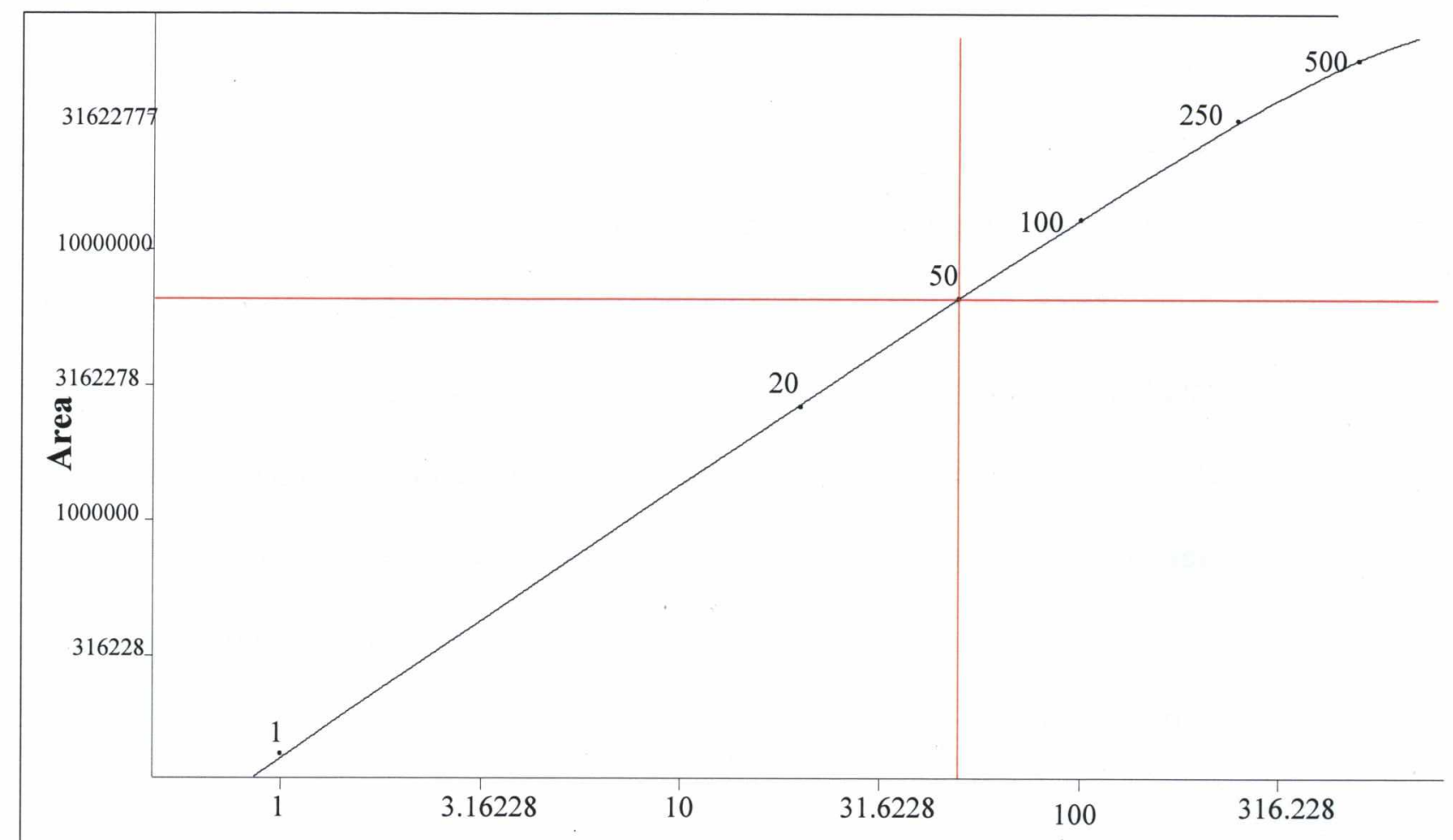

\section{$\overline{\text { Concentration (ng/ml) }}$}

$y=-69.8839 x^{2}+136935 x-4053.11$

$\mathrm{r}=0.99994$

\begin{tabular}{|c|c|c|c|c|c|c|}
\hline $\begin{array}{c}\text { CB Standard } \\
(\mathbf{n g} / \mathbf{m l})\end{array}$ & Height & Area & $\begin{array}{c}\text { Calc. } \\
\text { Conc. }\end{array}$ & $\begin{array}{c}\text { \% Diff. } \\
\text { Conc. }\end{array}$ & Weighting & RF \\
\hline 1 & 15898 & 137706 & 1.0358 & 3.5783 & 1 & 137706 \\
\hline 20 & 305432 & 2633644 & 19.456 & 2.7218 & 0.05 & 131682 \\
\hline 50 & 778460 & 6582715 & 49.344 & 1.3117 & 0.02 & 131654 \\
\hline 100 & 1494677 & 12904669 & 99.302 & 0.69834 & 0.01 & 129047 \\
\hline 250 & 3330444 & 30283225 & 254.14 & 1.6572 & 0.004 & 121133 \\
\hline 500 & 5382913 & 50810213 & 497.29 & 0.54154 & 0.002 & 101620 \\
\hline
\end{tabular}

Figure 4.10 Calibration curve and calibration table generated by ChromaTof 3.34 software for HCB. 
From the data obtained and presented in these figures along with the calibration for all the target analytes PCBs, OCs and CBz by GCxGC- $\mu$ ECD were quantified in the range: $1-500 \mathrm{ng}$. Above $500 \mathrm{ng} / \mathrm{ml}$ the ECD detector can become saturated for some of the target analytes, e.g. HCB (Figure 4.10).

The quantification by the external standard method for OCs and $\mathrm{CBz}$ involved the equations (4.1) and (4.2). The concentration of the target compounds in the sample extract is calculated by the instrument software using the formula (ChemStation Manual, Agilent Technologies):

$$
m_{x}=A_{x} \times \frac{c_{s t d_{x}}}{A s t d_{x}}
$$

Where:

$m_{x} \quad=$ concentration of compound $\mathrm{x}$ in the sample extract $(\mathrm{ng} / \mathrm{mL})$

$A_{x} \quad=$ area count of compound $\mathrm{x}$ peak in the sample extract

$c_{s t d x}=$ concentration of compound $\mathrm{x}$ in the standard $(\mathrm{ng} / \mathrm{mL})$

Astd $_{x}=$ area count of compound $\mathrm{x}$ peak in the standard

The concentration of the target compounds in the original sample (dilution is taken into account) is then calculated from the target compound concentration in the sample extract using the formula:

$$
\text { Amount }_{x}=\frac{m_{x} \times \text { Dilution Factor }_{\text {Sample Weight }} \times \text { Injection Volume }}{\text { Salu }}
$$


Where:
Amount $_{x}$
$=$ concentration of compound $\mathrm{x}$ in the sample $(\mathrm{ng} / \mathrm{g})$
$m_{x}$
$=$ concentration of compound $\mathrm{x}$ in the sample extract $(\mathrm{ng} / \mathrm{mL})$
Dilution Factor
$=$ factor converting the final extract volume to the original sample volume/amount
Sample Weight = weight of sample $(\mathrm{g})$
Injection Volume $\quad=$ the volume of injected sample extract $(\mu \mathrm{L})$

The PCB congeners were quantified using the internal standard procedure and the amounts of contaminants were calculated according to the formulas (4.3 and 4.4):

$$
\begin{aligned}
& R F=\frac{c_{\text {std }} \times{ }^{A_{I S T D}}}{c_{\text {ISTD }} \times A_{\text {stdx }}} \\
& m_{x}=\frac{A_{x}}{A_{\text {ISTD }}} \times R F_{x} \times(\text { Actual Amount of ISTD }) \times M \times D
\end{aligned}
$$

Where:

$\mathrm{C}_{\mathrm{ISTD}}=$ concentration of internal standard

$A_{\text {ISTD }}=$ area count of compound x peak in the standard

$\mathrm{M} \quad=$ multiplier

The other statistics such as mean, standard deviation and percentage relative standard deviation presented further in this study were also calculated. The SPSS software package (SPSS student version 14) and Excel were used for the calculations. 


\subsubsection{Limit of detection and Limit of quantitation}

The method detection limits and the estimated limit of quantification were obtained by analyzing eight replicates of a clean sediment matrix spiked (same matrix as the one used for blank) at the lowest level of the analytes in the calibration curve. The lowest level at which accurate quantitation can be achieved must be determined for each matrix. The calculations were based on the following standard equations $(4.5,4.6)$ :

$M D L=S D \cdot t_{n-1,1-a=0.99}$

$L O Q=3 \cdot M D L$

Where:

MDL = method detection limits

LOQ = limit of quantification

$t_{\mathrm{n}-1,0.01}=$ student's $\mathrm{t}$ value for the $99 \%$ confidence level with $n-1$ degrees of freedom

The low level spiked ( $1 \mathrm{ng} / \mathrm{mL}$ ) clean sediment samples were processed following the sample preparation steps described in the previous chapter and analyzed by GCxGCECD. Table 4.3 represents the data obtained and the appropriate statistical calculations for specific compounds. The MDLs varied from 0.06 to $3.5 \mathrm{ng} / \mathrm{g}$ while the estimated limits of quantification for $\mathrm{PCB} / \mathrm{OC} / \mathrm{CB}$ were found to be in the range of 1 to $10 \mathrm{ng} / \mathrm{g}$. The results for all the target analytes are presented in Appendix B - Method Validation. 
Table 4.3 Results representing MDL and LOQ calculations for selected target analytes.

\begin{tabular}{|c|c|c|c|c|c|c|}
\hline Compound Name & $\begin{array}{c}\text { Expected } \\
\text { Concentration } \\
\text { (ng/g) }\end{array}$ & $\begin{array}{c}\text { Mean } \\
\mathbf{n}=\mathbf{8}\end{array}$ & SD & \%RSD & $\begin{array}{c}\text { MDL } \\
\text { (ng/g) }\end{array}$ & $\begin{array}{c}\text { LOQ } \\
\text { (ng/g) }\end{array}$ \\
\hline Dioxin-like PCBs & & & & & & \\
\hline PCB77 & 1 & 1.09 & 0.14 & 13.10 & 0.43 & 1.28 \\
\hline PCB81 & 1 & 1.00 & 0.12 & 12.04 & 0.36 & 1.08 \\
\hline PCB126 & 1 & 1.11 & 0.08 & 6.99 & 0.23 & 0.70 \\
\hline PCB169 & 1 & 1.05 & 0.15 & 13.97 & 0.44 & 1.32 \\
\hline PCB105 & 1 & 1.10 & 0.08 & 7.10 & 0.23 & 0.70 \\
\hline PCB114/cis-nonachlor & 2 & & & & & \\
\hline PCB118 & 1 & 1.06 & 0.09 & 8.54 & 0.27 & 0.81 \\
\hline PCB123 & 1 & 0.99 & 0.15 & 15.31 & 0.45 & 1.36 \\
\hline PCB156 & 1 & 0.93 & 0.09 & 9.54 & 0.27 & 0.80 \\
\hline PCB157 & 1 & 1.04 & 0.13 & 12.41 & 0.39 & 1.16 \\
\hline PCB167 & 1 & 1.03 & 0.06 & 5.76 & 0.18 & 0.54 \\
\hline PCB189 & 1 & 1.12 & 0.15 & 13.53 & 0.45 & 1.36 \\
\hline EU Indicator PCBs & & & & & & \\
\hline PCB28 & 1 & $9.17 *$ & 0.72 & 7.86 & 2.16 & 6.48 \\
\hline PCB52 & 1 & $2.56 *$ & 0.19 & 7.38 & 0.57 & 1.70 \\
\hline PCB101 & 1 & 1.24 & 0.20 & 16.07 & 0.59 & 1.78 \\
\hline PCB118 & 1 & 1.06 & 0.09 & 8.54 & 0.27 & 0.81 \\
\hline PCB138 & 1 & 1.26 & 0.07 & 5.82 & 0.22 & 0.66 \\
\hline PCB153 & 1 & 1.29 & 0.09 & 6.64 & 0.26 & 0.77 \\
\hline OC Pesticides & & & & & & \\
\hline p,p'-DDE & 1 & 0.98 & 0.18 & 18.32 & 0.54 & 1.61 \\
\hline o,p'-DDT & 1 & 1.15 & 0.17 & 14.85 & 0.51 & 1.54 \\
\hline p,p'-DDD & 1 & 1.21 & 0.21 & 17.41 & 0.63 & 1.90 \\
\hline p,p'-DDT & 1 & 1.27 & 0.21 & 16.15 & 0.62 & 1.85 \\
\hline CBs & & & & & & \\
\hline HCB & 1 & 1.00 & 0.04 & 3.66 & 0.11 & 0.33 \\
\hline $1,2,4-T C B$ & 1 & & & & & \\
\hline $1,3,5-T C B$ & 1 & & & & & \\
\hline & & & & & & \\
\hline & 1 & & & & & \\
\hline
\end{tabular}

* Interference suspected - possible contamination during the sample preparation steps when using the glassware and evaporators prior used for different methods. 


\subsubsection{Precision: repeatability, reproducibility}

Method performance was measured by analyzing ten replicates of a clean sediment sample spiked with the $\mathrm{PCB} / \mathrm{OC} / \mathrm{CB}$ spiking solution. Both within-run (repeatability) and between-run (reproducibility and accuracy) method precision were assessed and the results are presented in this section.

Within-run precision has been calculated from ten replicates processed in the same run (Table 4.4).

Table 4.4 Within-run Method Precision for PCB, OC, CB for ten replicates of spiked sediment samples.

\begin{tabular}{|c|c|c|c|c|c|}
\hline Compound Name & $\mathbf{N}$ & $\begin{array}{c}\text { Expected } \\
\text { amount }(\mathrm{ng} / \mathrm{g})\end{array}$ & Mean & SD & $\%$ RSD \\
\hline \multicolumn{6}{|l|}{ Dioxin-like PCBs } \\
\hline PCB77 & 10 & 50 & 41.73 & 5.21 & 12.48 \\
\hline PCB81 & 10 & 50 & 50.03 & 5.98 & 11.95 \\
\hline PCB126 & 10 & 50 & 59.56 & 7.40 & 12.42 \\
\hline PCB169 & 10 & 50 & 49.87 & 6.33 & 12.68 \\
\hline PCB105 & 10 & 50 & 49.02 & 6.31 & 12.87 \\
\hline PCB114/cis-nonachlor & 10 & 100 (coelution) & 110.39 & 2.47 & 2.24 \\
\hline PCB118 & 10 & 50 & 53.28 & 5.12 & 9.60 \\
\hline PCB123 & 10 & 50 & 46.85 & 5.22 & 11.14 \\
\hline PCB156 & 10 & 50 & 49.42 & 6.38 & 12.92 \\
\hline PCB157 & 10 & 50 & 46.29 & 6.23 & 13.46 \\
\hline PCB167 & 10 & 50 & 49.11 & 6.25 & 12.73 \\
\hline PCB189 & 10 & 50 & 52.46 & 6.92 & 13.19 \\
\hline \multicolumn{6}{|l|}{ EU Indicator PCBs } \\
\hline PCB28 & 10 & 250 & 224.02 & 29.21 & 13.04 \\
\hline PCB52 & 10 & 50 & 50.24 & 6.60 & 13.13 \\
\hline PCB101 & 10 & 50 & 48.48 & 5.99 & 12.35 \\
\hline PCB118 & 10 & 50 & 53.28 & 5.12 & 9.60 \\
\hline PCB138 & 10 & 50 & 49.26 & 6.32 & 12.83 \\
\hline PCB153 & 10 & 50 & 48.89 & 6.18 & 12.65 \\
\hline \multicolumn{6}{|l|}{ OC Pesticides } \\
\hline p,p'-DDE & 10 & 50 & 47.44 & 1.03 & 2.18 \\
\hline$o, p^{\prime}-D D T$ & 10 & 50 & 52.90 & 3.46 & 6.53 \\
\hline p,p'-DDD & 10 & 50 & 51.96 & 1.17 & 2.25 \\
\hline p,p'-DDT & 10 & 50 & 52.90 & 3.46 & 6.53 \\
\hline \multicolumn{6}{|l|}{ CBs } \\
\hline HCB & 10 & 50 & 38.57 & 1.18 & 3.07 \\
\hline $1,2,4-\mathrm{TCB}$ & 10 & 50 & 34.53 & 4.74 & 13.72 \\
\hline
\end{tabular}


Chapter 4: Results

\begin{tabular}{|c|c|c|c|c|c|}
\hline Compound Name & $\mathbf{N}$ & $\begin{array}{c}\text { Expected } \\
\text { amount (ng/g) }\end{array}$ & Mean & SD & \%RSD \\
\hline $1,3,5-\mathrm{TCB}$ & 10 & 50 & 32.63 & 2.76 & 8.46 \\
\hline
\end{tabular}

Between-run precision has been calculated from eight replicates processed in the same run (Table 4.5).

Table 4.5 Between-run Method Precision

\begin{tabular}{|c|c|c|c|c|c|}
\hline Compound Name & $\mathbf{N}$ & $\begin{array}{c}\text { Expected } \\
\text { amount (ng/g) }\end{array}$ & Mean & SD & $\%$ RSD \\
\hline \multicolumn{6}{|l|}{ Dioxin-like PCBs } \\
\hline PCB77 & 6 & 50 & 47.64 & 5.20 & 10.92 \\
\hline PCB81 & 6 & 50 & 51.12 & 4.19 & 8.19 \\
\hline PCB126 & 6 & 50 & 65.00 & 5.99 & 9.21 \\
\hline PCB169 & 6 & 50 & 50.45 & 4.13 & 8.18 \\
\hline PCB105 & 6 & 50 & 48.8 & 3.3 & 6.69 \\
\hline PCB114/cis-nonachlor & 6 & 100 (coelution) & 113 & 8.5 & 7.49 \\
\hline PCB118 & 6 & 50 & 49.3 & 2.4 & 4.78 \\
\hline PCB123 & 6 & 50 & 44.0 & 4.6 & 10.42 \\
\hline PCB 156 & 6 & 50 & 51.9 & 2.1 & 4.03 \\
\hline PCB157 & 6 & 50 & 50.8 & 2.4 & 4.68 \\
\hline PCB167 & 6 & 50 & 49.7 & 3.5 & 6.98 \\
\hline PCB189 & 6 & 50 & 53.3 & 3.4 & 6.37 \\
\hline \multicolumn{6}{|l|}{ EU Indicator PCBs } \\
\hline PCB28 & 6 & 250 & 217 & 13.9 & 6.40 \\
\hline PCB52 & 6 & 50 & 49.3 & 2.0 & 4.01 \\
\hline PCB101 & 6 & 50 & 47.6 & 2.1 & 4.47 \\
\hline PCB118 & 6 & 50 & 49.3 & 2.4 & 4.78 \\
\hline PCB138 & 6 & 50 & 49.6 & 2.2 & 4.34 \\
\hline PCB153 & 6 & 50 & 50.9 & 3.4 & 6.77 \\
\hline \multicolumn{6}{|l|}{ OC Pesticides } \\
\hline p,p'-DDE & 8 & 50 & 49.66 & 8.17 & 16.44 \\
\hline o,p'-DDT & 8 & 50 & & & \\
\hline p,p'-DDD & 8 & 50 & 57.34 & 9.25 & 16.14 \\
\hline p,p'-DDT & 8 & 50 & 56.50 & 10.54 & 18.66 \\
\hline \multicolumn{6}{|l|}{ CBs } \\
\hline HCB & 8 & 50 & 39.84 & 7.99 & 20.06 \\
\hline $1,2,4-\mathrm{TCB}$ & 8 & 50 & 30.8 & 16.3 & 53.01 \\
\hline
\end{tabular}

From the RDS values presented in Tables 4.4 and 4.5 we see that between-run precision was better than within-run precision, oposite to what is usually expected. This 
might be because of the small data set (6 and 8 replicates) available when assessing the between-run precision.

\subsubsection{Accuracy - reference materials quantification}

The accuracy of the method was assessed by analyzing reference materials for different matrices. Sediment (SRM1944 and EC-8) and sludge (CNS-312) samples were processed according to the extraction, clean-up and instrumental methods and the calculated analyte amounts were compared to their reference values (Figure 4.11, 4.12a and b). Furthermore, the GCxGC- $\mu$ ECD data for SRM1944 and EC-8 was also compared with previous results obtained from the classical GC-ECD analysis (Figure 4.10a and b). The GC-ECD data was obtained using Ontario Ministry of the Environment, Dioxins and Toxic Organics Section Methods 3412 and 3270 (MoE Method 3412 and 3270, 2008). PCB congeners values for reference materials SRM1944 and EC-8 analysed by GC-ECD were provided by Tony Chen, Dioxin and Toxic Organics, Ontario Ministry of the Environment.

A comparison between the classical GC-ECD and $\mathrm{GCxGC}-\mu \mathrm{ECD}$ analyses of sediment and sludge samples is required at this point since all the reference materials data will be presented as a comparison of the two methods to illustrate the significance of the GCxGC technique. Table 4.6 points up the major steps of each method. 
Table 4.6 Comparison of GC-ECD vs. GCxGC- $\mu \mathrm{ECD}$ methods for sediments/sludge samples analysis.

\begin{tabular}{|c|c|c|}
\hline & $\begin{array}{l}\text { GC-ECD Methods 3270 and } 3412 \\
\text { (MOE, 2008): }\end{array}$ & GCxGC-ECD Method \\
\hline Extraction & $\begin{array}{l}\text { - Sonication and manual extraction } \\
\text { using acetone: DCM: hexane mixture } \\
\text { - Final volume: } 100 \mathrm{~mL}\end{array}$ & $\begin{array}{l}\text { - ASE: one static extraction with } \\
\text { DCM:hexane } \\
\text { - Final volume: approx. } 25 \mathrm{~mL}\end{array}$ \\
\hline Clean-up & $\begin{array}{l}\text { - Florisil clean-up: splitting in two } \\
\text { fractions } \\
\text { - Copper treatment to remove sulphur } \\
\text { interferences }\end{array}$ & $\begin{array}{l}\text { - Silica clean-up (pre-packed } \\
\text { cartridges) collecting one final } \\
\text { fraction } \\
\text { - Copper treatment to remove } \\
\text { the interferences prior to } \\
\text { analysis }\end{array}$ \\
\hline Analysis & $\begin{array}{l}\text { - } 4 \text { GC-ECD instruments: } \\
\text { DB-5 and DB-1701 for PCB } \\
\text { congeners determination in the } \\
1^{\text {st }} \text { fraction } \\
\text { - DB-17 for OCs and PCB total } \\
\text { analysis from } 1^{\text {st }} \text { fraction } \\
\text { - Rtx-CLP1 and Rtx-CLP2 for } \\
\text { OC determination in the } 2^{\text {nd }} \\
\text { fraction } \\
\text { DB-1 and DB- } 1701 \text { for CB } \\
\text { determination in the } 1^{\text {st }} \text { fraction }\end{array}$ & $\begin{array}{l}\text { - GCxGC- } \mu E C D \text { analysis: } \\
\quad \text { DB1 x Rtx-PCB } \\
\text { - PCBs, OCs, CBs quantified in } \\
\text { one single analysis ( } 45 \text { min run) }\end{array}$ \\
\hline
\end{tabular}

\section{SRM1944 - Sediment Reference Material (NIST)}

SRM 1944, provided by the National Institute of Standards \& Technology (NIST, USA), is a mixture of marine sediment collected near urban areas in New York and New Jersey. The purpose of this reference material is to evaluate analytical methods for the 
determination of selected polycyclic aromatic hydrocarbons (PAHs), polychlorinated biphenyl (PCB) congeners, chlorinated pesticides, and selected polychlorinated dibenzop-dioxin and polychlorinated dibenzofuran congeners in marine sediment and similar matrices. All of the certified compounds were naturally present in the sediment material before processing (SRM1944 - Certificate of Analysis, 2008).

SRM1944 samples were processed following both GC-ECD and GCxGC- $\mu$ ECD sample preparation and analysis steps and the results are presented in Table 4.7. In addition, the data was also plotted and presented in Figure 4.11 to better visualise the outcomes.

Table 4.7 Comparison data of selected PCBs, OCs and CBs analysed by classical GC$\mathrm{ECD}, \mathrm{GCx} G \mathrm{C}-\mu \mathrm{ECD}$ and their reference values for SRM1944.

\begin{tabular}{|c|c|c|c|c|c|}
\hline \multirow{2}{*}{ Name } & \multicolumn{2}{|c|}{$\begin{array}{c}\text { Certified amount } \\
(\mathrm{ng} / \mathrm{g})\end{array}$} & \multicolumn{2}{|c|}{$\begin{array}{c}\text { GCxGC- } \mu \text { ECD Mean } \\
(\mathrm{n}=3)\end{array}$} & \multirow{2}{*}{$\begin{array}{c}\begin{array}{c}\text { GC-ECD Mean } \\
(\mathrm{n}=3)\end{array} \\
\begin{array}{c}\text { Amount } \\
(\mathrm{ng} / \mathrm{g})\end{array}\end{array}$} \\
\hline & $\underset{(\mathrm{ng} / \mathrm{g})}{\text { Amount }}$ & SD & $\underset{(\mathrm{ng} / \mathrm{g})}{\operatorname{Amount}}$ & SD & \\
\hline PCB 28 & 80.8 & 2.7 & 105.1 & 6.5 & 111.0 \\
\hline PCB 52 & 79.4 & 2 & 89.5 & 2.9 & 87.8 \\
\hline PCB 101 & 73.4 & 2.5 & 74.3 & 0.2 & 74.2 \\
\hline PCB 118 & 58 & 4.3 & 57.2 & 2.5 & 55.3 \\
\hline PCB 138 & 62.1 & 3 & 69.8 & 1.8 & 67.7 \\
\hline PCB 153 & 74 & 2.9 & 64.1 & 1.9 & 62.3 \\
\hline PCB 156 & 6.5 & 0.66 & 7.0 & 0.2 & 6.9 \\
\hline PCB 170 & 22.6 & 1.4 & 20.9 & 0.9 & 21.4 \\
\hline PCB 180 & 44.3 & 1.2 & 44.7 & 1.1 & 43.5 \\
\hline $\mathrm{HCB}$ & 6.03 & 0.35 & 5.7 & 0.3 & 5.8 \\
\hline$\alpha$-chlordane & 16.5 & 0.83 & 18.7 & 0.7 & 18.5 \\
\hline $\mathrm{p}, \mathrm{p}^{\prime}-\mathrm{DDE}$ & 86 & 12 & 68.9 & 2.1 & 66.7 \\
\hline p,p'-DDD & 108 & 16 & 105.0 & 8.8 & 101.6 \\
\hline $\mathrm{p}, \mathrm{p}^{\prime}$-DDT & 119 & 11 & 114.6 & 2.6 & 117.2 \\
\hline
\end{tabular}




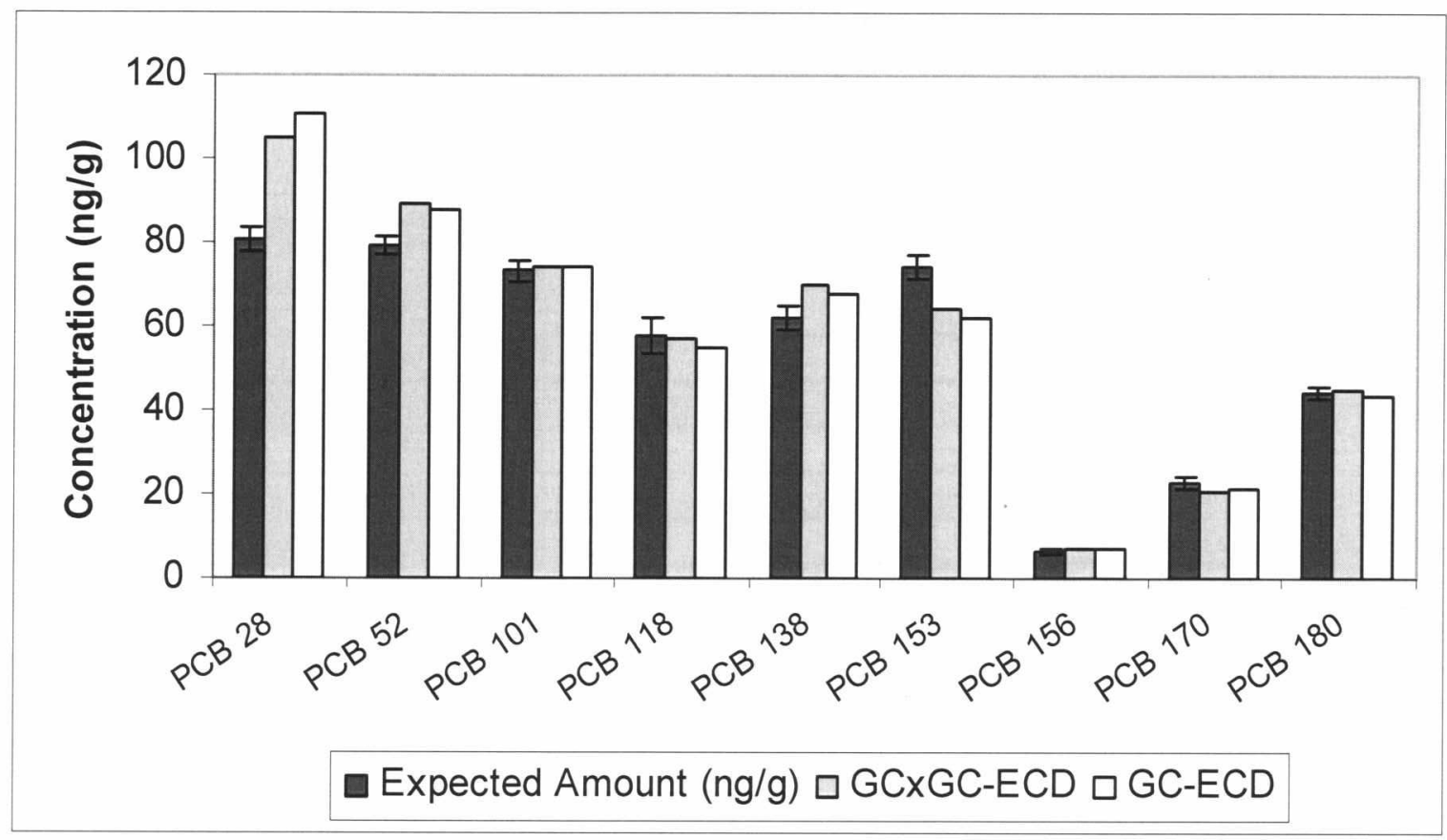

Figure 4.11 Graphical representations of specific PCB congeners amounts in SRM1944 analysed by GC-ECD, GCxGC- $\mu \mathrm{ECD}$ and their certified values.

\section{CNS312 - Sludge Reference Material (RTC)}

CNS312 is a sludge material collected from a sewage works serving a residential area with light industrial influence, located in the Western United States. According to the provider's certificate of analysis (RT Corp.), the matrix was air dried, sterilized, sieved and then homogenized. These sludge reference materials are "real-world" samples, thus the analyst is challenged by the same analytical problems as for similar matrices received by the laboratory for analysis. Table 4.8 represents the data obtained by GCxGC- $\mu \mathrm{ECD}$ analysis; GC-ECD data was not available for CNS312. 
Table 4.8 Data comparison of the GCxGC- $\mu$ ECD analysis ( 8 replicates) and the certified reference values for CNS312 sludge reference material (RTCorp. - CNS312 Certificate of Analysis).

\begin{tabular}{|c|c|c|c|c|c|}
\hline \multirow{2}{*}{ Name } & Certified & \multirow{2}{*}{$\begin{array}{c}\text { Reference } \\
\text { SD }\end{array}$} & \multicolumn{3}{|c|}{ GCxGC-ECD } \\
\cline { 5 - 6 } & & & Mean & Std. Deviation & \%RSD \\
\hline PCBs & & & & & \\
\hline PCB28 & 205 & 101 & 256.20 & 15.53 & 6.06 \\
\hline PCB52 & 263 & 50 & 306.95 & 12.88 & 4.20 \\
\hline PCB101 & 257 & 63 & 338.54 & 21.19 & 6.26 \\
\hline PCB118 & 73.6 & 15 & 77.35 & 3.31 & 4.28 \\
\hline PCB138 & 136 & 26.5 & 157.23 & 5.86 & 3.73 \\
\hline PCB153 & 214 & 39 & 234.53 & 6.71 & 2.86 \\
\hline PCB180 & 232 & 36 & 259.50 & 8.64 & 3.33 \\
\hline OCs & & & & & \\
\hline $2,4-D D T$ & 223 & 61 & 221.96 & 5.13 & 2.31 \\
\hline $4,4-D D D$ & 809 & 51.7 & 796.47 & 31.75 & 3.99 \\
\hline $4,4-D D E$ & 229 & 93.8 & 197.82 & 4.91 & 2.49 \\
\hline $4,4-D D T$ & 23.5 & 6.17 & 25.82 & 0.73 & 2.85 \\
\hline Aldrin & 221 & 79.1 & 139.57 & 2.27 & 1.63 \\
\hline$\alpha$-BHC & 137 & 72.3 & 109.32 & 4.05 & 3.71 \\
\hline$\beta$-BHC & 111 & 70.4 & 98.26 & 11.41 & 11.62 \\
\hline$\gamma$-BHC & 578 & 249 & 529.18 & 13.77 & 2.60 \\
\hline Dieldrin & 569 & 110 & 497.32 & 7.89 & 1.59 \\
\hline Endosulfan1 & 296 & 176 & 331.75 & 6.42 & 1.94 \\
\hline Endrin & 336 & 135 & 446.05 & 12.47 & 2.80 \\
\hline HCB & 689 & 277 & 456.48 & 12.79 & 2.80 \\
\hline Heptachlor & 197 & 65.4 & 160.25 & 1.37 & 0.86 \\
\hline Heptachlor-hepoxide & 104 & 50.1 & 190.35 & 3.36 & 1.77 \\
\hline & & & & &
\end{tabular}

Also, for better visualisation of the results, the data from Table 4.8 was plotted as bar graph and presented in Figures $4.12 \mathrm{a}$ and $\mathrm{b}$. 

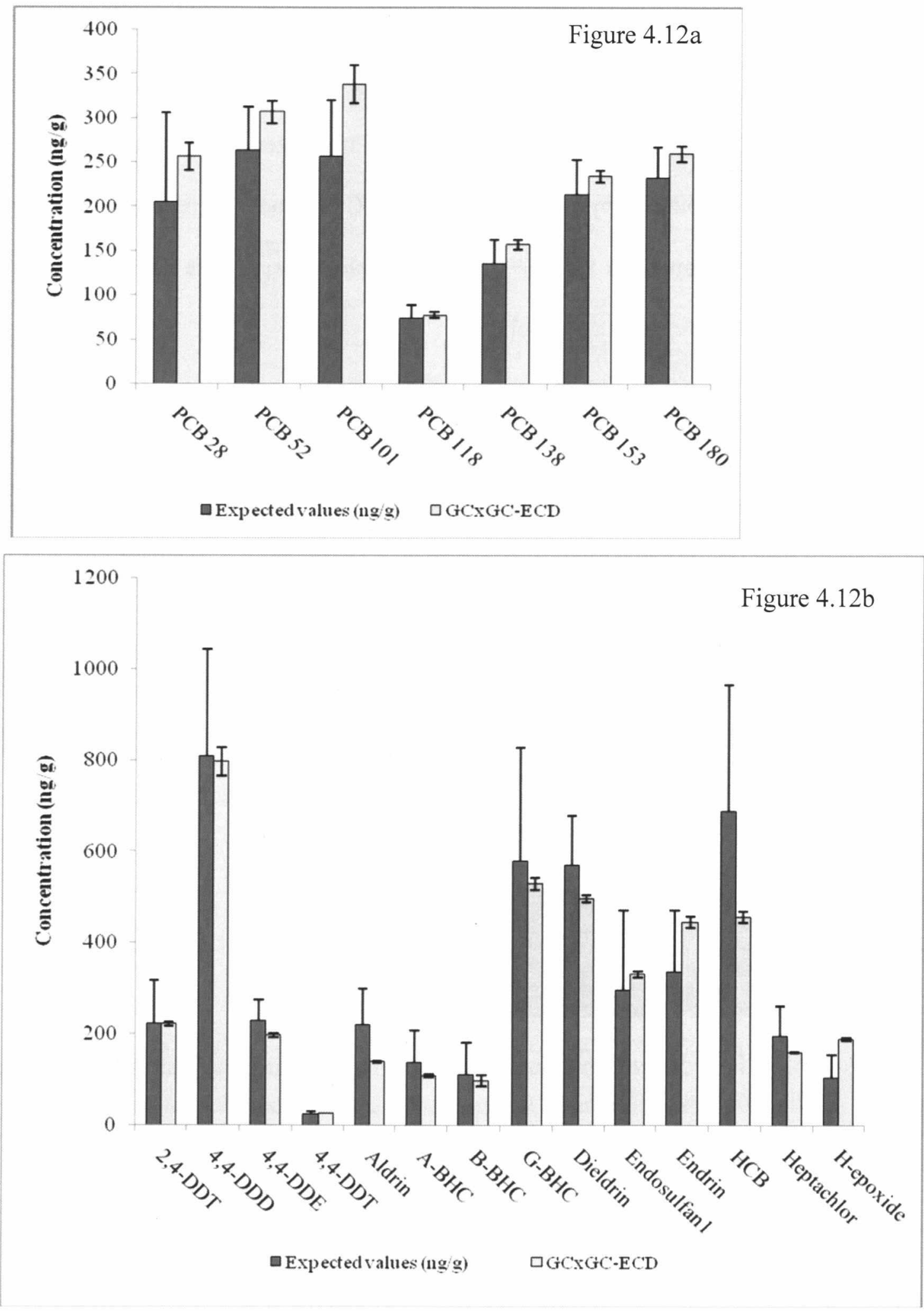

Figure 4.12 Graphical representations of selected compounds in CNS312 analysed by GCxGC- $\mu \mathrm{ECD}$ and compared to their certified values: a) PCB congeners and b) OC pesticides. 
EC-8 sediment reference material, provided by Environment Canada, is a lake sediment collected from the plume of the Niagara River in Lake Ontario. This sample was analysed to assess the quantification of chlorobenzenes by GCxGC- $\mu \mathrm{ECD}$ (Figure 4.13). The data obtained by both GC and GCxGC methods are presented in Figure 4.14. The coeluting compounds $1,2,3,5-/ 1,2,4,5$-tetrachlorobenzene are not resolved by the $2 \mathrm{D}$ column and were reported as a coelution.

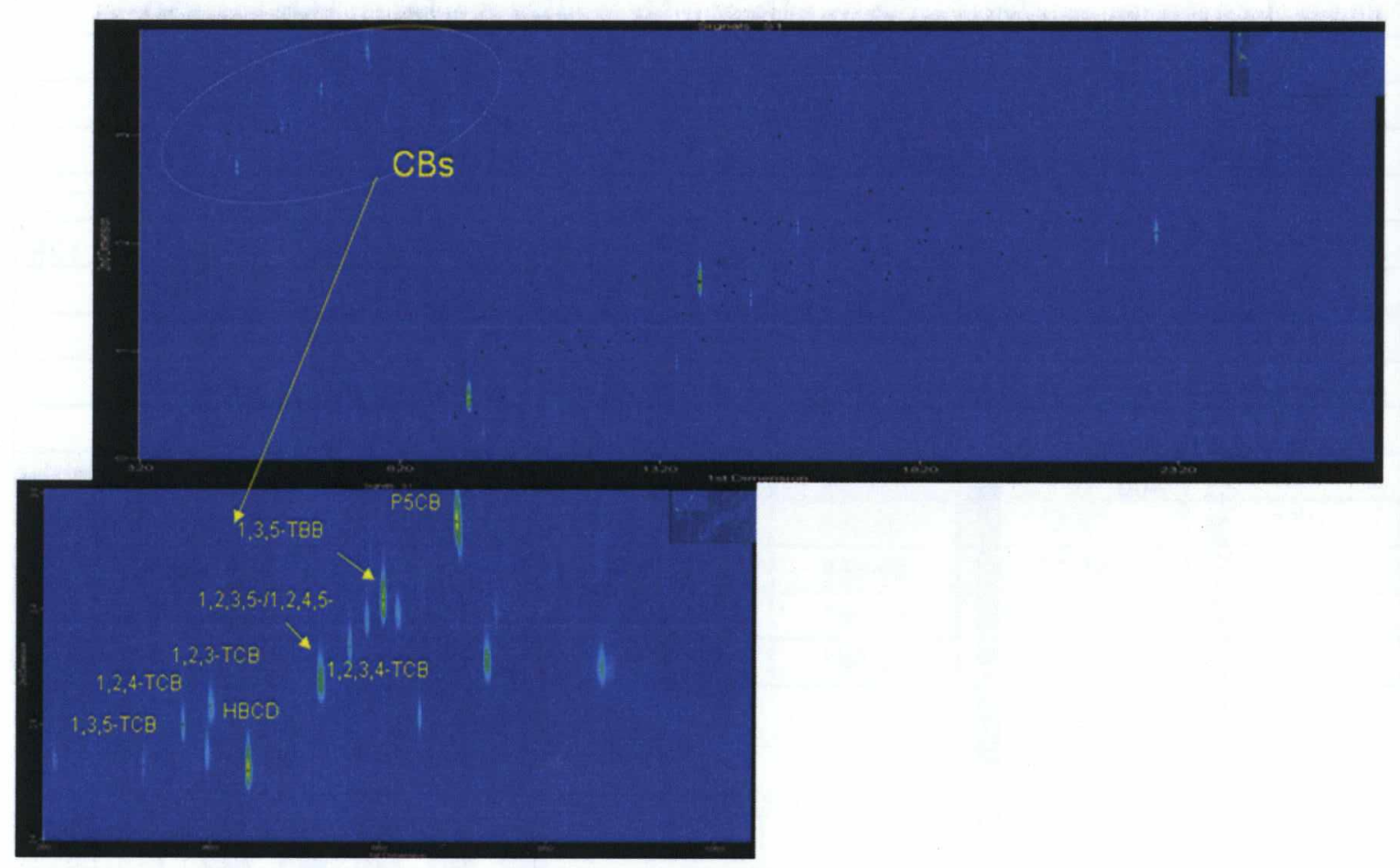

Figure 4.13 Two dimensional chromatograms representing the analysis of $\mathrm{CBz}$ in EC-8 sediment reference material. 


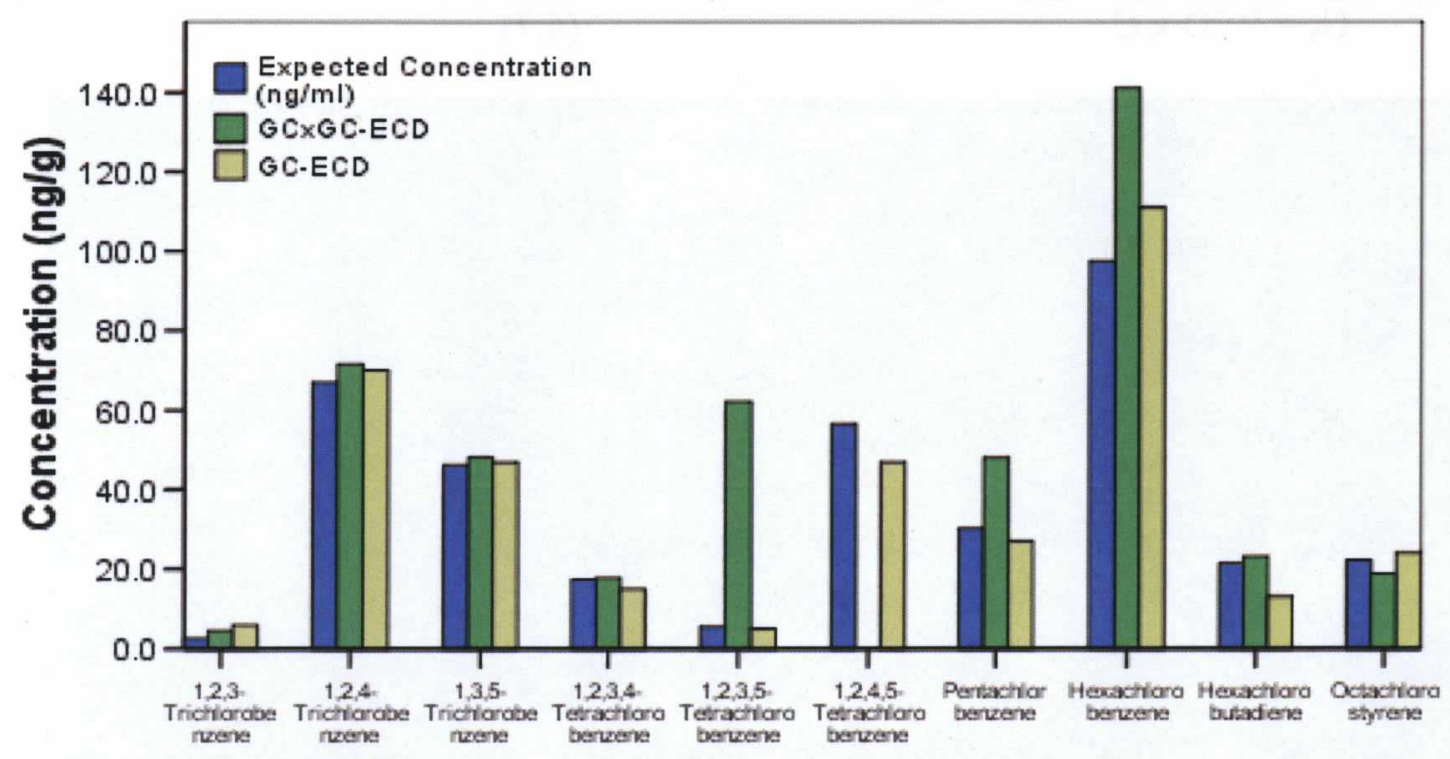

Compound Name

Figure 4.14 Data comparison for $\mathrm{CBz}$ determination in sediment reference material EC-8 by both GC-ECD and GCxGC- $\mu$ ECD methods.

As presented in Figures 4.11 to 4.13 , almost all of the quantified amounts for PCBs, OCs and $\mathrm{CBz}$ are within the specified standard deviation when compared to the reference concentration, demonstrating that the method produces accurate results.

\subsection{CALCULATIONS OF UNCERTAINTIES}

The uncertainty component $\left(\mathrm{U}_{\mathrm{x}}\right)$, standard uncertainty expressed as standard deviation $(\mathrm{SD})$, combined standard uncertainty $\left(\mathrm{U}_{\mathrm{c}}\right)$ and expanded uncertainty $(\mathrm{U})$ were calculated according to Laboratory Services Branch, LSBSOP.030 (MoE, 2008) for all the compounds analysed. These calculations give an estimation of uncertainty for any given result of any given parameter quantified with this method. The formulae 4.7 to 4.10 were used for obtaining the final results that are presented in Appendix C. 
$\mathrm{U}_{\mathrm{x}}=\mathrm{RSD} \times \mathrm{C}$

$\mathrm{Uc}=\sqrt{\mathrm{Ux}^{2}+\mathrm{Uo}^{2}}$

$\mathrm{U}_{\mathrm{o}}=\mathrm{W}=\mathrm{MDL} / 3$

$\mathrm{U}=2 \times \mathrm{Uc}$

Where:

$\mathrm{U}_{\mathrm{o}}=$ uncertainty at near zero concentration

$\mathrm{W}=$ limit of measurement

\subsection{SLUDGE AND SEDIMENT SAMPLES}

\subsubsection{Sludge Samples}

Sludge samples collected from a raw influent of a waste water treatment plant (WWTP) in Ontario have been previously submitted to Dioxin and Toxic Organics Section, MoE, for PCB total and OC pesticides analysis by GC-ECD (Method 3270 presented in Table 4.6). The samples were later re-analysed by $\mathrm{GCxGC}-\mu \mathrm{ECD}$ following the sample preparation steps and the results were compared to the ones obtained from classical analysis. The two dimensional chromatograms GCxGC- $\mu \mathrm{ECD}$ also revealed other classes of compounds present in the samples (Figure 4.14); for instance, patterns of polychlorinated alkanes were seen. Figure 4.15 shows a short chain PCA standard (55.5\%chlorinated) analysed with the same method offering a better identification of the unknown bands seen in these specific sludge samples. 


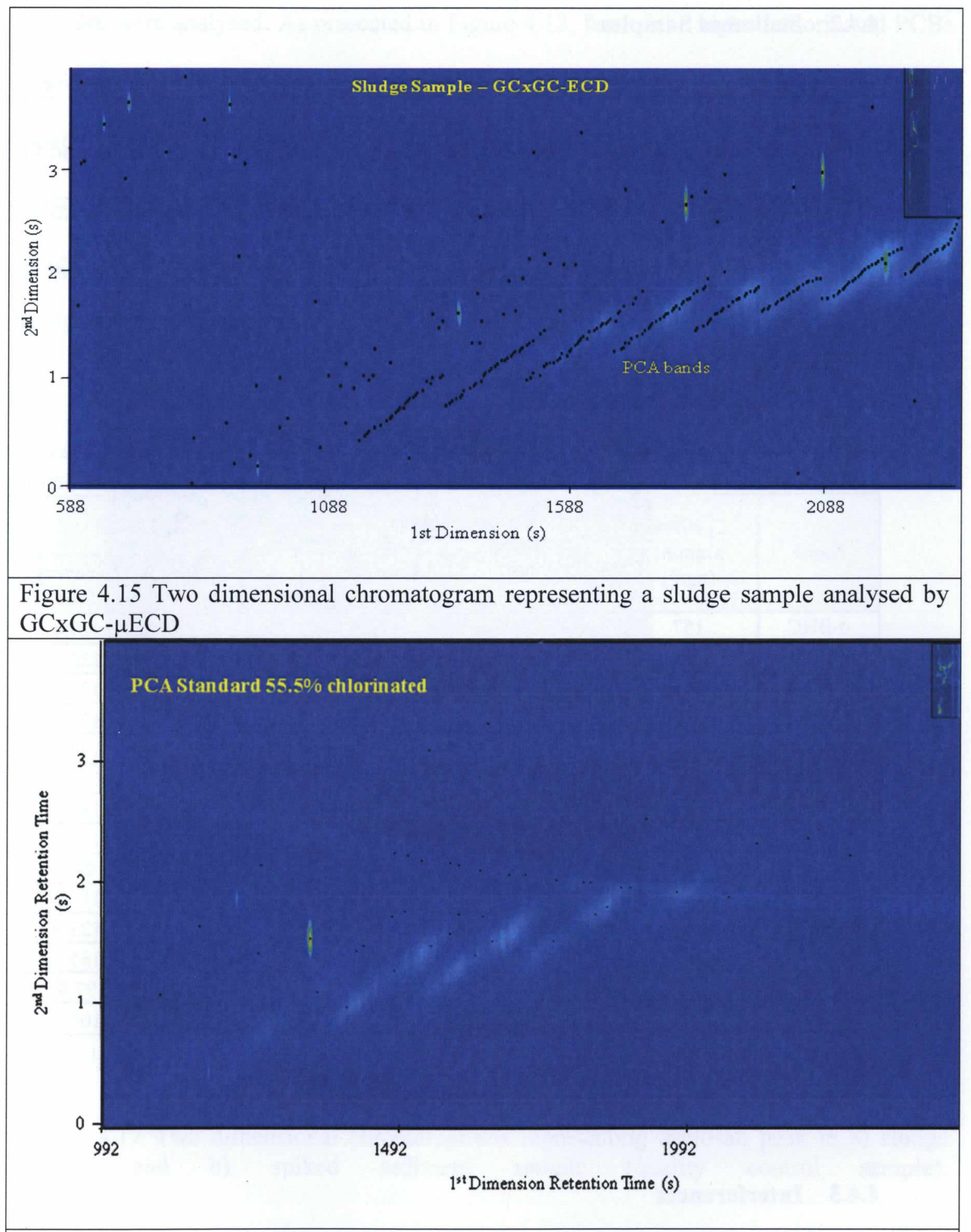

Figure 4.16 Two dimensional chromatogram representing PCA $\mathrm{C} 10-13,55.5 \% \mathrm{Cl}$ standard analysed by GCxGC- $\mu \mathrm{ECD}$ 


\subsubsection{Sediment Samples}

Sediments sample from an inter-laboratory study (New York State ELAP 0801Inter-laboratory Study for Solid Waste) was examined by both GC-ECD and GCxGCECD techniques for the determination of OC pesticides. The quantified results (Table 4.9) are comparable between the classical GC, GCxGC as well as the sediment expected values.

Table 4.9. The comparison of the obtained concentrations of selected OCs analysed by both GC-ECD and GCxGC $\mu$ ECD for New York State ELAP 08-01 sediment sample

\begin{tabular}{|c|c|c|c|c|c|}
\hline \multirow{2}{*}{ Name } & \multirow{2}{*}{$\begin{array}{c}\text { Certified } \\
\text { amount } \\
\text { (ng/g) }\end{array}$} & \multicolumn{2}{|c|}{ GCxGC- $\boldsymbol{\mu E C D}$} & \multicolumn{2}{c|}{ GC-ECD } \\
\cline { 3 - 6 } & & $\begin{array}{c}\text { Amount } \\
\text { (ng/g) }\end{array}$ & $\begin{array}{c}\text { Recovery } \\
\text { (\%) }\end{array}$ & $\begin{array}{c}\text { Amount } \\
\text { (ng/g) }\end{array}$ & $\begin{array}{c}\text { Recovery } \\
\text { (\%) }\end{array}$ \\
\hline$\alpha$-BHC & 157 & 186 & 118.5 & 200 & 127.4 \\
\hline$\beta$-BHC & 325 & 454 & 139.7 & 430 & 132.3 \\
\hline Y-BHC & 185 & 214 & 115.7 & 230 & 124.3 \\
\hline Y-CHLA & 216 & 296 & 137.0 & 280 & 129.6 \\
\hline Aldrin & 221 & 258 & 116.7 & 330 & 149.3 \\
\hline Endrin & 376 & 413 & 109.8 & 510 & 135.6 \\
\hline Dieldrin & 267 & 335 & 125.5 & 320 & 119.9 \\
\hline Endos 1 & 225 & 239 & 106.2 & 320 & 142.2 \\
\hline Endos S & 252 & 251 & 99.6 & 250 & 99.2 \\
\hline Heptachlor & 288 & 223 & 77.4 & 380 & 131.9 \\
\hline p,p'-DDD & 234 & 325 & 138.9 & 290 & 123.9 \\
\hline p,p'-DDE & 174 & 223 & 128.2 & 270 & 155.2 \\
\hline p,p'-DDT & 225 & 273 & 121.3 & 220 & 97.8 \\
\hline DMDT & 354 & 316 & 89.3 & 370 & 104.5 \\
\hline
\end{tabular}

\subsubsection{Interferences}

The sample preparation and clean-up steps along with the chromatographically separation employed with this method were optimized to allow only the analytes of interest to be detected. However, some interferences were noticed when "real-world" 
samples were analysed. As presented in Figure 4.13, few of the higher chlorinated PCBs interfere with PCA bands in some of the sludge samples analysed making their quantification difficult. In addition to PCAs, another unknown compound later identified as triclosan by GCxGC-TOFMS interfered with $\gamma$-chlordane in almost all of the samples (Figure $4.17 \mathrm{a}$ and $\mathrm{b}$ ). Although triclosan was present, $\gamma$-chlordane was manually reassigned and re-quantified.

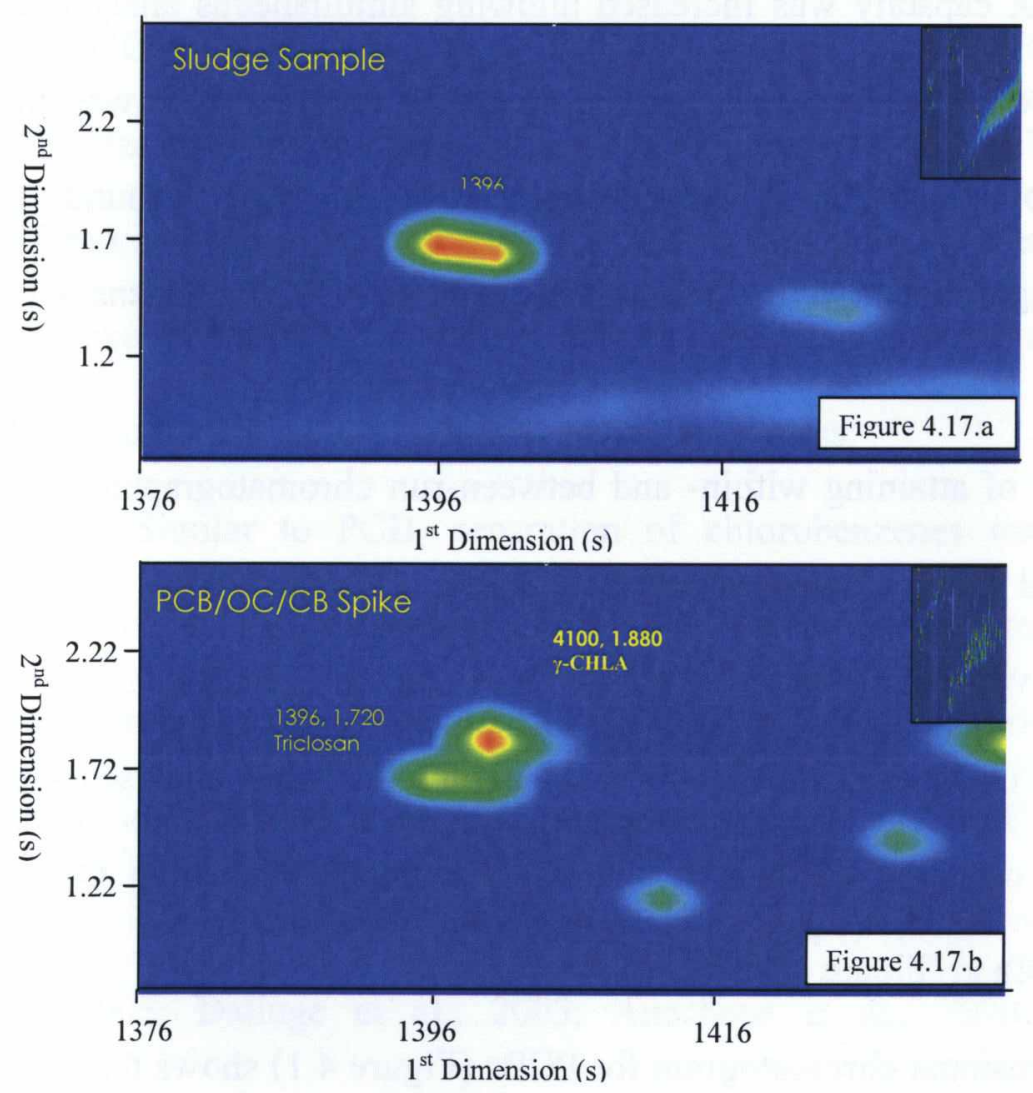

Figure 4.17 Two dimensional chromatograms representing triclosan peak in a) sludge sample and b) spiked sediment sample (quality control sample). 


\section{CHAPTER 5: DISCUSSION}

\subsection{GCXGC SEPARATION}

In this study, GCxGC- $\mu \mathrm{ECD}$ was observed to be a very powerful technique providing excellent chromatographic separations of the different contaminant classes of interest. By selecting the non-polar (DB1) and shape selective (Rtx-PCB) column combination, the peak capacity was increased allowing simultaneous analysis of more classes of halogenated contaminants in a single analytical run. Rtx-PCB was chosen as second dimension column due to its retentive properties for the compounds that can achieve planar configuration and its unique selectivity for PCB congeners (Stidsen, 2005).

The objective of attaining within- and between-run chromatographic separations was achieved for all three classes of interest: PCBs, OCs and CBs. Within-class separation was achieved with one coelution for PCB standard (PCB4/PCB10 - Figure 4.1) and CB standard (1,2,3,5-TCB/ 1,2,4,5-TCB - Figure 4.4) when analysed separately. No coelutions were observed for any of the 23 compounds present in OC standard analysed with this method (Figure 4.3).

The two dimensional chromatogram for PCBs (Figure 4.1) shows that orthogonal separation was achieved when using the DB1 x Rtx-PCB column combination. An ordered structure is observed and PCBs are seen as bands in the second dimension. The PCB congeners are separated according to their degree of chlorination. The dotted lines in Figure 4.1 represent the degree of chlorination of PCBs, from mono- to decachlorobiphenyl. The mono-ortho and non-ortho PCBs such as PCB37, PCB 77, PCB 
81, PCB 126, and PCB 169 elute later in the second dimension due to the selectivity of Rtx-PCB ((LECO, 2005) for the compounds that can achieve a planar configuration. These results are similar to previous data reported for different column combinations by Korytar et al. (2002, 2005 and 2006).

Using comprehensive dual gas chromatography, PCBs that coelute on a classical DB1 column (Frame and al., 1996) are further resolved by the second column (Korytar et al., 2002), in this case Rtx-PCB. Some examples of these coeluting pairs resolved by GCxGC are PCB81/PCB87, PCB77/PCB110, PCB123/PCB149, and PCB105/PCB153. The emphasis of the study was on the separation of the twelve dioxin-like PCBs (WHO PCBs) and the seven EU indicator PCBs (Appendix A: Methods and Materials). With one exception, PCB114 which coelutes with cis-nonachlor, all the others WHO and EU PCBs are resolved both within- and between-class.

Similar to PCB, separation of chlorobenzenes was achieved with only one coelution: 1,2,3,5-tetrachlorobenzene and 1,2,4,5- tetrachlorobenzene (Figure 4.4). These two compounds also coelute in a classical GC-ECD analysis when using DB-1 column (Method3270, MoE, 2008) and were not resolved by GCxGC.

As many studies and reviews have shown before (Korytar et al., 2002; Korytar et al. 2005; Dalluge et al., 2003; Adachour et al., 2006), comprehensive dual gas chromatography is a way to increase peak capacity supporting the hypothesis that more than one class of target environmental pollutants can be separated and quantified in one analysis with one detector for complex environmental matrices. Between-class separation was assessed and, without any necessary splitting into multiple fractions prior to GCxGC analysis, separation was achieved with only three between-class coelutions present: 
heptachlor-epoxide/PCB74, cis-nonachlor/PCB114, and methoxychlor/PCB171 (Figure4.6). Additionally, wrap-around is observed for chlorobenzenes in this separation (peaks that spend too much time in the second dimension column and do not elute in their own modulation time). Since the $\mathrm{CBz}$ do not interfere with any other analytes of interest in the chromatographic space, the wrap-around is not an issue for quantification purposes of these compounds. Furthermore, the separation is very reproducible between the analytical runs. Thus, the GCxGC method was able to chromatographically resolve 86 out of 96 compounds assessed in a relatively short analytical run (45 min.) using a fast sample preparation method as presented in Chapter 3. In addition to within- and betweenclass separations, GCxGC using DB-1 x Rtx-PCB column combination has significantly improved the separation of the target analytes from the matrix constituents.

To further emphasize the significance of this research, the GCxGC technique was compared to the classical GC method. While the $\mathrm{GCxGC}$ can analyse all the target compounds in a 45 minute analytical run, the classical GC-ECD uses multiple columns and instruments that analyse each different class of interest separately in four analytical runs (Method3412 and Method3270, MoE, 2008). Thus, the time gain is considerable when using GCxGC. Additionally, the sample preparation steps followed in the classical method are more time consuming and involve more solvent use and sample handling. Another advantage of GCxGC is that the non-ortho PCBs, lost in the clean-up procedure in the classical method (split in the second fraction), can now be separated and quantified. 


\subsection{SCREENING FOR OTHER PERSISTENT ORGANIC POLLUTANTS}

Since environmental samples are very complex matrices and may contain more classes of environmental pollutants than target analytes, other contaminant classes were evaluated for the DB1 x Rtx-PCB column combination. As presented in Chapter 4 (Figure 4.7 and Figure 4.14), five other groups were analysed by GCxGC: dioxins and furans, toxaphene, polychlorinated naphthalenes and polychlorinated alkanes. DB1 x RtxPCB provided orthogonal separation and ordered chromatograms for structurally related compounds such as toxaphene and PCNs, according to their degree of chlorination and planar configuration. Dioxins and furans were more retained in the second dimension due to their planarity (three-ring planar compounds) and some of them exhibited wraparound.

A polychlorinated alkanes standard was assessed after unknown clusters of contaminants were seen in the two dimensional chromatograms of some sludge extracts. PCA bands interfere with some of the higher chlorinated PCBs (PCB155, 151, 149, 188, $153,168,178,187,183,167,202,201,180,191,170,199,208$ and 209). As for other structurally related compounds, DB1 x Rtx-PCB showed ordered separation of PCA bands into various degrees of chlorination which later can simplify their challenging analysis and quantification.

The practicability of the method was demonstrated when reference samples were analysed and the presence of other classes of contaminants did not interfere with the PCBs, OCs and CBz. Previous studies, as presented in Chapter 2, discussed the separation of different classes of contaminants to demonstrate the advantages of the 
technique. However, in this method, not only the separation was achieved but also an accurate quantification of PCBs, OCs and $\mathrm{CBz}$.

\subsection{METHOD PERFORMANCE}

\subsubsection{Quantitative Performance}

The method performance data presented in the previous chapter shows that DB1 $\mathrm{x}$ Rtx-PCB is a very powerful column combination; thus, $\mathrm{GCxGC}$ is a feasible technique for environmental samples analyses of halogenated organics. The calibration curves based on the measurements of six solutions (six-level standards) presented correlation coefficients higher than 0.9995 . The method detection limits were calculated and their values varied from 0.06 to $3.5 \mathrm{ng} / \mathrm{g}$ while the estimated limits of quantification for $\mathrm{PCB} / \mathrm{OC} / \mathrm{CBz}$ were found to be in the range of 1 to $10 \mathrm{ng} / \mathrm{g}$ (Appendix B). Some of the chlorobenzenes in selected samples were impossible to quantify due to the presence of background interferences; therefore, MDLs were calculated for a lower number of replicates than PCBs and OCs. Higher LODs were also observed for specific PCBs (i.e., PCB8, 18, 52); this can be due to a possible contamination from the lab environment.

The ChromaTof software used for data handling and processing automatically assigns and quantifies the compounds set-up in the calibration tables except for three coeluting pairs that needed manual manipulation: PCB70/oxy-chlordane, PCB99/ $\alpha$ chlordane and PCB44/aldrin. These peaks are not baseline resolved and they need to be determined manually in order to obtain a proper integration and quantification.

Method performance was also assessed by calculating the repeatability (withinrun precision) and reproducibility (between-run precision) and expressed as percentage 
RSD. The data presented in Appendix B shows that better repeatability than reproducibility was obtained for some of the target compound while for others showed the opposite. This outcome for better between-run precision might be associated with the small number of replicates (6 and 8) available at the time. The percentage relative standard deviation for repeatability falls in the range of 2 to $14 \%$ while for reproducibility falls in the accepted $\pm 25 \%$ limits proposed for this method.

Along with method precision, the accuracy of the method was confirmed by analysing reference materials for different matrices: sludge and sediment. The final results were compared with both the reference values and previous GC-ECD data that were available. As presented in Figures 4.11 and 4.12, the quantified amounts for PCBs and OCs are within the specified standard deviation when compared to their reference concentration, demonstrating that the method produces accurate results. The GCxGC chromatograms also revealed different classes of compounds present in the reference samples that can be identified and quantified later if required. A previous study with regards to the contaminant composition for NIST reference materials (Wise et al., 2006) showed that other halogenated compounds were present in SRM1944 (e.g. BDEs), confirming the presence of the unknown peaks seen in the two dimensional chromatograms. Thus, this method can assess the presence of other classes of contaminants in environmental samples. It is important to note at this point that none of the other compounds present in these reference samples has interfered with our target analytes.

To further assess the method, the uncertainties were calculated and expressed as standard uncertainty, combined standard uncertainty and expanded uncertainty 
(Appendix C). When the percentage relative standard deviation of expanded uncertainty was calculated, the values varied from 2 to $25 \%$ with one exception, PCB157 at $27 \%$.

\subsubsection{Samples Quantification and Method Interferences}

This method was shown to be precise and accurate for the standards and reference materials tested, indicating that it could be a method suitable for "real-life" samples testing. The quantification of sediment and sludge samples obtained from engineered and environmental systems confirmed that GCxGC analysis is a viable procedure for their analysis.

The results obtained for OC pesticides in New York State ELAP08-01 sediment samples were comparable when examined by both GC-ECD and GCxGC-ECD techniques (Figure 4.15). A second set of sediment samples (Lake Simcoe Sediment Survey, MoE, 2008) previously analysed by GC-ECD for PCB congeners (Method 3412, MoE, 2008) were analysed with the same GCxGC instrumental set-up and the results were compared. The final data for target PCB congeners was comparable (Table 4.10) between the techniques. Also p,p'-DDE was detected at a very low level with both methods. In addition to the PCBs and p,p'-DDE, other "unknown" classes of compounds are seen (chromatogram not shown) which may be identified and quantified later.

The quantified PCBs by GCxGC-ECD for the sludge samples collected from a raw influent of a WWTP were compared to previous data from the GC-ECD analysis. While only p, p'-DDE and very low amount of total PCBs were found by conventional analysis, GCxGC-ECD revealed other classes of compounds present in the samples (Figure 4.13). One of the challenges encountered when analysing these sludge extracts, was the presence of polychlorinated alkanes bands that interfered with some of the higher 
chlorinated PCBs (i.e. PCB170, PCB180) making their quantification difficult by $\mu \mathrm{ECD}$ only, thus requires TOFMS for accurate identification and quantification. In addition, a more rigorous clean-up procedure can be established. When sludges from a different source were analysed, the PCA bands were not present thus no interferences compromised the results (not presented in this study).

Besides the PCA clusters, another problem was the interference of an unknown compound, later identified as triclosan by GCxGC-TOFMS, with $\gamma$-chlordane (Figure 4.16a). A possible source of contamination might be the detergent used for washing the glassware, where triclosan is one of its constituents. In order to eliminate this potential interference a more rigorous cleaning procedure needs to be established. Depending of the background interference, $\gamma$-chlordane was properly quantified and chromatographically separated from triclosan. In a "real" sample, the analyst should pay careful attention to $\gamma$-chlordane's retention time and compare it with a control sample, such as matrix spike when using ECD as the detection of choice (Figure 4.16b). It was observed that triclosan was quantified as $\gamma$-chlordane when the $\gamma$-chlordane was not present; thus, manual integration was required to accurately quantify $\gamma$-chlordane or to remove the analyte assignment. 


\subsection{ENVIRONMENTAL SIGNIFICANCE}

While classical gas chromatography permits the analysis of target classes of contaminants, GCxGC could be both a target analysis method as well as a screening method. When "real-life" sediment and sludge samples were analysed by GCxGC in this study, the two dimensional chromatograms revealed many others compounds present along with $\mathrm{PCBs}$, OCs and $\mathrm{CBs}$. Unknown classes of compounds at the time of analysis could be possibly identified by using available retention time data also pointed out in this study. The technique could be used as screening method for the determination of dioxins, dioxin-like compounds, and new emerging contaminants in the environment. Previously saved data can be qualitatively and quantitatively interpreted and historical trends can be determined offering several advantages to conventional approaches. 


\section{CHAPTER 6: CONCLUSION AND RECOMMENDATIONS}

The objectives of this study were to accurately identify and quantify the PCBs, OCs and CBs present in sludge and sediment samples in a single analytical run by using the GCxGC technique. The increased peak capacity and enhanced resolving power of GCxGC allowed the separation of PCBs, OCs, and CBs without fractionation prior to instrumental analysis. The separation of the three classes of interest was achieved and the method validation results demonstrated that this technique can be used for environmental samples analysis.

The following conclusions can be drawn from the results presented in this study:

i. PCBs, OCs and CBs were separated within- and between- class in a single analytical run when using the column combination DB-1 x Rtx-PCB. With only few coelutions present, this method resolved 86 out of 96 compounds in a 45 minute run.

ii. This method was shown to be precise and accurate for the standards and the reference materials tested. The results obtained by $\mathrm{GCxGC}$ are comparable with the reference values as well as with previous GC data.

iii. The quantification of sediment and sludge samples obtained from engineered and environmental systems confirmed that GCxGC analysis is a viable procedure for their analysis. The quantified results compared to previous GC data.

iv. Some other classes of compounds were present in the two dimensional chromatograms and this method can be used for screening potential 
contaminants. With the exception PCA clusters found to interfere with higher chlorinated PCBs, no other compounds were found to significantly affect the PCBs, OCs and CBs quantification. When PCAs are present, further TOFMS analysis may be required for accurate analysis.

v. The GCxGC method can result in significant savings in time of analysis.

The sediment and sludge extracts are very complex, and many unidentified compounds were observed in the two dimensional chromatograms obtained. One of the advantages of using comprehensive dual gas chromatography is its increased peak capacity therefore, allowing to more than one class of target environmental pollutants to be separated in one analysis. Some of the groups or compounds might interfere with the target analytes and improvements need to be considered to avoid any unnecessary contamination or background interferences. Others could be possibly identified by using available data also pointed out in this study and the technique could be used as screening method for the determination of dioxins, dioxin-like compounds, and new emerging contaminants in the environment. In addition, any unknown peaks can be identified in the future. Previously saved data can be qualitatively and quantitatively interpreted and historical trends can be determined offering several advantages to conventional approaches.

For the first time, the GCxGC method can potentially replace the classical GC multiple instrumental analysis. This would result in significant time savings and reduction in analysis costs with subsequent increase in data quality. Sediment and sludge samples can be routinely analysed using GCxGC- $\mu$ ECD. The GCxGC-TOFMS may be 
required when PCA interferences are present, thus this method needs to be further validated for the TOFMS use.

The recent advances and publications in the field of GCxGC have shown that the technique is applicable to other environmental matrices than sediments and sludges. Since DB-1 x Rtx-PCB column combination selected for the GCxGC system yielded excellent within- and between- class separations, further research might be employed for the analysis of different matrices such as biota and vegetation samples. 


\section{CHAPTER 7: REFERENCES}

Adahchour, M., Beens, J., \& Brinkman, U. A. T. (2008). Recent developments in the application of comprehensive two-dimensional gas chromatography. Journal of Chromatography A, 1186(1-2), 67-108.

Adahchour, M., Beens, J., Vreuls, R. J. J., \& Brinkman, U. A. T. (2006). Recent developments in comprehensive two-dimensional gas chromatography (GCxGC). Trends in Analytical Chemistry, 25(5), 438-454.

Adahchour, M., Beens, J., Vreuls, R. J. J., \& Brinkman, U. A. T. (2006). Recent developments in comprehensive two-dimensional gas chromatography (GCxGC). Trends in Analytical Chemistry, 25(6), 540-553.

Adahchour, M., Beens, J., Vreuls, R. J. J., \& Brinkman, U. A. T. (2006). Recent developments in comprehensive two-dimensional gas chromatography (GCxGC). Trends in Analytical Chemistry, 25(7), 726-741.

Adahchour, M., Beens, J., Vreuls, R. J. J., \& Brinkman, U. A. T. (2006). Recent developments in comprehensive two-dimensional gas chromatography (GCxGC). Trends in Analytical Chemistry, 25(8), 821-840.

Adahchour, M., Brandt, M., Baier, H. U., Vreuls, R. J. J., Batenburg, A. M., \& Brinkman, U. A. T. (2005). Comprehensive two-dimensional gas chromatography coupled to a rapid-scanning quadrupole mass spectrometer: Principles and applications. Journal of Chromatography A, 1067(1-2), 245-254.

Beens, J., Blomberg, J., \& Schoenmakers, P. J. (2000). Proper tuning of comprehensive two-dimensional gas chromatography (GC\&times;GC) to optimize the separation of complex oil fractions. Journal of High Resolution Chromatography, 23(3), 182-188.

Beens, J., Boelens, ,Hans, Tijssen, R., \& Blomberg, J. (1998). Quantitative aspects of comprehensive two-dimensional gas chromatography (GCxGC). Journal of High Resolution Chromatography, 21(1), 47-54.

Beens, J., Tijssen, R., \& Blomberg, J. (1998). Comprehensive two-dimensional gas chromatography (GC\&times;GC) as a diagnostic tool. Journal of High Resolution Chromatography, 21(1), 63-64.

Bernes, C. (1998). Persistent Organic Pollutants: A Swedish View of an International Problem, Swedish Environmental Protection Agency. 
Bertsch, W. (2000). Two-dimensional gas chromatography. concepts, instrumentation, and applications - part 2: Comprehensive two-dimensional gas chromatography. Journal of High Resolution Chromatography, 23(3), 167-181.

Blumberg, L. M. (2003). Comprehensive two-dimensional gas chromatography: Metrics, potentials, limits. Journal of Chromatography A, 985(1-2), 29-38.

Bordajandi, L. R., Ramos, J. J., Sanz, J., Gonzalez, M. J., \& Ramos, L. (2008). Comprehensive two-dimensional gas chromatography in the screening of persistent organohalogenated pollutants in environmental samples. Journal of Chromatography A, 1186(1-2), 312-324.

Bordajandi, L. R., Korytár, P., de Boer, J., \& González, M. J. (2005). Enantiomeric separation of chiral polychlorinated biphenyls on \&beta;-cyclodextrin capillary columns by means of heart-cut multidimensional gas chromatography and comprehensive twodimensional gas chromatography. application to food samples. Journal of Separation Science, 28(2), 163-171.

Dallüge, J., Beens, J., \& Brinkman, U. A. T. (2003). Comprehensive two-dimensional gas chromatography: A powerful and versatile analytical tool. Journal of Chromatography A, 1000(1-2), 69-108.

Dallüge, J., van Rijn, M., Beens, J., Vreuls, R. J. J., \& Brinkman, U. A. T. (2002). Comprehensive two-dimensional gas chromatography with time-of-flight mass spectrometric detection applied to the determination of pesticides in food extracts. Journal of Chromatography A, 965(1-2), 207-217.

Danielsson, C., Wiberg, K., Korytar, P., Bergek, S., Brinkman, U. A. T., \& Haglund, P. (2005). Trace analysis of polychlorinated dibenzo-p-dioxins, dibenzofurans and WHO polychlorinated biphenyls in food using comprehensive two-dimensional gas chromatography with electron-capture detection. Journal of Chromatography A, 1086(12), 61-70.

Dimandja, J. D., Clouden, G. C., Colón, I., Focant, J., Cabey, W. V., \& Parry, R. C. (2003). Standardized test mixture for the characterization of comprehensive twodimensional gas chromatography columns: The phillips mix. Journal of Chromatography A, 1019(1-2), 261-272.

Dorman, F. L., Schettler, P. D., Vogt, L. A., \& Cochran, J. W. (2008). Using computer modeling to predict and optimize separations for comprehensive two-dimensional gas chromatography. Journal of Chromatography A, 1186(1-2), 196-201.

Erickson M. D. (1997), Analytical Chemisty of PCBs, New York: Lewis Publishers.

Focant, J. F., Eppe, G., Scippo, M. L., Massart, A. C., Pirard, C., Maghuin-Rogister, G., et al. (2005). Comprehensive two-dimensional gas chromatography with isotope dilution 
time-of-flight mass spectrometry for the measurement of dioxins and polychlorinated biphenyls in foodstuffs. Journal of Chromatography A, 1086(1-2), 45-60.

Focant, J. F., Pirard, C., Eppe, G., \& De Pauw, E. (2005). Recent advances in mass spectrometric measurement of dioxins. Journal of Chromatography A, 1067(1-2), 265275.

Focant, J., Reiner, E. J., MacPherson, K., Kolic, T., Sjödin, A., Patterson Jr, D. G., et al. (2004). Measurement of PCDDs, PCDFs, and non-ortho-PCBs by comprehensive twodimensional gas chromatography-isotope dilution time-of-flight mass spectrometry (GC \&times; GC-IDTOFMS). Talanta, 63(5), 1231-1240.

Focant, J., Sjödin, A., \& Patterson Jr, D. G. (2004). Improved separation of the 209 polychlorinated biphenyl congeners using comprehensive two-dimensional gas chromatography-time-of-flight mass spectrometry. Journal of Chromatography A, 1040(2), 227-238.

Górecki, T., Harynuk, J., Panic O. (2004). The evolution of comprehensive twodimensional gas chromatography (GC\&times;GC). Journal of Separation Science, 27(56), 359-379.

Górecki, T., Panic O., \& Oldridge, N. (2006). Recent advances in comprehensive Twodimensional gas chromatography (GC\&times;GC). Journal of Liquid Chromatography \& Related Technologies, 29(7-8), 1077-1104.

Haglund, P., Harju, M., Ong, R., \& Marriott, P. (2001). Shape selectivity: A key factor in comprehensive two\&hyphen;dimensional gas chromatographic analysis of toxic PCBs. Journal of Microcolumn Separations, 13(7), 306-311.

Harju, M., Bergman, A., Olsson, M., Roos, A., \& Haglund, P. (2003). Determination of atropisomeric and planar polychlorinated biphenyls, their enantiomeric fractions and tissue distribution in grey seals using comprehensive 2D gas chromatography. Journal of Chromatography A, 1019(1-2), 127-142.

Harju, M., Danielsson, C., \& Haglund, P. (2003). Comprehensive two-dimensional gas chromatography of the 209 polychlorinated biphenyls. Journal of Chromatography A, 1019(1-2), 111-126.

Harju, M., \& Haglund, P. (2001). Comprehensive two\&hyphen;dimensional gas chromatography \&lpar;GC\&times;GC\&rpar; of atropisomeric PCBs, combining a narrow bore \&beta;\&hyphen;cyclodextrin column and a liquid crystal column. Journal of Microcolumn Separations, 13(7), 300-305.

Harynuk, J., \& Gorecki, T. (2006). Comparison of comprehensive two-dimensional gas chromatography in conventional and stop-flow modes. Journal of Chromatography A, 1105(1-2), 159-167. 
Harynuk, J., Gorecki, T., \& Zeeuw, J. d. (2005). Overloading of the second-dimension column in comprehensive two-dimensional gas chromatography. Journal of Chromatography A, 1071(1-2), 21-27.

Harynuk, J. J., Kwong, A. H., \& Marriott, P. J. (2008). Modulation-induced error in comprehensive two-dimensional gas chromatographic separations. Journal of Chromatography A, 1200(1), 17-27.

Harynuk, J., \& Górecki, T. (2002). Design considerations for a GCxGC system. Journal of Separation Science, 25(5-6), 304-310.

Harynuk, J., \& Górecki, T. (2004). Comprehensive two-dimensional gas chromatography in stop-flow mode. Journal of Separation Science, 27(5-6), 431-441.

Harynuk, J., \& Marriott, P. J. (2006). Fast GC and GCxGC with short primary columns. Analytical Chemistry, 78(6), 2028-2034.

Hubert A., K. D. Wenzel, M. Manz, L. Weissflog, W. Engewald, G.Schuurmann (2000), High Extraction Efficiency for POPs in Real Contaminated Soil Samples Using Accelerated Solvent Extraction, Anal. Chem., 72, 1294-1300.

Kannan N. (2000) In: Paasivirta J. (ed) The Handbook of Environmental Chemistry, Vol. 3, pp 127-157, Heidelberg Berlin New York: Springer-Verlag.

Khummueng, W., Morrison, P., \& Marriott, P. J. (2008). Dual NPD and ECD detection in comprehensive two-dimensional gas chromatography for multiclass pesticide analysis. Journal of Separation Science, 31(19), 3404-3415.

Korytar, P., Covaci, A., Leonards, P. E. G., de Boer, J., \& Brinkman, U. A. T. (2005). Comprehensive two-dimensional gas chromatography of polybrominated diphenyl ethers. Journal of Chromatography A, 1100(2), 200-207.

Korytár, P., Danielsson, C., Leonards, P. E. G., Haglund, P., de Boer, J., \& Brinkman, U. A. T. (2004). Separation of seventeen 2,3,7,8-substituted polychlorinated dibenzo- $p$ dioxins and dibenzofurans and 12 dioxin-like polychlorinated biphenyls by comprehensive two-dimensional gas chromatography with electron-capture detection. Journal of Chromatography A, 1038(1-2), 189-199.

Korytar, P., Haglund, P., de Boer, J., \& Brinkman, U. A. T. (2006). Comprehensive twodimensional gas chromatography for the analysis of organohalogenated microcontaminants. Trends in Analytical Chemistry, 25(4), 373-396.

Korytar, P., Parera, J., Leonards, P. E. G., Santos, F. J., de Boer, J., \& Brinkman, U. A. T. (2005). Characterization of polychlorinated n-alkanes using comprehensive twodimensional gas chromatography-electron-capture negative ionisation time-of-flight mass spectrometry. Journal of Chromatography A, 1086(1-2), 71-82. 
Korytár, P., van Stee, L. L. P., Leonards, P. E. G., de Boer, J., \& Brinkman, U. A. T. (2003). Attempt to unravel the composition of toxaphene by comprehensive twodimensional gas chromatography with selective detection. Journal of Chromatography A, 994(1-2), 179-189.

Korytár, P., Leonards, P. E. G., de Boer, J., \& Brinkman, U. A. T. (2002). Highresolution separation of polychlorinated biphenyls by comprehensive two-dimensional gas chromatography. Journal of Chromatography A, 958(1-2), 203-218.

Kristenson, E. M., Korytár, P., Danielsson, C., Kallio, M., Brandt, M., Mäkelä, J., et al. (2003). Evaluation of modulators and electron-capture detectors for comprehensive twodimensional GC of halogenated organic compounds. Journal of Chromatography A, 1019(1-2), 65-77.

Kristenson, E. M., Neidig, H. C., Vreuls, R. J. J., \& Brinkman, U. A. T. (2005). Fast miniaturised sample preparation for the screening and comprehensive two-dimensional gas chromatographic determination of polychlorinated biphenyls in sludge. Journal of Separation Science, 28(11), 1121-1128.

LECO Corporation (2005). Separation Science Application Note: "Quantification of Dioxin-Like Polychlorinated Biphenyls Using GCxGC-ECD with a Selective Column in the Second Dimension", Retrieved: July 14, 2006, From: http://www.leco.com

LECO Corporation (2005). Separation Science Application Note: "Organochlorine Pesticides by GCxGC-ECD”, Retrieved: July 14, 2006. From: http://www.leco.com

LECO Corporation (2008). GCxGC Comprehensive Two-Dimensional Gas Chromatography . Retrieved: November 14, 2008. From: http://www.leco.com

Marriott, P. (2004). Comprehensive two-dimensional gas chromatography - GCxGC. Journal of Separation Science, 27(5-6), 357-357.

Marriott, P. J., Haglund, P., \& Ong, R. C. Y. (2003). A review of environmental toxicant analysis by using multidimensional gas chromatography and comprehensive GC. Clinica Chimica Acta, 328(1-2), 1-19.

Marriott, P. J., \& Kinghorn, R. M. (2000). New operational modes for multidimensional and comprehensive gas chromatography by using cryogenic modulation. Journal of Chromatography A, 866(2), 203-212.

Marriott J. P., M. Kinghorn, R., Ong, R., Morrison, P., Haglund, P., \& Harju, M. (2000). Comparison of thermal sweeper and cryogenic modulator technology for comprehensive gas chromatography. Journal of High Resolution Chromatography, 23(3), 253-258. 
Marriott, P. J., Massil, T., \& Hügel, H. (2004). Molecular structure retention relationships in comprehensive two-dimensional gas chromatography. Journal of Separation Science, 27(15-16), 1273-1284.

Marriott, P., \& Shellie, R. (2002). Principles and applications of comprehensive twodimensional gas chromatography. TrAC Trends in Analytical Chemistry, 21(9-10), 573583.

Oldridge, N., Panic, O., \& Górecki, T. (2008). Stop-flow comprehensive twodimensional gas chromatography with pneumatic switching. Journal of Separation Science, 31(19), 3375-3384.

Ong, R., Marriott, P., Morrison, P., \& Haglund, P. (2002). Influence of chromatographic conditions on separation in comprehensive gas chromatography. Journal of Chromatography A, 962(1-2), 135-152.

Ong, R., Shellie, R., \& Marriott, P. (2001). Observation of non-linear chromatographic peaks in comprehensive two-dimensional gas chromatography. Journal of Separation Science, 24(5), 367-377.

Ontario Ministry of the Environment, Method 3270 (2008). The determination of polychlorinated biphenyls $(\mathrm{PCBs})$, organochlorines $(\mathrm{OCs})$ and chlorobenzenes $(\mathrm{CBs})$ in soil and sediments by gas liquid chromatography - electron capture detection (GLCECD).

Ontario Ministry of the Environment, Method 3412 (2008). The determination of polychlorinated biphenyl congeners (PCBs) in soil, sediment and vegetation by gas liquid chromatography - electron capture detection (GLC-ECD).

Ontario Ministry of the Environment, LSBSOP.030 (2008). Laboratory services branch guidelines for the determination and documentation of uncertainty of chemical measurements.

Phillips, John B., \& Beens, J. (1999). Comprehensive two-dimensional gas chromatography: A hyphenated method with strong coupling between the two dimensions. Journal of Chromatography A, 856(1-2), 331-347.

Pierce, K. M., Hoggard, J. C., Mohler, R. E., \& Synovec, R. E. (2008). Recent advancements in comprehensive two-dimensional separations with chemometrics. Journal of Chromatography A, 1184(1-2), 341-352.

Ramos L., E.M. Kristenson, U.A.Th. Brinkman (2002), Current use of pressurised liquid extraction and subcritical water extraction in environmental analysis, Journal of Chromatography A, 975 3-29. 
Ryan, D., Morrison, P., \& Marriott, P. (2005). Orthogonality considerations in comprehensive two-dimensional gas chromatography. Journal of Chromatography A, 1071(1-2), 47-53.

Santos, F. J., \& Galceran, M. T. (2002). The application of gas chromatography to environmental analysis. TrAC Trends in Analytical Chemistry, 21(9-10), 672-685.

Schantz M. (2006), Pressurized liquid extraction in environmental analysis, Anal Bioanal Chem 386: 1043-1047.

Shellie, R. A., Xie, L., \& Marriott, P. J. (2002). Retention time reproducibility in comprehensive two-dimensional gas chromatography using cryogenic modulation. Journal of Chromatography A, 968(1-2), 161-170.

Saito K., A. Sjödin, C. D. Sandau, M. D. Davis, H. Nakazawa, Y. Matsuki, D. G. Patterson Jr. (2004), Development of an accelerated solvent extraction and gel permeation chromatography analytical method for measuring persistent organohalogen compounds in adipose and organ tissue analysis, Chemosphere 57 373-381.

van Leeuwen, S. P. J., \& de Boer, J. (2008). Advances in the gas chromatographic determination of persistent organic pollutants in the aquatic environment. Journal of Chromatography A, 1186(1-2), 161-182.

von Mühlen, C., Khummueng, W., Alcaraz Zini, C., Bastos Caramão, E., \& Marriott, P. J. (2006). Detector technologies for comprehensive two-dimensional gas chromatography. Journal of Separation Science, 29(12), 1909-1921. 


\section{APPENDIX A: METHODS AND MATERIALS}

\section{List of PCB Standards - (Wellington Laboratories, Guelph, ON, Canada)}

\begin{tabular}{|c|c|c|c|c|c|c|}
\hline IUPAC\# & PCB Native & $\begin{array}{l}\text { BP-EC } \\
(\mu \mathrm{g} / \mathrm{ml})\end{array}$ & $\begin{array}{l}\text { BP-MS } \\
(\mu \mathrm{g} / \mathrm{ml})\end{array}$ & $\begin{array}{c}\text { BP-MS- } \\
\text { PL1 } \\
(\mu \mathrm{g} / \mathrm{ml})\end{array}$ & $\begin{array}{c}\text { BP-MS- } \\
\text { PL2 } \\
(\mu \mathrm{g} / \mathrm{ml})\end{array}$ & $\begin{array}{c}\text { BP-MS- } \\
\text { PL3 } \\
(\mu \mathrm{g} / \mathrm{ml})\end{array}$ \\
\hline & Monochlorobiphenyl & & & & & \\
\hline 1 & 2-Monochlorobiphenyl & 50 & 2 & & & \\
\hline \multirow[t]{2}{*}{3} & 4-Monochlorobiphenyl & 50 & 2 & & & \\
\hline & Dichlorobiphenyl & & & & & \\
\hline 4 & 2,2'-Dichlorobiphenyl & 10 & 2 & & & \\
\hline 8 & 2,4'-Dichlorobiphenyl & 10 & 2 & & & \\
\hline 10 & 2,6-Dichlorobiphenyl & 10 & 2 & & & \\
\hline \multirow[t]{2}{*}{15} & 4,4'-Dichlorobiphenyl & 10 & 2 & & & \\
\hline & Trichlorobiphenyl & & & & & \\
\hline 18 & 2,2',5-Trichlorobiphenyl & 5 & 2 & & & \\
\hline 19 & 2,2',6-Trichlorobiphenyl & 5 & 2 & & & \\
\hline 22 & 2,3,4'-Trichlorobiphenyl & 5 & 2 & & & \\
\hline 28 & 2,4,4'-Trichlorobiphenyl & 5 & 2 & & & \\
\hline 33 & 2',3,4-Trichlorobiphenyl & 5 & 2 & & & \\
\hline \multirow[t]{2}{*}{37} & 3,4,4'-Trichlorobiphenyl & 5 & 2 & & & \\
\hline & Tetrachlorobiphenyl & & & & & \\
\hline 44 & 2,2',3,5'-Tetrachlorobiphenyl & 1 & 2 & & & \\
\hline 49 & 2,2',4,5'-Tetrachlorobiphenyl & 1 & 2 & & 2 & \\
\hline 52 & 2,2',5,5'-Tetrachlorobiphenyl & 1 & 2 & 2 & & \\
\hline 54 & 2,2',6,6'-Tetrachlorobiphenyl & 1 & 2 & & & \\
\hline 70 & 2,3',4',5-Tetrachlorobiphenyl & 1 & 2 & 2 & & \\
\hline 74 & 2,4,4',5-Tetrachlorobiphenyl & 1 & 2 & & 2 & 1 \\
\hline 77 & 3,3',4,4'-Tetrachlorobiphenyl & 1 & 2 & & & 2 \\
\hline \multirow[t]{2}{*}{81} & 3,4,4',5-Tetrachlorobiphenyl & 1 & 2 & & & \\
\hline & Pentachlorobiphenyl & & & & & \\
\hline 87 & 2,2',3,4,5'-Pentachlorobiphenyl & 1 & 2 & 2 & & \\
\hline 95 & 2,2',3,5',6-Pentachlorobiphenyl & 1 & 2 & & 2 & \\
\hline 99 & 2,2',4,4',5-Pentachlorobiphenyl & 1 & 2 & & 2 & \\
\hline 101 & 2,2',4,5,5'-Pentachlorobiphenyl & 1 & 2 & 2 & & \\
\hline 104 & 2,3,3',4,4'-Pentachlorobiphenyl & 1 & 2 & & & \\
\hline 105 & $2,2^{\prime}, 4,6,6$ '-Pentachlorobiphenyl & 1 & 2 & & & \\
\hline 110 & 2,3,3',4',6-Pentachlorobiphenyl & 1 & 2 & 2 & & \\
\hline 114 & 2,3,4,4',6-Pentachlorobiphenyl & 1 & 2 & & & \\
\hline 118 & 2,3',4,4',5-Pentachlorobiphenyl & 1 & 2 & & & \\
\hline 119 & 2,3',4,4',6-Pentachlorobiphenyl & 1 & 2 & & & \\
\hline 123 & 2',3,4,4',5-Pentachlorobiphenyl & 1 & 2 & & & \\
\hline \multirow[t]{2}{*}{126} & 3,3',4,4',5-Pentachlorobiphenyl & 1 & 2 & & & \\
\hline & Hexachlorobiphenyl & & & & & \\
\hline 128 & 2,2',3,3'4,4'-Hexachlorobiphenyl & 1 & 2 & & & 2 \\
\hline
\end{tabular}




\begin{tabular}{|c|c|c|c|c|c|c|}
\hline IUPAC\# & PCB Native & $\begin{array}{c}\text { BP-EC } \\
(\mu \mathrm{g} / \mathrm{ml})\end{array}$ & $\begin{array}{l}\text { BP-MS } \\
(\mu \mathrm{g} / \mathrm{ml})\end{array}$ & $\begin{array}{c}\text { BP-MS- } \\
\text { PL1 } \\
(\mu \mathrm{g} / \mathrm{ml})\end{array}$ & $\begin{array}{c}\text { BP-MS- } \\
\text { PL2 } \\
(\mu \mathrm{g} / \mathrm{ml})\end{array}$ & $\begin{array}{c}\text { BP-MS- } \\
\text { PL3 } \\
(\mu \mathrm{g} / \mathrm{ml})\end{array}$ \\
\hline 138 & $2,2^{\prime}, 3,4,4^{\prime}, 5^{\prime}-$ Hexachlorobiphenyl & 1 & 2 & 2 & & \\
\hline 149 & $2,2^{\prime}, 3,4^{\prime}, 5^{\prime}, 6$-Hexachlorobiphenyl & 1 & 2 & + & 2 & \\
\hline 151 & $2,2^{\prime}, 3,5,5 ', 6-$ Hexachlorobiphenyl & 1 & 2 & & 2 & \\
\hline 153 & $2,2^{\prime}, 4,4^{\prime}, 5,5^{\prime}$-Hexachlorobiphenyl & 1 & 2 & 2 & & \\
\hline 155 & $2,2^{\prime}, 4,4^{\prime}, 6,6^{\prime}-$ Hexachlorobiphenyl & 1 & 2 & 2 & 9 & \\
\hline 156 & 2,3,3',4,4',5-Hexachlorobiphenyl & 1 & 2 & & & \\
\hline 157 & $2,3,3^{\prime}, 4,4^{\prime}, 5^{\prime}-$ Hexachlorobiphenyl & 1 & 2 & & & \\
\hline 158 & 2,3,3',4,4',6-Hexachlorobiphenyl & 1 & 2 & & 2 & \\
\hline 167 & 2,3',4,4',5,5'-Hexachlorobiphenyl & 1 & 2 & & & \\
\hline 168 & 2,3',4,4',5',6-Hexachlorobiphenyl & 1 & 2 & & 2 & \\
\hline \multirow[t]{2}{*}{169} & 3,3',4,4',5,5'-Hexachlorobiphenyl & 1 & 2 & & & \\
\hline & Heptachlorobiphenyl & & & & & \\
\hline 170 & $2,2^{\prime}, 3,3^{\prime}, 4,4^{\prime}, 5$-Heptachlorobiphenyl & 1 & 2 & & & \\
\hline 171 & $2,2^{\prime}, 3,3^{\prime}, 4,44^{\prime}, 6$-Heptachlorobiphenyl & 1 & 2 & & 2 & \\
\hline 177 & $2,2^{\prime}, 3,3^{\prime}, 4^{\prime}, 5,6-$ Heptachlorobiphenyl & 1 & 2 & 2 & & \\
\hline 178 & 2,2',3,3',5,5',6-Heptachlorobiphenyl & 1 & 2 & & & 2 \\
\hline 180 & $2,2^{\prime}, 3,4,4^{\prime}, 5,5^{\prime}$-Heptachlorobiphenyl & 1 & 2 & 2 & & \\
\hline 183 & $2,2^{\prime}, 3,4,4^{\prime}, 5^{\prime}, 6-$ Heptachlorobiphenyl & 1 & 2 & & & \\
\hline 187 & 2,2',3,4',5,5',6-Heptachlorobiphenyl & 1 & 2 & & & \\
\hline 188 & $2,2^{\prime}, 3,4 ', 5,6,6$ '-Heptachlorobiphenyl & 1 & 2 & 2 & & \\
\hline 189 & $2,3,3^{\prime}, 4,4^{\prime}, 5,5^{\prime}$-Heptachlorobiphenyl & 1 & 2 & & & \\
\hline \multirow[t]{2}{*}{191} & 2,3,3',4,4',5',6-Heptachlorobiphenyl & 1 & 2 & & & \\
\hline & Octachlorobiphenyl & & & & & \\
\hline 194 & $2,2^{\prime}, 3,3^{\prime}, 4,4^{\prime}, 5,5$ '-Octachlorobiphenyl & 1 & 2 & & & \\
\hline 199 & $2,2^{\prime}, 3,3^{\prime}, 4,5,5^{\prime}, 6^{\prime}-$ Octachlorobiphenyl & 1 & 2 & & & \\
\hline 201 & $2,2^{\prime}, 3,3^{\prime}, 4,5^{\prime}, 6,6^{\prime}-$ Octachlorobiphenyl & 1 & 2 & 2 & & \\
\hline 202 & $2,2^{\prime}, 3,3^{\prime}, 5,5^{\prime}, 6,66^{\prime}$-Octachlorobiphenyl & 1 & 2 & & & 2 \\
\hline \multirow[t]{2}{*}{205} & $2,3,3^{\prime}, 4,4^{\prime}, 5,5$ ',6-Octachlorobiphenyl & 1 & 2 & & & \\
\hline & Nonachlorobiphenyl & & & & & \\
\hline 206 & $2,2^{\prime}, 3,3^{\prime}, 4,4^{\prime}, 5,5^{\prime}, 6$-Nonachlorobiphenyl & 1 & 2 & & & \\
\hline \multirow[t]{2}{*}{208} & $2,2^{\prime}, 3,3^{\prime}, 4,5,5^{\prime}, 6,6^{\prime}$-Nonachlorobiphenyl & 1 & 2 & & & \\
\hline & Decachlorobiphenyl & & & & & \\
\hline 209 & $2,2^{\prime}, 3,3^{\prime}, 4,44^{\prime}, 5,5^{\prime}, 6,6^{\prime}$-Decachlorobiphenyl & 1 & 2 & & & \\
\hline
\end{tabular}




\section{List of WHO PCBs and EU indicator PCBs}

\begin{tabular}{|c|c|}
\hline IUPAC\# & PCB \\
\hline \multicolumn{2}{|c|}{ WHO (dioxin-like) PCBs } \\
\hline 77 & 3,3',4,4'-Tetrachlorobiphenyl \\
\hline 81 & 3,4,4',5-Tetrachlorobiphenyl \\
\hline 126 & 3,3',4,4',5-Pentachlorobiphenyl \\
\hline 169 & 3,3',4,4',5,5'-Hexachlorobiphenyl \\
\hline 105 & 2,3,3',4,4'-Pentachlorobiphenyl \\
\hline 114 & 2,3,4,4',6-Pentachlorobiphenyl \\
\hline 118 & 2,3',4,4',5-Pentachlorobiphenyl \\
\hline 123 & 2',3,4,4',5-Pentachlorobiphenyl \\
\hline 156 & 2,3,3',4,4',5-Hexachlorobiphenyl \\
\hline 157 & 2,3,3',4,4',5'-Hexachlorobiphenyl \\
\hline 167 & 2,3',4,4',5,5'-Hexachlorobiphenyl \\
\hline 189 & 2,3,3',4,4',5,5'-Heptachlorobiphenyl \\
\hline \multicolumn{2}{|c|}{ EU indicator PCBs } \\
\hline 28 & 2,4,4'-Trichlorobiphenyl \\
\hline 52 & 2,2',5,5'-Tetrachlorobiphenyl \\
\hline 101 & 2,2',4,5,5'-Pentachlorobiphenyl \\
\hline 118 & 2,3',4,4',5-Pentachlorobiphenyl \\
\hline 138 & $2,2^{\prime}, 3,4,4^{\prime}, 5^{\prime}-$ Hexachlorobiphenyl \\
\hline 153 & $2,2^{\prime}, 4,44^{\prime}, 5,5^{\prime}-$ Hexachlorobiphenyl \\
\hline 180 & 2,2',3,4,4',5,5'-Heptachlorobiphenyl \\
\hline
\end{tabular}


List of OC Standards (UltraScientific, North Kingstown, RI, USA)

\begin{tabular}{|c|c|c|}
\hline OCs & $\begin{array}{c}\text { Concentration } \\
(\mathrm{g} / \mathrm{mL})\end{array}$ & Custom Std. \# \\
\hline$\alpha-\mathrm{BHC}$ & 100 & CUS-3935 \\
\hline$\beta$-BHC & 100 & CUS-3935 \\
\hline$\gamma$-BHC & 100 & CUS-3935/CUS-5641 \\
\hline Heptachlor & 100 & CUS-3935/CUS-5641 \\
\hline Aldrin & 100 & CUS-3935/CUS-5641 \\
\hline Heptachlor-epoxide & 100 & CUS-3935 \\
\hline$\alpha$-chlordane & 100 & CUS-3935 \\
\hline$\gamma$-chlordane & 100 & CUS-3935 \\
\hline Oxychlordane & 100 & CUS-3935 \\
\hline Cis-nonachlor & 100 & CUS-3935 \\
\hline Trans-nonachlor & 100 & CUS-3935 \\
\hline Dieldrin & 100 & CUS-3935 \\
\hline Endrin & 100 & CUS-3935 \\
\hline Endosulfan 1 & 100 & CUS-3935 \\
\hline Endosulfan 2 & 100 & CUS-3935 \\
\hline Endosulfan sulfate & 100 & CUS-3935 \\
\hline $\mathrm{p}, \mathrm{p}^{\prime}-\mathrm{DDE}$ & 100 & CUS-3935/CUS-5641 \\
\hline o,p'-DDT & 100 & CUS-3935/CUS-5641 \\
\hline p,p'-DDT & 100 & CUS-3935 \\
\hline p,p'-DDD & 100 & CUS-3935 \\
\hline Methoxychlor (DMDT) & 100 & CUS-3935 \\
\hline Mirex & 100 & CUS-3935/CUS-5641 \\
\hline
\end{tabular}


List of CB Standards (UltraScientific, North Kingstown, RI, USA)

\begin{tabular}{|c|c|c|}
\hline CBz & $\begin{array}{c}\text { Concentration } \\
(\mathbf{g} / \mathbf{m L})\end{array}$ & Custom Std. \# \\
\hline Hexachlorobenzenes & 100 & CUS-5641/CUS-3935/CUS3939 \\
\hline Hexachloroethane & 100 & CUS3939 \\
\hline $1,3,5-$ Triclorobenzene & 100 & CUS3939 \\
\hline $1,2,4-$ Triclorobenzene & 100 & CUS3939 \\
\hline $1,2,3-$ Triclorobenzene & 100 & CUS3939 \\
\hline Hexachlorobutadiene & 100 & CUS3939 \\
\hline $2,4,5-$ Trichlorotoluene & 100 & CUS3939 \\
\hline $2,3,6-$ Trichlorotoluene & 100 & CUS3939 \\
\hline $1,2,3,5$-Tetraclorobenzene & 100 & CUS3939 \\
\hline $1,2,4,5$-Tetraclorobenzene & 100 & CUS3939 \\
\hline $1,2,3,4-$ Tetraclorobenzene & 100 & CUS3939 \\
\hline A-2,6-Trichlorotoluene & 100 & CUS3939 \\
\hline Pentachlorobenzene & 100 & CUS-5641/CUS3939 \\
\hline Octachlorostyrene & 100 & CUS3939 \\
\hline $1,3,5$-Tribromobenzene & 100 & \\
\hline
\end{tabular}

\section{List of solvents/materials used for sample preparation and analysis}

\begin{tabular}{|c|c|}
\hline Solvents & Provider \\
\hline Iso-octane & Caledon Lboratories LTD., Georgetown, ON, Canada \\
\hline Dichloromethane & Caledon Lboratories LTD., Georgetown, ON, Canada \\
\hline Hexane & Caledon Lboratories LTD., Georgetown, ON, Canada \\
\hline Copper 20-30 Mesh & J.T.Baker, Phillisburg, NJ, USA \\
\hline
\end{tabular}

Note: All solvents used are distilled in glass grade. 
APPENDIX B METHOD VALIDATION

Calculations of MDL and LOQ for PCBs, OCs and CBs spiked sediment samples analysed by GCxGC- $\mu$ ECD

\begin{tabular}{|c|c|c|c|c|c|c|c|}
\hline Name & $\begin{array}{c}\text { Expected } \\
\text { amount } \\
(\mathrm{ng} / \mathrm{mL})\end{array}$ & $\mathbf{N}$ & Avg. & $\begin{array}{c}\text { Std. } \\
\text { Deviation }\end{array}$ & $\%$ RSD & MDL & LOQ \\
\hline PCB8 & 1 & 8 & 5.70 & 0.53 & 9.35 & 1.60 & 4.79 \\
\hline PCB15 & 1 & 8 & 1.79 & 0.26 & 14.58 & 0.78 & 2.35 \\
\hline PCB18 & 1 & 8 & 9.77 & 1.10 & 11.24 & 3.29 & 9.87 \\
\hline PCB19 & 1 & 8 & 1.12 & 0.08 & 6.97 & 0.23 & 0.70 \\
\hline PCB22 & 1 & 8 & 2.52 & 0.18 & 7.14 & 0.54 & 1.62 \\
\hline PCB28 & 1 & 8 & 9.17 & 0.72 & 7.86 & 2.16 & 6.48 \\
\hline PCB33 & 1 & 8 & 4.11 & 0.32 & 7.71 & 0.95 & 2.85 \\
\hline PCB37 & 1 & 8 & 1.46 & 0.12 & 8.06 & 0.35 & 1.06 \\
\hline PCB44 & 1 & 8 & 1.39 & 0.10 & 6.99 & 0.29 & 0.87 \\
\hline PCB49 & 1 & 8 & 1.67 & 0.18 & 10.76 & 0.54 & 1.62 \\
\hline PCB52 & 1 & 8 & 2.56 & 0.19 & 7.38 & 0.57 & 1.70 \\
\hline PCB54 & 1 & 8 & 1.05 & 0.12 & 11.68 & 0.37 & 1.10 \\
\hline PCB70 & 1 & 8 & 1.92 & 0.30 & 15.61 & 0.90 & 2.70 \\
\hline PCB77 & 1 & 8 & 1.09 & 0.14 & 13.10 & 0.43 & 1.28 \\
\hline PCB81 & 1 & 8 & 1.00 & 0.12 & 12.04 & 0.36 & 1.08 \\
\hline PCB87 & 1 & 8 & 1.02 & 0.13 & 13.24 & 0.40 & 1.21 \\
\hline PCB95 & 1 & 8 & 1.01 & 0.09 & 8.62 & 0.26 & 0.78 \\
\hline $\begin{array}{l}\text { PCB99 } \\
\end{array}$ & 1 & 8 & 1.13 & 0.07 & 6.34 & 0.21 & 0.64 \\
\hline PCB101 & 1 & 8 & 1.24 & 0.20 & 16.07 & 0.59 & 1.78 \\
\hline PCB104 & 1 & 8 & 0.90 & 0.15 & 17.09 & 0.46 & 1.38 \\
\hline PCB105 & 1 & 8 & 1.10 & 0.08 & 7.10 & 0.23 & 0.70 \\
\hline PCB110 & 1 & 8 & 1.44 & 0.13 & 9.11 & 0.39 & 1.18 \\
\hline PCB118 & 1 & 8 & 1.06 & 0.09 & 8.54 & 0.27 & 0.81 \\
\hline PCB119 & 1 & 8 & 1.02 & 0.09 & 8.77 & 0.27 & 0.81 \\
\hline PCB123 & 1 & 8 & 0.99 & 0.15 & 15.31 & 0.45 & 1.36 \\
\hline PCB126 & 1 & 8 & 1.11 & 0.08 & 6.99 & 0.23 & 0.70 \\
\hline PCB128 & 1 & 8 & 1.11 & 0.07 & 5.94 & 0.20 & 0.59 \\
\hline PCB138 & 1 & 8 & 1.26 & 0.07 & 5.82 & 0.22 & 0.66 \\
\hline PCB149 & 1 & 8 & 1.04 & 0.17 & 16.72 & 0.52 & 1.56 \\
\hline PCB151 & 1 & 8 & 1.14 & 0.06 & 5.23 & 0.18 & 0.54 \\
\hline PCB153 & 1 & 8 & 1.29 & 0.09 & 6.64 & 0.26 & 0.77 \\
\hline PCB155 & 1 & 8 & 0.97 & 0.08 & 8.33 & 0.24 & 0.72 \\
\hline PCB156 & 1 & 8 & 0.93 & 0.09 & 9.54 & 0.27 & 0.80 \\
\hline PCB157 & 1 & 8 & 1.04 & 0.13 & 12.41 & 0.39 & 1.16 \\
\hline PCB158 & 1 & 8 & 1.11 & 0.08 & 7.55 & 0.25 & 0.75 \\
\hline PCB167 & 1 & 8 & 1.03 & 0.06 & 5.76 & 0.18 & 0.54 \\
\hline
\end{tabular}




\begin{tabular}{|c|c|c|c|c|c|c|c|}
\hline Name & $\begin{array}{c}\text { Expected } \\
\text { amount } \\
(\mathrm{ng} / \mathrm{mL})\end{array}$ & $\mathbf{N}$ & Avg. & $\begin{array}{c}\text { Std. } \\
\text { Deviation }\end{array}$ & $\%$ RSD & MDL & LOQ \\
\hline PCB168 & 1 & 8 & 1.24 & 0.21 & 17.32 & 0.64 & 1.93 \\
\hline PCB169 & 1 & 8 & 1.05 & 0.15 & 13.97 & 0.44 & 1.32 \\
\hline PCB170 & 1 & 8 & 1.07 & 0.18 & 16.82 & 0.54 & 1.62 \\
\hline PCB177 & 1 & 8 & 1.18 & 0.13 & 10.69 & 0.38 & 1.13 \\
\hline PCB178 & 1 & 8 & 1.05 & 0.08 & 7.98 & 0.25 & 0.75 \\
\hline PCB180 & 1 & 8 & 1.20 & 0.07 & 6.14 & 0.22 & 0.66 \\
\hline PCB183 & 1 & 8 & 0.91 & 0.09 & 9.49 & 0.26 & 0.78 \\
\hline PCB187 & 1 & 8 & 1.11 & 0.07 & 6.57 & 0.22 & 0.66 \\
\hline PCB188 & 1 & 8 & 0.93 & 0.09 & 9.82 & 0.27 & 0.82 \\
\hline PCB189 & 1 & 8 & 1.12 & 0.15 & 13.53 & 0.45 & 1.36 \\
\hline PCB191 & 1 & 8 & 0.83 & 0.09 & 11.20 & 0.28 & 0.84 \\
\hline PCB194 & 1 & 8 & 1.09 & 0.16 & 14.40 & 0.47 & 1.40 \\
\hline PCB199 & 1 & 8 & 1.14 & 0.07 & 6.26 & 0.21 & 0.64 \\
\hline РCB201 & 1 & 8 & 0.93 & 0.11 & 11.73 & 0.33 & 0.98 \\
\hline PCB202 & 1 & 8 & 0.83 & 0.09 & 10.42 & 0.26 & 0.78 \\
\hline PCB205 & 1 & 8 & 1.10 & 0.09 & 8.47 & 0.28 & 0.84 \\
\hline РCB206 & 1 & 8 & 1.13 & 0.10 & 8.99 & 0.30 & 0.91 \\
\hline PCB208 & 1 & 8 & 1.09 & 0.19 & 17.70 & 0.58 & 1.74 \\
\hline PCB209 & 1 & 8 & 0.99 & 0.08 & 8.10 & 0.24 & 0.72 \\
\hline HCB & 1 & 8 & 1.00 & 0.04 & 3.66 & 0.11 & 0.33 \\
\hline A-BHC & 1 & 8 & 1.14 & 0.05 & 4.67 & 0.16 & 0.48 \\
\hline B-BHC & 1 & 8 & 0.55 & 0.03 & 5.28 & 0.09 & 0.26 \\
\hline G-BHC & 1 & 8 & 1.47 & 0.03 & 2.01 & 0.09 & 0.27 \\
\hline A-CHLA & 1 & 8 & 1.21 & 0.02 & 1.68 & 0.06 & 0.18 \\
\hline G-CHLA & 1 & 8 & 5.32 & 2.29 & 42.99 & 6.86 & 20.58 \\
\hline Oxy-CHLA & 1 & 8 & 1.12 & 0.04 & 3.12 & 0.11 & 0.32 \\
\hline Aldrin & 1 & 8 & 0.96 & 0.02 & 2.48 & 0.07 & 0.21 \\
\hline Endrin & 1 & 8 & 1.37 & 0.03 & 1.88 & 0.08 & 0.23 \\
\hline Dieldrin & 1 & 8 & 1.03 & 0.13 & 12.88 & 0.40 & 1.19 \\
\hline Endos 1 & 1 & 8 & 1.07 & 0.12 & 11.37 & 0.36 & 1.09 \\
\hline Endos 2 & 1 & 8 & 0.74 & 0.11 & 15.21 & 0.34 & 1.02 \\
\hline Endos S & 1 & 8 & 0.79 & 0.09 & 10.96 & 0.26 & 0.78 \\
\hline Heptachlor & 1 & 8 & 1.22 & 0.03 & 2.24 & 0.08 & 0.25 \\
\hline OCSTYR & 1 & 8 & 1.15 & 0.08 & 7.17 & 0.25 & 0.74 \\
\hline Trans-Nonachlor & 1 & 8 & 1.06 & 0.16 & 15.49 & 0.49 & 1.47 \\
\hline o,p'-DDT & 1 & 8 & 1.15 & 0.17 & 14.85 & 0.51 & 1.54 \\
\hline p,p'-DDD & 1 & 8 & 1.21 & 0.21 & 17.41 & 0.63 & 1.90 \\
\hline$p, p^{\prime}-D D E$ & 1 & 8 & 0.98 & 0.18 & 18.32 & 0.54 & 1.61 \\
\hline p,p'-DDT & 1 & 8 & 1.27 & 0.21 & 16.15 & 0.62 & 1.85 \\
\hline Mirex & 1 & 8 & 1.04 & 0.20 & 19.31 & 0.60 & 1.81 \\
\hline p-Mirex & 1 & 8 & 1.07 & 0.22 & 20.94 & 0.67 & 2.02 \\
\hline
\end{tabular}


Within-run repeatability for PCB, OC, CB standards analysed by GCxGC- $\mu$ ECD

\begin{tabular}{|c|c|c|c|c|c|c|}
\hline Name & $\begin{array}{c}\text { Expected } \\
\text { amount }(\mathrm{ng} / \mathrm{mL})\end{array}$ & $\mathbf{N}$ & $\%$ Rec. & Mean & $\begin{array}{c}\text { Std. } \\
\text { Deviation }\end{array}$ & $\%$ RSD \\
\hline PCB8 & 500 & 10 & 109.73 & 548.66 & 9.51 & 1.73 \\
\hline PCB15 & 500 & 10 & 110.27 & 551.34 & 20.13 & 3.65 \\
\hline PCB18 & 250 & 10 & 107.41 & 268.53 & 7.64 & 2.84 \\
\hline PCB19 & 250 & 10 & 110.67 & 276.67 & 1.79 & 0.65 \\
\hline PCB22 & 250 & 10 & 105.26 & 263.15 & 1.25 & 0.47 \\
\hline PCB28 & 250 & 10 & 104.93 & 262.32 & 0.75 & 0.29 \\
\hline PCB33 & 250 & 10 & 105.38 & 263.44 & 0.90 & 0.34 \\
\hline PCB37 & 250 & 10 & 107.60 & 268.99 & 1.23 & 0.46 \\
\hline PCB44 & 50 & 10 & 97.04 & 48.52 & 2.09 & 4.31 \\
\hline PCB49 & 50 & 10 & 107.84 & 53.92 & 0.08 & 0.15 \\
\hline PCB52 & 50 & 10 & 109.25 & 54.62 & 0.14 & 0.25 \\
\hline PCB54 & 50 & 10 & 115.81 & 57.91 & 1.91 & 3.29 \\
\hline PCB70 & 50 & 10 & 110.38 & 55.19 & 2.39 & 4.33 \\
\hline PCB77 & 50 & 10 & 94.87 & 47.44 & 1.29 & 2.72 \\
\hline PCB81 & 50 & 10 & 108.79 & 54.40 & 0.28 & 0.51 \\
\hline PCB87 & 50 & 10 & 108.01 & 54.01 & 0.33 & 0.61 \\
\hline PCB95 & 50 & 10 & 108.44 & 54.22 & 0.49 & 0.90 \\
\hline PCB99 & 50 & 10 & 95.85 & 47.93 & 1.47 & 3.06 \\
\hline PCB101 & 50 & 10 & 105.47 & 52.74 & 0.16 & 0.30 \\
\hline PCB104 & 50 & 10 & 109.01 & 54.51 & 0.30 & 0.55 \\
\hline PCB105 & 50 & 10 & 104.31 & 52.16 & 0.30 & 0.58 \\
\hline PCB110 & 50 & 10 & 105.66 & 52.83 & 0.23 & 0.43 \\
\hline PCB118 & 50 & 10 & 111.81 & 55.91 & 1.57 & 2.80 \\
\hline PCB119 & 50 & 10 & 107.88 & 53.94 & 0.22 & 0.41 \\
\hline PCB123 & 50 & 10 & 105.10 & 52.55 & 0.62 & 1.18 \\
\hline PCB126 & 50 & 10 & 126.35 & 63.18 & 1.17 & 1.84 \\
\hline PCB128 & 50 & 10 & 109.45 & 54.73 & 0.36 & 0.66 \\
\hline PCB138 & 50 & 10 & 105.07 & 52.54 & 0.29 & 0.56 \\
\hline PCB149 & 50 & 10 & 89.22 & 44.61 & 0.69 & 1.54 \\
\hline PCB151 & 50 & 10 & 110.27 & 55.13 & 0.20 & 0.36 \\
\hline PCB153 & 50 & 10 & 103.47 & 51.74 & 1.42 & 2.74 \\
\hline PCB155 & 50 & 10 & 112.45 & 56.23 & 1.09 & 1.94 \\
\hline PCB156 & 50 & 10 & 108.91 & 54.45 & 0.71 & 1.30 \\
\hline PCB157 & 50 & 10 & 108.12 & 54.06 & 0.40 & 0.74 \\
\hline PCB158 & 50 & 10 & 108.16 & 54.08 & 0.35 & 0.65 \\
\hline PCB167 & 50 & 10 & 104.34 & 52.17 & 0.34 & 0.66 \\
\hline PCB168 & 50 & 10 & 107.20 & 53.60 & 0.76 & 1.43 \\
\hline PCB169 & 50 & 10 & 104.80 & 52.40 & 0.51 & 0.97 \\
\hline PCB170 & 50 & 10 & 105.40 & 52.70 & 0.42 & 0.81 \\
\hline PCB177 & 50 & 10 & 106.85 & 53.42 & 0.37 & 0.70 \\
\hline PCB178 & 50 & 10 & 106.38 & 53.19 & 0.21 & 0.40 \\
\hline PCB180 & 50 & 10 & 109.00 & 54.50 & 0.60 & 1.10 \\
\hline
\end{tabular}




\begin{tabular}{|c|c|c|c|c|c|c|}
\hline Name & $\begin{array}{c}\text { Expected } \\
\text { amount }(\mathrm{ng} / \mathrm{mL})\end{array}$ & $\mathbf{N}$ & \% Rec. & Mean & $\begin{array}{c}\text { Std. } \\
\text { Deviation }\end{array}$ & $\%$ RSD \\
\hline PCB183 & 50 & 10 & 105.14 & 52.57 & 0.36 & 0.68 \\
\hline PCB187 & 50 & 10 & 105.32 & 52.66 & 0.30 & 0.57 \\
\hline PCB188 & 50 & 10 & 107.85 & 53.93 & 0.27 & 0.51 \\
\hline PCB189 & 50 & 10 & 111.76 & 55.88 & 1.05 & 1.89 \\
\hline PCB191 & 50 & 10 & 112.99 & 56.50 & 0.54 & 0.96 \\
\hline PCB194 & 50 & 10 & 97.83 & 48.91 & 0.53 & 1.08 \\
\hline PCB199 & 50 & 10 & 106.46 & 53.23 & 0.48 & 0.89 \\
\hline PCB201 & 50 & 10 & 104.63 & 52.32 & 0.39 & 0.75 \\
\hline PCB202 & 50 & 10 & 110.73 & 55.36 & 0.35 & 0.64 \\
\hline PCB205 & 50 & 10 & 105.65 & 52.83 & 0.58 & 1.10 \\
\hline PCB206 & 50 & 10 & 92.64 & 46.32 & 0.60 & 1.30 \\
\hline PCB208 & 50 & 10 & 100.87 & 50.43 & 0.59 & 1.18 \\
\hline PCB209 & 50 & 10 & 106.74 & 53.37 & 0.62 & 1.16 \\
\hline HCB & 50 & 10 & 93.69 & 46.85 & 0.50 & 1.06 \\
\hline HCBD & 50 & 10 & 103.43 & 51.71 & 0.70 & 1.35 \\
\hline HCE & 50 & 10 & 102.17 & 51.08 & 2.44 & 4.77 \\
\hline 1,2,3,4-TCB & 50 & 10 & 96.21 & 48.11 & 0.51 & 1.05 \\
\hline $1,2,3,5-/ 1,2,4,5-T C B$ & 100 & 10 & 92.32 & 92.32 & 1.15 & 1.24 \\
\hline 1,2,3-TCB & 50 & 10 & 93.87 & 46.94 & 0.90 & 1.92 \\
\hline 1,2,4-TCB & 50 & 10 & 98.58 & 49.29 & 1.65 & 3.36 \\
\hline 1,3,5-TBB & 50 & 10 & 97.15 & 48.57 & 0.48 & 0.99 \\
\hline 1,3,5-TCB & 50 & 10 & 98.46 & 49.23 & 0.75 & 1.53 \\
\hline 2,3,6-TCT & 50 & 10 & 90.11 & 45.05 & 0.69 & 1.54 \\
\hline 2,4,5-TCT & 50 & 10 & 95.73 & 47.87 & 0.80 & 1.67 \\
\hline P5CB & 50 & 10 & 99.86 & 49.93 & 0.51 & 1.01 \\
\hline A2,6-TCT & 50 & 10 & 95.88 & 47.94 & 0.73 & 1.52 \\
\hline A-BHC & 50 & 10 & 100.56 & 50.28 & 0.50 & 0.99 \\
\hline B-BHC & 20 & 10 & 107.22 & 21.44 & 0.21 & 0.97 \\
\hline G-BHC & 50 & 10 & 98.74 & 49.37 & 0.58 & 1.17 \\
\hline A-CHLA & 50 & 10 & 103.55 & 51.78 & 3.77 & 7.29 \\
\hline G-CHLA & 50 & 10 & 104.09 & 52.04 & 0.56 & 1.07 \\
\hline Oxy-CHLA & 50 & 10 & 108.82 & 54.41 & 0.71 & 1.30 \\
\hline Aldrin & 50 & 10 & 86.90 & 43.45 & 0.49 & 1.13 \\
\hline Endrin & 50 & 10 & 121.14 & 60.57 & 2.95 & 4.88 \\
\hline $\begin{array}{l}\text { Dieldrin } \\
\end{array}$ & 50 & 10 & 104.08 & 52.04 & 0.58 & 1.11 \\
\hline Endos 1 & 50 & 10 & 108.12 & 54.06 & 0.59 & 1.09 \\
\hline Endos 2 & 50 & 10 & 103.57 & 51.78 & 0.51 & 0.99 \\
\hline Endos S & 50 & 10 & 103.93 & 51.97 & 1.57 & 3.02 \\
\hline Heptachlor & 50 & 10 & 111.55 & 55.77 & 0.69 & 1.23 \\
\hline OCSTYR & 50 & 10 & 95.41 & 47.71 & 0.56 & 1.17 \\
\hline Trans-Nonachlor & 50 & 10 & 98.99 & 49.50 & 0.53 & 1.07 \\
\hline o,p'-DDT & 50 & 10 & 100.71 & 50.35 & 0.71 & 1.42 \\
\hline$p, p '-D D D$ & 50 & 10 & 101.89 & 50.94 & 0.95 & 1.87 \\
\hline p,p'-DDE & 50 & 10 & 97.50 & 48.75 & 0.56 & 1.14 \\
\hline p,p'-DDT & 50 & 10 & 101.53 & 50.77 & 0.75 & 1.47 \\
\hline
\end{tabular}




\begin{tabular}{|c|c|c|c|c|c|c|}
\hline Name & $\begin{array}{c}\text { Expected } \\
\text { amount }(\mathbf{n g} / \mathbf{m L})\end{array}$ & $\mathbf{N}$ & \% Rec. & Mean & $\begin{array}{c}\text { Std. } \\
\text { Deviation }\end{array}$ & \%RSD \\
\hline Mirex & 50 & 10 & 100.10 & 50.05 & 2.27 & 4.54 \\
\hline p-Mirex & 50 & 10 & 110.96 & 55.48 & 0.60 & 1.09 \\
\hline DMDT/PCB171 & 100 & 10 & 104.74 & 104.74 & 1.56 & 1.49 \\
\hline Cis-Nonachlor/PCB114 & 100 & 10 & 113.64 & 113.64 & 1.20 & 1.06 \\
\hline H-Epoxide/PCB74 & 100 & 10 & 112.74 & 112.74 & 1.47 & 1.30 \\
\hline
\end{tabular}

Within-run method precision (repeatability) for PCBs, OCs, CBs spiked sediment samples analysed by GCxGC- $\mu$ ECD

\begin{tabular}{|c|c|c|c|c|c|c|}
\hline Name & $\begin{array}{c}\text { Expected } \\
\text { amount (ng/mL) }\end{array}$ & N & \% Rec. & Mean & $\begin{array}{c}\text { Std. } \\
\text { Deviation }\end{array}$ & \%RSD \\
\hline PCB8 & 500 & 9 & 83.66 & 418.32 & 44.19 & 10.56 \\
\hline PCB15 & 500 & 9 & 86.58 & 432.91 & 42.45 & 9.81 \\
\hline PCB18 & 250 & 9 & 86.63 & 216.57 & 21.88 & 10.10 \\
\hline PCB19 & 250 & 9 & 85.50 & 213.74 & 20.21 & 9.46 \\
\hline PCB22 & 250 & 9 & 89.11 & 222.77 & 19.56 & 8.78 \\
\hline PCB28 & 250 & 9 & 89.34 & 223.35 & 19.76 & 8.85 \\
\hline PCB33 & 250 & 9 & 92.22 & 230.55 & 25.75 & 11.17 \\
\hline PCB37 & 250 & 9 & 92.25 & 230.62 & 23.47 & 10.18 \\
\hline PCB44 & 50 & 9 & 103.40 & 51.70 & 5.42 & 10.49 \\
\hline PCB49 & 50 & 9 & 91.92 & 45.96 & 5.12 & 11.13 \\
\hline PCB52 & 50 & 9 & 98.14 & 49.07 & 5.76 & 11.74 \\
\hline PCB54 & 50 & 9 & 98.46 & 49.23 & 5.23 & 10.63 \\
\hline PCB70 & 50 & 9 & 103.42 & 51.71 & 5.17 & 9.99 \\
\hline PCB77 & 50 & 9 & 85.85 & 42.93 & 5.15 & 12.01 \\
\hline PCB81 & 50 & 9 & 97.93 & 48.96 & 5.17 & 10.56 \\
\hline PCB87 & 50 & 9 & 94.72 & 47.36 & 4.80 & 10.14 \\
\hline PCB95 & 50 & 9 & 96.83 & 48.41 & 5.10 & 10.53 \\
\hline PCB99 & 50 & 9 & 93.72 & 46.86 & 3.67 & 7.83 \\
\hline PCB101 & 50 & 9 & 94.55 & 47.27 & 4.89 & 10.34 \\
\hline PCB104 & 50 & 9 & 93.90 & 46.95 & 4.98 & 10.61 \\
\hline PCB105 & 50 & 9 & 95.44 & 47.72 & 5.04 & 10.56 \\
\hline PCB110 & 50 & 9 & 94.28 & 47.14 & 5.21 & 11.04 \\
\hline PCB118 & 50 & 9 & 105.28 & 52.64 & 4.84 & 9.19 \\
\hline PCB119 & 50 & 9 & 96.98 & 48.49 & 5.07 & 10.46 \\
\hline PCB123 & 50 & 9 & 94.38 & 47.19 & 5.01 & 10.61 \\
\hline PCB126 & 50 & 9 & 114.26 & 57.13 & 3.61 & 6.31 \\
\hline PCB128 & 50 & 9 & 100.94 & 50.47 & 5.34 & 10.57 \\
\hline PCB138 & 50 & 9 & 95.88 & 47.94 & 5.04 & 10.52 \\
\hline PCB151 & 50 & 9 & 91.14 & 45.57 & 6.38 & 13.99 \\
\hline & 50 & 9 & 100.70 & 50.35 & 5.17 & 10.28 \\
\hline
\end{tabular}




\begin{tabular}{|c|c|c|c|c|c|c|}
\hline Name & $\begin{array}{c}\text { Expected } \\
\text { amount }(\mathrm{ng} / \mathrm{mL})\end{array}$ & $\mathbf{N}$ & $\%$ Rec. & Mean & $\begin{array}{c}\text { Std. } \\
\text { Deviation }\end{array}$ & $\%$ RSD \\
\hline PCB153 & 50 & 9 & 98.33 & 49.17 & 5.55 & 11.28 \\
\hline PCB155 & 50 & 9 & 100.73 & 50.36 & 4.80 & 9.53 \\
\hline PCB156 & 50 & 9 & 96.47 & 48.23 & 5.08 & 10.53 \\
\hline PCB157 & 50 & 9 & 90.45 & 45.22 & 5.56 & 12.29 \\
\hline PCB158 & 50 & 9 & 97.89 & 48.94 & 5.11 & 10.44 \\
\hline PCB167 & 50 & 9 & 95.69 & 47.85 & 5.08 & 10.61 \\
\hline PCB168 & 50 & 9 & 96.76 & 48.38 & 4.82 & 9.97 \\
\hline PCB169 & 50 & 9 & 97.12 & 48.56 & 5.07 & 10.44 \\
\hline PCB170 & 50 & 9 & 97.43 & 48.72 & 5.04 & 10.35 \\
\hline PCB177 & 50 & 9 & 93.65 & 46.83 & 5.32 & 11.36 \\
\hline PCB178 & 50 & 9 & 98.34 & 49.17 & 5.05 & 10.27 \\
\hline PCB180 & 50 & 9 & 101.21 & 50.60 & 5.15 & 10.18 \\
\hline PCB183 & 50 & 9 & 95.44 & 47.72 & 5.04 & 10.55 \\
\hline PCB187 & 50 & 9 & 96.47 & 48.24 & 5.08 & 10.54 \\
\hline PCB188 & 50 & 9 & 99.38 & 49.69 & 5.14 & 10.34 \\
\hline PCB189 & 50 & 9 & 103.21 & 51.60 & 5.02 & 9.73 \\
\hline PCB191 & 50 & 9 & 105.73 & 52.86 & 5.46 & 10.33 \\
\hline PCB194 & 50 & 9 & 92.60 & 46.30 & 4.83 & 10.43 \\
\hline PCB199 & 50 & 9 & 98.93 & 49.47 & 5.22 & 10.56 \\
\hline PCB201 & 50 & 9 & 94.78 & 47.39 & 5.03 & 10.61 \\
\hline PCB202 & 50 & 9 & 99.75 & 49.87 & 5.48 & 11.00 \\
\hline PCB205 & 50 & 9 & 101.77 & 50.89 & 5.69 & 11.18 \\
\hline PCB206 & 50 & 9 & 90.07 & 45.04 & 4.64 & 10.31 \\
\hline PCB208 & 50 & 9 & 95.79 & 47.90 & 5.25 & 10.97 \\
\hline РCB209 & 50 & 9 & 104.36 & 52.18 & 5.30 & 10.16 \\
\hline HCB & 50 & 9 & 77.58 & 38.79 & 1.21 & 3.11 \\
\hline HCBD & 50 & 9 & 62.10 & 31.05 & 3.64 & 11.72 \\
\hline HCE & 50 & 9 & 49.94 & 24.97 & 3.70 & 14.80 \\
\hline 1,2,3,4-TCB & 50 & 9 & 63.93 & 31.96 & 2.69 & 8.41 \\
\hline $1,2,3,5-/ 1,2,4,5-$ TCB & 100 & 9 & 60.46 & 60.46 & 4.86 & 8.03 \\
\hline 1,2,3-TCB & 50 & 9 & 52.68 & 26.34 & 1.98 & 7.52 \\
\hline 1,2,4-ТCB & 50 & 9 & 69.06 & 34.53 & 4.74 & 13.72 \\
\hline $1,3,5-$ TBB & 50 & 9 & 65.25 & 32.63 & 2.76 & 8.46 \\
\hline 1,3,5-TCB & 50 & 9 & 59.87 & 29.93 & 3.76 & 12.57 \\
\hline $2,3,6-\mathrm{TCT}$ & 50 & 9 & 57.98 & 28.99 & 2.20 & 7.57 \\
\hline $2,4,5-\mathrm{TCT}$ & 50 & 9 & 61.56 & 30.78 & 2.89 & 9.40 \\
\hline P5CB & 50 & 9 & 69.34 & 34.67 & 2.24 & 6.47 \\
\hline A2,6-TCT & 50 & 9 & 69.17 & 34.58 & 4.04 & 11.69 \\
\hline A-BHC & 50 & 9 & 80.76 & 40.38 & 1.14 & 2.82 \\
\hline B-BHC & 20 & 9 & 99.60 & 19.92 & 0.54 & 2.69 \\
\hline G-BHC & 50 & 9 & 86.31 & 43.15 & 1.12 & 2.59 \\
\hline A-CHLA & 50 & 9 & 104.03 & 52.01 & 3.15 & 6.06 \\
\hline G-CHLA & 50 & 9 & 108.08 & 54.04 & 1.69 & 3.12 \\
\hline Oxy-CHLA & 50 & 9 & 104.52 & 52.26 & 0.93 & 1.77 \\
\hline Aldrin & 50 & 9 & 78.84 & 39.42 & 0.97 & 2.47 \\
\hline
\end{tabular}




\begin{tabular}{|c|c|c|c|c|c|c|}
\hline Name & $\begin{array}{c}\text { Expected } \\
\text { amount (ng/mL) }\end{array}$ & $\mathbf{N}$ & \% Rec. & Mean & $\begin{array}{c}\text { Std. } \\
\text { Deviation }\end{array}$ & \%RSD \\
\hline Endrin & 50 & 9 & 118.85 & 59.42 & 1.97 & 3.32 \\
\hline Dieldrin & 50 & 9 & 103.25 & 51.63 & 1.18 & 2.29 \\
\hline Endos 1 & 50 & 9 & 108.16 & 54.08 & 1.23 & 2.27 \\
\hline Endos 2 & 50 & 9 & 94.33 & 47.16 & 2.27 & 4.80 \\
\hline Endos S & 50 & 9 & 85.30 & 42.65 & 2.82 & 6.62 \\
\hline Heptachlor & 50 & 9 & 99.02 & 49.51 & 1.56 & 3.14 \\
\hline OCSTYR & 50 & 9 & 89.68 & 44.84 & 1.29 & 2.88 \\
\hline Trans-Nonachlor & 50 & 9 & 97.32 & 48.66 & 1.15 & 2.37 \\
\hline o,p'-DDT & 50 & 9 & 99.84 & 49.92 & 0.97 & 1.93 \\
\hline p,p'-DDD & 50 & 9 & 103.88 & 51.94 & 1.24 & 2.39 \\
\hline p,p'-DDE & 50 & 9 & 94.95 & 47.47 & 1.11 & 2.33 \\
\hline p,p'-DDT & 50 & 9 & 104.76 & 52.38 & 3.40 & 6.50 \\
\hline Mirex & 50 & 9 & 105.81 & 52.91 & 1.10 & 2.08 \\
\hline p-Mirex & 50 & 9 & 109.25 & 54.62 & 1.39 & 2.55 \\
\hline DMDT/PCB171 & 100 & 9 & 97.50 & 97.50 & 2.65 & 2.72 \\
\hline Cis-Nonachlor/PCB114 & 100 & 9 & 110.39 & 110.39 & 2.47 & 2.24 \\
\hline H-Epoxide/PCB74 & 100 & 9 & 109.42 & 109.42 & 4.47 & 4.08 \\
\hline
\end{tabular}

Between-run method precision (reproducibility) for $\mathrm{PCBs}, \mathrm{OCs}$, CBs spiked sediment samples analysed by GCxGC- $\mu$ ECD

\begin{tabular}{|c|c|c|c|c|c|}
\hline Name & $\begin{array}{c}\text { Expected } \\
\text { amounts } \\
\text { (ng/g) }\end{array}$ & N & Mean & $\begin{array}{c}\text { Std. } \\
\text { Deviation }\end{array}$ & \%RSD \\
\hline PCB8 & 500 & 7 & 416.6 & 54.4 & 13.0 \\
\hline PCB15 & 500 & 7 & 437.2 & 58.1 & 13.3 \\
\hline PCB18 & 250 & 7 & 218.5 & 25.4 & 11.6 \\
\hline PCB19 & 250 & 7 & 209.6 & 26.2 & 12.5 \\
\hline PCB22 & 250 & 7 & 222.8 & 24.0 & 10.8 \\
\hline PCB28 & 250 & 7 & 218.6 & 24.6 & 11.3 \\
\hline PCB33 & 250 & 7 & 232.3 & 25.8 & 11.1 \\
\hline PCB37 & 250 & 7 & 227.5 & 38.9 & 17.1 \\
\hline PCB44 & 50 & 7 & 40.1 & 6.0 & 14.9 \\
\hline PCB49 & 50 & 7 & 47.7 & 5.2 & 11.0 \\
\hline PCB52 & 50 & 7 & 50.2 & 6.9 & 13.7 \\
\hline PCB54 & 50 & 7 & 51.4 & 5.5 & 10.8 \\
\hline PCB70 & 50 & 7 & 52.9 & 7.0 & 13.2 \\
\hline PCB77 & 50 & 7 & 46.6 & 4.5 & 9.7 \\
\hline PCB81 & 50 & 7 & 48.4 & 6.4 & 13.3 \\
\hline PCB87 & 50 & 7 & 47.4 & 5.8 & 12.3 \\
\hline
\end{tabular}




\begin{tabular}{|c|c|c|c|c|c|}
\hline Name & $\begin{array}{c}\text { Expected } \\
\text { amounts } \\
(\mathrm{ng} / \mathrm{g})\end{array}$ & $\mathbf{N}$ & Mean & $\begin{array}{c}\text { Std. } \\
\text { Deviation }\end{array}$ & $\%$ RSD \\
\hline PCB95 & 50 & 7 & 49.3 & 6.3 & 12.8 \\
\hline PCB99 & 50 & 7 & 46.0 & 8.8 & 19.2 \\
\hline PCB101 & 50 & 7 & 48.0 & 5.7 & 11.9 \\
\hline PCB104 & 50 & 7 & 46.0 & 6.5 & 14.2 \\
\hline PCB105 & 50 & 7 & 48.9 & 6.6 & 13.5 \\
\hline PCB110 & 50 & 7 & 47.8 & 6.1 & 12.7 \\
\hline PCB118 & 50 & 7 & 49.9 & 6.9 & 13.8 \\
\hline PCB119 & 50 & 7 & 49.0 & 6.1 & 12.5 \\
\hline PCB123 & 50 & 7 & 43.9 & 6.9 & 15.7 \\
\hline PCB126 & 50 & 7 & 58.8 & 7.3 & 12.4 \\
\hline PCB128 & 50 & 7 & 49.6 & 6.6 & 13.3 \\
\hline PCB138 & 50 & 7 & 49.6 & 5.5 & 11.1 \\
\hline PCB149 & 50 & 7 & 50.8 & 6.3 & 12.3 \\
\hline PCB151 & 50 & 7 & 50.9 & 5.7 & 11.2 \\
\hline PCB153 & 50 & 7 & 50.9 & 5.2 & 10.2 \\
\hline PCB155 & 50 & 7 & 50.1 & 5.4 & 10.8 \\
\hline PCB156 & 50 & 7 & 50.3 & 6.4 & 12.6 \\
\hline PCB157 & 50 & 7 & 50.4 & 6.1 & 12.1 \\
\hline PCB158 & 50 & 7 & 50.9 & 7.2 & 14.1 \\
\hline PCB167 & 50 & 7 & 50.8 & 3.0 & 5.9 \\
\hline PCB168 & 50 & 7 & 51.3 & 4.4 & 8.6 \\
\hline PCB169 & 50 & 7 & 48.7 & 6.9 & 14.2 \\
\hline PCB170 & 50 & 7 & 50.2 & 6.2 & 12.4 \\
\hline PCB177 & 50 & 7 & 51.3 & 5.7 & 11.1 \\
\hline PCB178 & 50 & 7 & 50.5 & 5.6 & 11.2 \\
\hline PCB180 & 50 & 7 & 52.3 & 6.6 & 12.6 \\
\hline PCB183 & 50 & 7 & 49.5 & 6.2 & 12.5 \\
\hline PCB187 & 50 & 7 & 49.7 & 5.6 & 11.2 \\
\hline PCB188 & 50 & 7 & 51.2 & 5.3 & 10.4 \\
\hline PCB189 & 50 & 7 & 52.6 & 7.1 & 13.5 \\
\hline PCB191 & 50 & 7 & 53.8 & 6.6 & 12.3 \\
\hline PCB194 & 50 & 7 & 46.9 & 6.0 & 12.7 \\
\hline PCB199 & 50 & 7 & 50.1 & 5.9 & 11.8 \\
\hline PCB201 & 50 & 7 & 49.5 & 5.9 & 11.9 \\
\hline PCB202 & 50 & 7 & 51.7 & 5.6 & 10.8 \\
\hline PCB205 & 50 & 7 & 50.3 & 6.4 & 12.8 \\
\hline PCB206 & 50 & 7 & 45.5 & 5.6 & 12.2 \\
\hline PCB208 & 50 & 7 & 48.6 & 6.1 & 12.6 \\
\hline PCB209 & 50 & 7 & 56.5 & 5.1 & 9.1 \\
\hline $\mathrm{HCB}$ & 50 & 8 & 38.3 & 8.6 & 22.5 \\
\hline HCBD & 50 & 7 & 34.7 & 8.5 & 24.6 \\
\hline $\mathrm{HCE}$ & 50 & 8 & 30.5 & 7.7 & 25.2 \\
\hline $1,2,3,4-\mathrm{TCB}$ & 50 & 8 & 33.2 & 7.9 & 23.8 \\
\hline $1,2,3,5-/ 1,2,4,5-\mathrm{TCB}$ & 100 & 8 & 64.5 & 14.9 & 23.1 \\
\hline
\end{tabular}




\begin{tabular}{|c|c|c|c|c|c|}
\hline Name & $\begin{array}{c}\text { Expected } \\
\text { amounts } \\
(\mathrm{ng} / \mathrm{g})\end{array}$ & $\mathbf{N}$ & Mean & $\begin{array}{c}\text { Std. } \\
\text { Deviation }\end{array}$ & $\%$ RSD \\
\hline $1,2,3-\mathrm{TCB}$ & 50 & 8 & 28.3 & 6.8 & 24.2 \\
\hline $1,2,4-\mathrm{TCB}$ & 50 & 8 & 34.6 & 8.9 & 25.6 \\
\hline $1,3,5-\mathrm{TBB}$ & 50 & 8 & 51.1 & 21.4 & 41.8 \\
\hline $1,3,5-\mathrm{TCB}$ & 50 & 8 & 31.3 & 7.6 & 24.3 \\
\hline $2,3,6-\mathrm{TCT}$ & 50 & 8 & 31.0 & 6.6 & 21.3 \\
\hline $2,4,5-\mathrm{TCT}$ & 50 & 8 & 32.1 & 7.5 & 23.3 \\
\hline P5CB & 50 & 8 & 36.5 & 9.7 & 26.6 \\
\hline $\mathrm{A} 2,6-\mathrm{TCT}$ & 50 & 8 & 34.5 & 7.4 & 21.4 \\
\hline A-BHC & 50 & 8 & 40.9 & 8.0 & 19.5 \\
\hline B-BHC & 20 & 8 & 20.6 & 4.1 & 19.8 \\
\hline G-BHC & 50 & 8 & 43.8 & 7.4 & 16.8 \\
\hline A-CHLA & 50 & 8 & 51.1 & 7.5 & 14.7 \\
\hline G-CHLA & 50 & 8 & 55.3 & 5.9 & 10.6 \\
\hline Oxy-CHLA & 50 & 8 & 48.1 & 4.2 & 8.7 \\
\hline Aldrin & 50 & 8 & 44.3 & 5.9 & 13.3 \\
\hline Endrin & 50 & 8 & 64.1 & 25.5 & 39.8 \\
\hline Dieldrin & 50 & 8 & 53.9 & 7.4 & 13.7 \\
\hline Endos 1 & 50 & 8 & 54.2 & 8.9 & 16.4 \\
\hline Endos 2 & 50 & 8 & 44.4 & 18.3 & 41.1 \\
\hline Endos S & 50 & 8 & 42.1 & 16.0 & 37.9 \\
\hline Heptachlor & 50 & 8 & 51.9 & 7.6 & 14.7 \\
\hline OCSTYR & 50 & 8 & 45.5 & 5.2 & 11.3 \\
\hline Trans-Nonachlor & 50 & 8 & 53.1 & 7.8 & 14.6 \\
\hline o,p'-DDT & 50 & 8 & 52.8 & 6.0 & 11.4 \\
\hline p,p'-DDD & 50 & 8 & 53.5 & 2.2 & 4.2 \\
\hline p,p'-DDE & 50 & 8 & 46.7 & 2.2 & 4.7 \\
\hline p,p'-DDT & 50 & 8 & 51.6 & 2.9 & 5.7 \\
\hline Mirex & 50 & 8 & 52.8 & 6.0 & 11.4 \\
\hline p-Mirex & 50 & 8 & 54.4 & 4.2 & 7.8 \\
\hline DMDT/PCB171 & 100 & 7 & 104.2 & 19.6 & 18.8 \\
\hline Cis-Nonachlor/PCB114 & 100 & 7 & 114.4 & 10.0 & 8.8 \\
\hline H-Epoxide/PCB74 & 100 & 7 & 106.3 & 6.5 & 6.1 \\
\hline
\end{tabular}




\section{APPENDIX C: UNCERTAINTIES CALCULATIONS}

\section{Uncertainties Calculations for PCB congeners}

\begin{tabular}{|c|c|c|c|c|c|c|c|c|}
\hline Name & $\begin{array}{c}\text { Expected } \\
\text { amount } \\
(\mathrm{ng} / \mathrm{g})\end{array}$ & SD & $\%$ RSD & $\mathbf{w}$ & $\mathbf{U}_{\mathbf{x}}$ & $\sum \mathbf{U}_{x}{ }^{2}+\mathbf{U}_{0}{ }^{2}$ & Uc & $\mathbf{U}$ \\
\hline PCB8 & 500 & 44.19 & 10.56 & 0.53 & 52.82 & 2790.38 & 52.82 & 105.65 \\
\hline PCB15 & 500 & 42.45 & 9.81 & 0.26 & 49.03 & 2404.03 & 49.03 & 98.06 \\
\hline PCB18 & 250 & 21.88 & 10.10 & 1.10 & 25.26 & 639.03 & 25.28 & 50.56 \\
\hline PCB19 & 250 & 20.21 & 9.46 & 0.08 & 23.64 & 558.84 & 23.64 & 47.28 \\
\hline PCB22 & 250 & 19.56 & 8.78 & 0.18 & 21.95 & 481.83 & 21.95 & 43.90 \\
\hline PCB28 & 250 & 19.76 & 8.85 & 0.72 & 22.11 & 489.55 & 22.13 & 44.25 \\
\hline PCB33 & 250 & 25.75 & 11.17 & 0.32 & 27.93 & 779.97 & 27.93 & 55.86 \\
\hline PCB37 & 250 & 23.47 & 10.18 & 0.12 & 25.44 & 647.43 & 25.44 & 50.89 \\
\hline PCB44 & 50 & 5.42 & 10.49 & 0.10 & 5.24 & 27.51 & 5.25 & 10.49 \\
\hline PCB49 & 50 & 5.12 & 11.13 & 0.18 & 5.57 & 31.03 & 5.57 & 11.14 \\
\hline PCB52 & 50 & 5.76 & 11.74 & 0.19 & 5.87 & 34.48 & 5.87 & 11.74 \\
\hline PCB54 & 50 & 5.23 & 10.63 & 0.12 & 5.32 & 28.28 & 5.32 & 10.64 \\
\hline PCB70 & 50 & 5.17 & 9.99 & 0.30 & 5.00 & 25.04 & 5.00 & 10.01 \\
\hline PCB77 & 50 & 5.15 & 12.01 & 0.14 & 6.00 & 36.07 & 6.01 & 12.01 \\
\hline PCB81 & 50 & 5.17 & 10.56 & 0.12 & 5.28 & 27.91 & 5.28 & 10.57 \\
\hline PCB87 & 50 & 4.80 & 10.14 & 0.13 & 5.07 & 25.74 & 5.07 & 10.15 \\
\hline PCB95 & 50 & 5.10 & 10.53 & 0.09 & 5.27 & 27.73 & 5.27 & 10.53 \\
\hline PCB99 & 50 & 3.67 & 7.83 & 0.07 & 3.91 & 15.31 & 3.91 & 7.83 \\
\hline PCB101 & 50 & 4.89 & 10.34 & 0.20 & 5.17 & 26.77 & 5.17 & 10.35 \\
\hline PCB104 & 50 & 4.98 & 10.61 & 0.15 & 5.30 & 28.16 & 5.31 & 10.61 \\
\hline PCB105 & 50 & 5.04 & 10.56 & 0.08 & 5.28 & 27.88 & 5.28 & 10.56 \\
\hline PCB110 & 50 & 5.21 & 11.04 & 0.13 & 5.52 & 30.50 & 5.52 & 11.05 \\
\hline PCB118 & 50 & 4.84 & 9.19 & 0.09 & 4.60 & 21.12 & 4.60 & 9.19 \\
\hline PCB119 & 50 & 5.07 & 10.46 & 0.09 & 5.23 & 27.36 & 5.23 & 10.46 \\
\hline PCB123 & 50 & 5.01 & 10.61 & 0.15 & 5.30 & 28.16 & 5.31 & 10.61 \\
\hline PCB126 & 50 & 3.61 & 6.31 & 0.08 & 3.16 & 9.97 & 3.16 & 6.31 \\
\hline PCB128 & 50 & 5.34 & 10.57 & 0.07 & 5.29 & 27.95 & 5.29 & 10.57 \\
\hline PCB138 & 50 & 5.04 & 10.52 & 0.07 & 5.26 & 27.67 & 5.26 & 10.52 \\
\hline PCB149 & 50 & 6.38 & 13.99 & 0.17 & 7.00 & 48.97 & 7.00 & 14.00 \\
\hline PCB151 & 50 & 5.17 & 10.28 & 0.06 & 5.14 & 26.40 & 5.14 & 10.28 \\
\hline PCB153 & 50 & 5.55 & 11.28 & 0.09 & 5.64 & 31.81 & 5.64 & 11.28 \\
\hline PCB155 & 50 & 4.80 & 9.53 & 0.08 & 4.77 & 22.72 & 4.77 & 9.53 \\
\hline PCB156 & 50 & 5.08 & 10.53 & 0.09 & 5.27 & 27.74 & 5.27 & 10.53 \\
\hline PCB157 & 50 & 5.56 & 12.29 & 0.13 & 6.15 & 37.79 & 6.15 & 12.30 \\
\hline PCB158 & 50 & 5.11 & 10.44 & 0.08 & 5.22 & 27.26 & 5.22 & 10.44 \\
\hline PCB167 & 50 & 5.08 & 10.61 & 0.06 & 5.31 & 28.15 & 5.31 & 10.61 \\
\hline PCB168 & 50 & 4.82 & 9.97 & 0.21 & 4.98 & 24.87 & 4.99 & 9.97 \\
\hline PCB169 & 50 & 5.07 & 10.44 & 0.15 & 5.22 & 27.26 & 5.22 & 10.44 \\
\hline PCB170 & 50 & 5.04 & 10.35 & 0.18 & 5.18 & 26.82 & 5.18 & 10.36 \\
\hline PCB177 & 50 & 5.32 & 11.36 & 0.13 & 5.68 & 32.26 & 5.68 & 11.36 \\
\hline
\end{tabular}




\begin{tabular}{|c|c|c|c|c|c|c|c|c|}
\hline Name & $\begin{array}{c}\text { Expected } \\
\text { amount } \\
\text { (ng/g) }\end{array}$ & SD & \%RSD & $\mathbf{W}$ & $\mathbf{U}_{\mathbf{x}}$ & $\sum \mathbf{U}_{\mathbf{x}}{ }^{2}+\mathbf{U}_{\mathbf{0}}{ }^{2}$ & $\mathbf{U}$ & $\mathbf{U}$ \\
\hline PCB178 & 50 & 5.05 & 10.27 & 0.08 & 5.14 & 26.39 & 5.14 & 10.27 \\
\hline PCB180 & 50 & 5.15 & 10.18 & 0.07 & 5.09 & 25.92 & 5.09 & 10.18 \\
\hline PCB183 & 50 & 5.04 & 10.55 & 0.09 & 5.28 & 27.86 & 5.28 & 10.56 \\
\hline PCB187 & 50 & 5.08 & 10.54 & 0.07 & 5.27 & 27.78 & 5.27 & 10.54 \\
\hline PCB188 & 50 & 5.14 & 10.34 & 0.09 & 5.17 & 26.73 & 5.17 & 10.34 \\
\hline PCB189 & 50 & 5.02 & 9.73 & 0.15 & 4.86 & 23.67 & 4.87 & 9.73 \\
\hline PCB191 & 50 & 5.46 & 10.33 & 0.09 & 5.17 & 26.70 & 5.17 & 10.33 \\
\hline PCB194 & 50 & 4.83 & 10.43 & 0.16 & 5.22 & 27.23 & 5.22 & 10.44 \\
\hline PCB199 & 50 & 5.22 & 10.56 & 0.07 & 5.28 & 27.88 & 5.28 & 10.56 \\
\hline PCB201 & 50 & 5.03 & 10.61 & 0.11 & 5.31 & 28.18 & 5.31 & 10.62 \\
\hline PCB202 & 50 & 5.48 & 11.00 & 0.09 & 5.50 & 30.24 & 5.50 & 11.00 \\
\hline PCB205 & 50 & 5.69 & 11.18 & 0.09 & 5.59 & 31.25 & 5.59 & 11.18 \\
\hline PCB206 & 50 & 4.64 & 10.31 & 0.10 & 5.15 & 26.57 & 5.15 & 10.31 \\
\hline PCB208 & 50 & 5.25 & 10.97 & 0.19 & 5.48 & 30.12 & 5.49 & 10.98 \\
\hline PCB209 & 50 & 5.30 & 10.16 & 0.08 & 5.08 & 25.79 & 5.08 & 10.16 \\
\hline
\end{tabular}

\section{Uncertainties Calculations for OC pesticides}

\begin{tabular}{|c|c|c|c|c|c|c|c|c|}
\hline Name & $\begin{array}{c}\text { Expected } \\
\text { amount } \\
(\mathrm{ng} / \mathrm{g})\end{array}$ & SD & $\%$ RSD & W & $\mathbf{U x}$ & $\sum \mathbf{U}_{\mathbf{x}}^{2}+\mathbf{U}_{0}^{2}$ & Uc & $\mathbf{U}$ \\
\hline A-BHC & 50 & 1.14 & 2.82 & 0.05 & 1.41 & 1.99 & 1.41 & 2.82 \\
\hline B-BHC & 20 & 0.54 & 2.69 & 0.03 & 0.54 & 0.29 & 0.54 & 1.08 \\
\hline G-BHC & 50 & 1.12 & 2.59 & 0.03 & 1.29 & 1.67 & 1.29 & 2.59 \\
\hline A-CHLA & 50 & 3.15 & 6.06 & 0.02 & 3.03 & 9.18 & 3.03 & 6.06 \\
\hline G-CHLA & 50 & 1.69 & 3.12 & 2.29 & 1.56 & 7.67 & 2.77 & 5.54 \\
\hline Oxy-CHLA & 50 & 0.93 & 1.77 & 0.04 & 0.89 & 0.79 & 0.89 & 1.77 \\
\hline Aldrin & 50 & 0.97 & 2.47 & 0.02 & 1.23 & 1.52 & 1.23 & 2.47 \\
\hline Endrin & 50 & 1.97 & 3.32 & 0.03 & 1.66 & 2.75 & 1.66 & 3.32 \\
\hline Dieldrin & 50 & 1.18 & 2.29 & 0.13 & 1.14 & 1.33 & 1.15 & 2.30 \\
\hline Endos 1 & 50 & 1.23 & 2.27 & 0.12 & 1.13 & 1.30 & 1.14 & 2.28 \\
\hline Endos 2 & 50 & 2.27 & 4.80 & 0.11 & 2.40 & 5.78 & 2.40 & 4.81 \\
\hline Endos S & 50 & 2.82 & 6.62 & 0.09 & 3.31 & 10.95 & 3.31 & 6.62 \\
\hline Heptachlor & 50 & 1.56 & 3.14 & 0.03 & 1.57 & 2.47 & 1.57 & 3.14 \\
\hline OCSTYR & 50 & 1.29 & 2.88 & 0.08 & 1.44 & 2.08 & 1.44 & 2.88 \\
\hline $\begin{array}{c}\text { Trans- } \\
\text { nonachlor }\end{array}$ & 50 & 1.15 & 2.37 & 0.16 & 1.18 & 1.43 & 1.20 & 2.39 \\
\hline o,p'-DDT & 50 & 0.97 & 1.93 & 0.17 & 0.97 & 0.96 & 0.98 & 1.96 \\
\hline p,p'-DDD & 50 & 1.24 & 2.39 & 0.21 & 1.19 & 1.47 & 1.21 & 2.43 \\
\hline p,p'-DDE & 50 & 1.11 & 2.33 & 0.18 & 1.17 & 1.39 & 1.18 & 2.36 \\
\hline $\mathrm{p}, \mathrm{p}^{\prime}-\mathrm{DDT}$ & 50 & 3.40 & 6.50 & 0.21 & 3.25 & 10.60 & 3.26 & 6.51 \\
\hline Mirex & 50 & 1.10 & 2.08 & 0.20 & 1.04 & 1.12 & 1.06 & 2.11 \\
\hline p-Mirex & 50 & 1.39 & 2.55 & 0.22 & 1.27 & 1.67 & 1.29 & 2.59 \\
\hline
\end{tabular}




\section{APPENDIX D: GC COLUMNS}

LC-50 50\% liquid crystalline-methylpolysiloxane

007-65HT $\quad 65 \%$ phenyl-methylpolysiloxane

VF-23ms proprietary (70-90\% cyano-containing polymer)

VF-1ms $\quad 100 \%$ methylpolysiloxane

HT-8 8\% phenyl-methylpolysiloxane (carborane)

DB-1/HP-1 $\quad 100 \%$ dimethylpolysiloxane

RTX-5/DB-5 5\% diphenyl-dimethylpolysiloxane

DB-Wax polyethylene glycol

DB-XLB proprietary

Rtx-PCB proprietary

SupelcoWax-10 polyethylene glycol

DB-1701 14\% (cyanopropyl-phenyl)-methylpolysiloxane

DB-17HT 50\% phenyl-methylpolysiloxane

DB-210 trifluoropropylmethyl polysiloxane

BPX-50 50\% phenyl-methylpolysiloxane (silphenylene)

007-210 $50 \%$ trifluoropropyl-methylpolysiloxane 
(3) $B C-15-89$ 